\title{
MEDUSA-2.0: an intermediate complexity biogeochemical model of the marine carbon cycle for climate change and ocean acidification studies
}

\author{
A. Yool, E. E. Popova, and T. R. Anderson \\ National Oceanography Centre; University of Southampton Waterfront Campus, European Way, Southampton SO14 3ZH, UK
}

Correspondence to: A. Yool (axy@noc.ac.uk)

Received: 31 January 2013 - Published in Geosci. Model Dev. Discuss.: 21 February 2013

Revised: 5 September 2013 - Accepted: 10 September 2013 - Published: 29 October 2013

\begin{abstract}
Medusa-1.0 (Model of Ecosystem Dynamics, nutrient Utilisation, Sequestration and Acidification) was developed as an "intermediate complexity" plankton ecosystem model to study the biogeochemical response, and especially that of the so-called "biological pump", to anthropogenically driven change in the World Ocean (Yool et al., 2011). The base currency in this model was nitrogen from which fluxes of organic carbon, including export to the deep ocean, were calculated by invoking fixed $\mathrm{C}: \mathrm{N}$ ratios in phytoplankton, zooplankton and detritus. However, due to anthropogenic activity, the atmospheric concentration of carbon dioxide $\left(\mathrm{CO}_{2}\right)$ has significantly increased above its natural, inter-glacial background. As such, simulating and predicting the carbon cycle in the ocean in its entirety, including ventilation of $\mathrm{CO}_{2}$ with the atmosphere and the resulting impact of ocean acidification on marine ecosystems, requires that both organic and inorganic carbon be afforded a more complete representation in the model specification. Here, we introduce MEDUSA-2.0, an expanded successor model which includes additional state variables for dissolved inorganic carbon, alkalinity, dissolved oxygen and detritus carbon (permitting variable $\mathrm{C}: \mathrm{N}$ in exported organic matter), as well as a simple benthic formulation and extended parameterizations of phytoplankton growth, calcification and detritus remineralisation. A full description of MEDUSA-2.0, including its additional functionality, is provided and a multi-decadal spin-up simulation (1860-2005) is performed. The biogeochemical performance of the model is evaluated using a diverse range of observational data, and MEDUSA-2.0 is assessed relative to comparable models using output from the Coupled Model Intercomparison Project (CMIP5).
\end{abstract}

\section{Introduction}

Since the beginning of the industrial era, the atmospheric concentration of carbon dioxide $\left(\mathrm{CO}_{2}\right)$ has significantly increased above its natural, inter-glacial background concentration. Further increases are predicted by climate models, e.g. to $450-650 \mathrm{ppm}$ by the mid-21st century (Houghton et al., 2001). Rising atmospheric $\mathrm{CO}_{2}$ is mitigated by uptake on land and in the ocean, with the latter accounting for about $30 \%$ of anthropogenic emissions (Sabine et al., 2004). This uptake by the ocean is driven by what are known as the solubility and biological pumps, the former via dissolution of $\mathrm{CO}_{2}$ in cold waters that are mixed to depth, and the latter as the sinking and downward mixing of organic matter into the ocean interior (Volk and Hoffert, 1985). Global warming will likely cause significant changes in ocean circulation, ecosystems and carbon export (Doney et al., 2012). Some analyses of phytoplankton suggest that change is already detectable and that abundance is declining in response to rising sea surface temperatures (Boyce et al., 2010). Modelling studies have similarly indicated that increased stratification in response to future $\mathrm{CO}_{2}$ emission scenarios leads to decreased primary production and associated export of carbon (e.g. Bopp et al., 2001; Steinacher et al., 2010; but see Taucher and Oschlies, 2011).

The potential of the ocean to take up $\mathrm{CO}_{2}$ from the atmosphere is vast because $\mathrm{CO}_{2}$ is buffered by the carbonate chemistry of seawater, keeping concentrations low relative to other components $\left(\mathrm{HCO}_{3}^{-}\right.$and $\left.\mathrm{CO}_{3}^{2-}\right)$. Ocean acidification is a further consequence of the chemical equilibrium in seawater because, as anthropogenic $\mathrm{CO}_{2}$ invades, it combines with $\mathrm{H}_{2} \mathrm{O}$ to form $\mathrm{HCO}_{3}^{-}$and $\mathrm{H}^{+}$. Model hindcasts indicate that 
surface ocean $\mathrm{pH}$ has declined from its preindustrial value of 8.2-8.1 today, an increase in acidity of $30 \%$ (Orr et al., 2005). Forward predictions indicate substantial further decreases, e.g. 0.3-0.4 pH units, by 2050 depending on future $\mathrm{CO}_{2}$ emissions (Orr et al., 2005). The chemical impact of ocean acidification has the potential to affect ocean ecosystems and associated biogeochemistry in many ways (Doney et al., 2009). In particular, it leads to decreasing saturation state for the two main forms of calcium carbonate $\left(\mathrm{CaCO}_{3}\right)$ produced by marine calcifiers, aragonite and calcite. Coccolithophores, foraminiferans and pteropods are thus particularly vulnerable to such changes (Fabry et al., 2008; Gangst $\varnothing$ et al., 2011). Acidification and decreasing $\mathrm{CaCO}_{3}$ production have several consequences for the ocean carbon cycle. Production of $\mathrm{CaCO}_{3}$ removes twice as much alkalinity as it does $\mathrm{CO}_{2}$ from seawater (Frankignoulle et al., 1994) such that decreasing $\mathrm{CaCO}_{3}$ leads to elevated $p \mathrm{CO}_{2}$ and a negative feedback with the atmosphere. On the other hand, the rain ratio, i.e. the ratio of $\mathrm{CaCO}_{3}$ : POC in sinking particulate organic carbon (Archer, 1991) will decline and with it carbon export flux to the deep ocean. Furthermore, if the export of organic carbon is closely bound by ballasting minerals including carbonate (Armstrong et al., 2002; Klaas and Archer, 2002), a decrease in $\mathrm{CaCO}_{3}$ production could lead to a substantial shallowing of the depth scale of remineralisation (Heinze, 2004).

Previously, we introduced an "intermediate complexity" plankton model, MedusA-1.0: Model of Ecosystem Dynamics, nutrient Utilisation, Sequestration and Acidification (Yool et al., 2011). This model expanded beyond the traditional nutrient-phytoplankton-zooplanktondetritus (NPZD) models by having multiple currencies (N, $\mathrm{Si}$ and $\mathrm{Fe}$ ) and by separating plankton into "small" and "large" size classes, yet incorporated sufficiently few tracers to be readily tractable in global ocean general circulation models. A multi-decadal spin-up simulation was undertaken and results presented for global nutrient fields, primary production, distributions of phytoplankton types and export of detritus. Here, we introduce MedusA-2.0, an expanded successor model which represents dissolved inorganic carbon (DIC) and $p \mathrm{CO}_{2}$ in the ocean, thereby allowing the calculation of air-sea $\mathrm{CO}_{2}$ fluxes as well as an explicit representation of ocean acidification and its impact on ecosystem processes. The new model includes additional state variables for dissolved inorganic carbon, alkalinity, dissolved oxygen and detritus carbon (permitting variable $\mathrm{C}: \mathrm{N}$ in exported organic matter), as well as a simple benthic formulation and extended parameterizations of phytoplankton growth and detritus remineralisation. A full description of the additional functionality of MEDUSA-2.0 is provided. A multi-decadal spin-up simulation is described (1860-2005), and this is used to provide a means of evaluating the performance of MedusA-2.0.

\section{Medusa-2.0}

\subsection{State variables}

MedusA-1.0 resolves 11 state variables distributed between the nitrogen (6), silicon (2) and iron (1) cycles. The remaining 2 state variables denote chlorophyll for each of the model's 2 phytoplankton classes. Because of its key role in organising marine productivity, nitrogen is MEDUSA-1.0's primary currency. In this framework, the cycling of carbon (and other elements) can only be estimated from the explicitly modelled elemental cycles, and then only if fixed stoichiometric relationships are assumed.

In order to incorporate the carbon and oxygen cycles, MEdusA-2.0 adds a further 4 state variables to the existing framework. These include total dissolved inorganic carbon (DIC), total alkalinity (TA) and dissolved oxygen. The final additional state variable is detrital carbon for the slowsinking component of non-living particulate organic carbon (POC). For simplicity, Medusa-2.0 retains Medusa-1.0's assumption of fixed $\mathrm{C}: \mathrm{N}$ ratios for the plankton pools (phytoplankton, zooplankton), but since these pools do not have identical $\mathrm{C}: \mathrm{N}$ ratios (e.g. zooplankton are assumed to have a lower ratio; Anderson, 2005) the flow of organic material to detrital pools, both slow- and fast-sinking, has a variable $\mathrm{C}: \mathrm{N}$ ratio depending upon which processes (plankton mortality, zooplankton egestion) contribute to it. In the case of fast-sinking detritus, this is still handled implicitly within MedusA-2.0, so can be easily accommodated. Since slowsinking detritus is already represented by an explicit nitrogen state variable, a corresponding carbon variable must be added to accommodate this. Note that, again for simplicity, iron is still coupled rigidly to nitrogen, so there is no corresponding state variable for detrital iron. Figure 1 presents a schematic diagram of MEDUSA-2.0, showing the state variables (pelagic and benthic) and the ecological connections between them.

The full list of 3-D water column state variables for MedusA-2.0 is as follows:

\begin{tabular}{|c|c|c|}
\hline $\mathrm{Pn}$ & Non-diatom phytoplankton & $\mathrm{mmolNm}^{-3}$ \\
\hline $\mathrm{Pd}$ & Diatom phytoplankton & $\mathrm{mmolNm}^{-3}$ \\
\hline $\mathrm{Chl}_{\mathrm{Pn}}$ & Chlorophyll in non-diatoms & $\mathrm{mg} \operatorname{chl~m}{ }^{-3}$ \\
\hline $\mathrm{Chl}_{\mathrm{Pd}}$ & Chlorophyll in diatoms & $\operatorname{mg} \operatorname{chl~m}^{-3}$ \\
\hline $\mathrm{Pd}_{\mathrm{Si}}$ & Diatom phytoplankton (silicon) & $\mathrm{mmolSim}^{-3}$ \\
\hline $\mathrm{Z} \mu$ & Microzooplankton & $\mathrm{mmolNm}^{-3}$ \\
\hline $\mathrm{Zm}$ & Mesozooplankton & $\mathrm{mmolNm}^{-3}$ \\
\hline $\mathrm{D}$ & Slow-sinking detritus $(\mathrm{N})$ & $\mathrm{mmolNm}^{-3}$ \\
\hline $\mathrm{D}_{\mathrm{C}}$ & Slow-sinking detritus (C) & $\mathrm{mmolCm}^{-3}$ \\
\hline $\mathrm{N}$ & Nitrogen nutrient & $\mathrm{mmolNm}^{-3}$ \\
\hline S & Silicic acid & $\mathrm{mmolSim}^{-3}$ \\
\hline $\mathrm{F}$ & Iron nutrient & $\mathrm{mmolFem}^{-3}$ \\
\hline DIC & Dissolved inorganic carbon & $\mathrm{mmolCm}^{-3}$ \\
\hline ALK & Total alkalinity & $\mathrm{meq}^{-3}$ \\
\hline $\mathrm{O}_{2}$ & Dissolved oxygen & $\mathrm{mmolO}_{2} \mathrm{~m}^{-3}$ \\
\hline
\end{tabular}




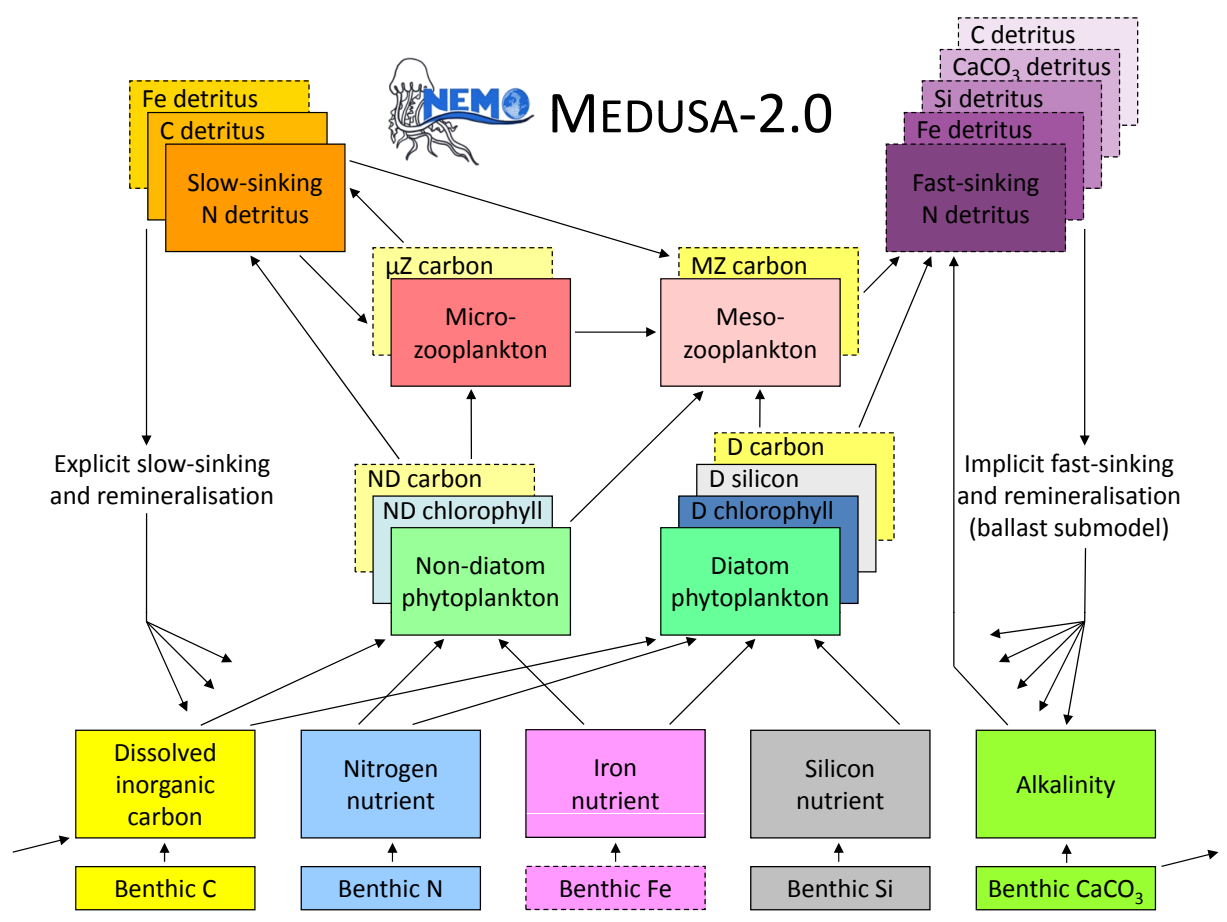

Fig. 1. Schematic diagram of the components and interactions in the MEDUSA-2.0 model. Boxes with solid borders indicate explicitly modelled state variables, while boxes with dashed borders indicate implicitly modelled components. Overlapping boxes indicate components for which multiple currencies are modelled (e.g. different elements, chlorophyll). The smaller boxes at the bottom of the diagram refer to benthic reservoirs of model currencies that are fed by sinking detrital material (slow- and fast-sinking). For reasons of diagrammatic clarity, dissolved oxygen and its connections to other state variables are omitted here. Note that the dissolution of benthic $\mathrm{CaCO}_{3}$ releases both $\mathrm{DIC}$ and alkalinity.

In addition to the state variables for the 3-D water column, 4 further state variables have been added to represent 2-D pools of organic and biogenic material at the seafloor. These pools permit temporary storage of particulate material before it is returned to dissolved pools, and they represent an extremely crude submodel of the benthic ecosystem. This approach contrasts with that in MEDUSA-1.0 in which all particulate material reaching the seafloor is instantaneously remineralised (or dissolved). The primary motivation for this addition is to prevent the unrealistic acceleration of nutrient regeneration at the seafloor caused by such simplified model assumptions. This is particularly an issue in the shelf regions of the World Ocean where shallower water columns and strong vertical mixing can quickly return regenerated nutrients to surface waters and unrealistically fuel extra productivity. The simplicity of the submodel used in MedusA-2.0 means that it does not resolve the complex interplay between benthic ecosystems and seafloor sediments, but instead serves as a precursor to the inclusion of a more sophisticated treatment (e.g. Rowe and Deming, 2011). As in the case of the detritus (slow- and fast-sinking) that fuels these seafloor pools, iron is rigidly coupled to nitrogen and does not have a separate benthic state variable. In principle, it could alternatively be coupled to carbon, but for parity with MEDUSA-1.0, its fate remains bound to that of nitrogen. The full list of 2-D state variables represented are:
$\mathrm{B}_{\mathrm{N}} \quad$ Benthic organic nitrogen
$\mathrm{mmolNm}^{-2}$
$\mathrm{B}_{\mathrm{C}}$ Benthic organic carbon
$\mathrm{B}_{\mathrm{Si}}$ Benthic inorganic silicon
$\mathrm{B}_{\mathrm{Ca}}$ Benthic inorganic $\mathrm{CaCO}_{3}$
$\mathrm{mmolCm} \mathrm{C}^{-2}$
$\mathrm{mmolSim}^{-2}$
$\mathrm{mmolCm} \mathrm{m}^{-2}$

Similarly to MedusA-1.0, the oceanic inventories of nitrogen and silicon are fixed, and biogeochemical processes effectively only move these elements between modelled pools. Processes which act to add or remove these elements to or from the ocean (whether "abiotic" such as rivers or burial, or "biotic" such as nitrogen fixation or denitrification) are ignored here. This approach is adopted partly because these unmodelled processes are assumed to be of limited magnitude relative to modelled processes, in part because they are less well-understood and more difficult to model, and partly to simply limit model complexity. (As an aside, note that the residence time of these elements within the ocean is considerably longer than the duration of all simulations of NEMO-MEDUSA-2.0 to date.) In MEdusA-2.0, this same fixed inventory also applies to alkalinity, but the remaining elemental cycles - iron, carbon and oxygen - have connections to reservoirs external to the ocean. In the case of 
iron, aeolian deposition and dissolution of benthic sediments supply this element to seawater, while scavenging actively removes it. Meanwhile, both carbon and oxygen are actively exchanged with the atmosphere at the ocean's surface. However, oxygen also occupies an unusual station in that - as far as the modelled inventory is concerned - within the water column it is both generated from "nothing" by primary production, and dissipated to "nothing" by respiration.

The inclusion of the cycles of carbon, alkalinity and oxygen introduces a number of features to MEDUSA-2.0 that are relevant for studies of future climate change or ocean acidification. These include:

- gas exchange of dissolved $\mathrm{CO}_{2}$ and $\mathrm{O}_{2}$ with the atmosphere,

- a carbonate chemistry module for calculating properties such as the concentrations of carbonate species $\left(\mathrm{H}_{2} \mathrm{CO}_{3}, \mathrm{HCO}_{3}^{-}, \mathrm{CO}_{3}^{2-}\right), p \mathrm{CO}_{2}$ and $\mathrm{pH}$,

- a dynamic lysocline depth calculated from the 3-D saturation state of calcium carbonate (specifically the calcite polymorph).

Alongside these major additions, MEDUS A-2.0 has a number of less significant differences from MEDUSA-1.0 that relate to aspects such as parameterization and forcing. These differences include:

- forcing field of aeolian iron deposition replaced with that of Mahowald (2005),

- parameterization of seafloor supply of dissolved iron added,

- phytoplankton growth parameterization extended to include option of Liebig "law of the minimum" functionality,

- Martin et al. (1987) and Henson et al. (2011) parameterizations of the remineralisation of fastsinking detritus optionally available,

- options to use either fixed or dynamic rain ratios and lysocline depths.

A separate development with bearing on the work described here is the utilisation of surface forcing derived from coupled ocean-atmosphere models. This supplants the observationally derived reanalysis forcing (DFS4.1; DRAKKAR Group, 2007) used previously with MEDUSA-1.0 (Yool et al., 2011). As well as permitting forecast simulations, adoption of such model-derived forcing permits spin-up or hindcast simulations of the pre-industrial past prior to the ongoing anthropogenic transient. The specific forcing used here is described in Sect. 3.1.

\subsection{Differential equations}

The following partial differential equations describe the biogeochemical tendency terms that operate on MEDUSA-2.0's state variables. Abbreviations used in the bracketed descriptions are: "PP" for primary production; " $\mu \mathrm{zoo"} \mathrm{for} \mathrm{micro-}$ zooplankton; "mzoo" for mesozooplankton; "non-lin" for non-linear; "remin" for remineralisation of organic material; "diss" for dissolution of inorganic material (e.g. opal or $\mathrm{CaCO}_{3}$ ). The functional forms and parameters used in these equations are expanded upon in Sects. 2.3 and 2.4.

$$
\begin{aligned}
\frac{\partial \mathrm{Pn}}{\partial t} & =+\underbrace{\left[\mathrm{PP} P_{\mathrm{Pn}} \cdot \mathrm{Pn}\right]}_{\text {non-diatom PP }}-\underbrace{\left[\mathrm{G} \mu_{\mathrm{Pn}}\right]}_{\mu z \text { og graze }}-\underbrace{\left[\mathrm{Gm}_{\mathrm{Pn}}\right]}_{\text {mzoograze }} \\
& -\underbrace{\left[\mathrm{M} 1_{\mathrm{Pn}}\right]}_{\text {linearlosses }}-\underbrace{\left[\mathrm{M} 2_{\mathrm{Pn}}\right]}_{\text {non-linlosses }}
\end{aligned}
$$

$$
\frac{\partial \mathrm{Pd}}{\partial t}=+\underbrace{\left[\mathrm{PP} \mathrm{Pd}_{\mathrm{Pd}} \cdot \mathrm{Pd}\right]}_{\text {diatom PP }}-\underbrace{\left[\mathrm{Gm} \mathrm{m}_{\mathrm{Pd}}\right]}_{\text {mzoograze }}-\underbrace{\left[\mathrm{M} 1_{\mathrm{Pd}}\right]}_{\text {linearlosses }}-\underbrace{\left[\mathrm{M} 2_{\mathrm{Pd}}\right]}_{\text {non-lin losses }}
$$

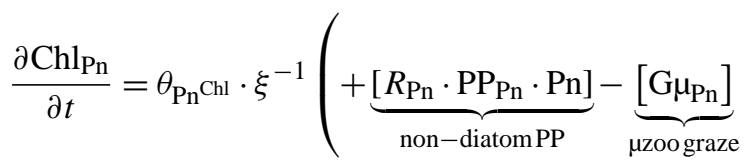

$$
\begin{aligned}
& -\underbrace{\left[\mathrm{Gm} m_{\mathrm{Pn}}\right]}_{\text {mzoo graze }}-\underbrace{\left[\mathrm{M} 1_{\mathrm{Pn}}\right]}_{\text {linearlosses }}-\underbrace{\left[\mathrm{M} 2_{\mathrm{Pn}}\right]}_{\text {non-linlosses }})
\end{aligned}
$$

$$
\begin{aligned}
& \frac{\partial \mathrm{Chl}_{\mathrm{Pd}}}{\partial t}=\theta_{\mathrm{Pd}}^{\mathrm{Chl}} \cdot \xi^{-1}(+\underbrace{\left[R_{\mathrm{Pd}} \cdot \mathrm{PP} P \mathrm{Pd}\right.}_{\text {diatom PP }} \cdot \underbrace{\left[\mathrm{Gm}_{\mathrm{Pd}}\right]}_{\text {mzoo graze }} \\
& -\underbrace{\left[\mathrm{M} 1_{\mathrm{Pd}}\right]}_{\text {linearlosses }}-\underbrace{\left[\mathrm{M} 2_{\mathrm{Pd}}\right]}_{\text {non-linlosses }})
\end{aligned}
$$

$$
\begin{aligned}
\frac{\partial \mathrm{Pd}_{\mathrm{Si}}}{\partial t} & =+\underbrace{\left[\mathrm{PP}_{\mathrm{Pd}_{\mathrm{Si}}} \cdot \mathrm{Pd}_{\mathrm{Si}}\right]}_{\text {diatomPP }}-\underbrace{\left[\mathrm{Gm}_{\mathrm{Pd}_{\mathrm{Si}}}\right]}_{\text {mzoo graze }}-\underbrace{\left[\mathrm{M}_{\mathrm{Pd}_{\mathrm{Si}}}\right]}_{\text {linearlosses }} \\
& -\underbrace{\left[\mathrm{M} 2_{\mathrm{Pd}_{\mathrm{Si}}}\right]}_{\text {non-lin losses }}-\underbrace{\left[\mathrm{DS}_{\mathrm{Pd}_{\mathrm{Si}}}\right]}_{\text {dissolution }}
\end{aligned}
$$

$$
\frac{\partial \mathrm{Z} \mu}{\partial t}=+\underbrace{\left[F_{\mathrm{Z} \mu}\right]}_{\text {all grazing }}-\underbrace{\left[\mathrm{Gm}_{\mathrm{Z} \mu}\right]}_{\text {mzoo graze }}-\underbrace{\left[\mathrm{M} 1_{\mathrm{Z} \mu}\right]}_{\text {linearlosses }}-\underbrace{\left[\mathrm{M} 2_{\mathrm{Z} \mu}\right]}_{\text {non-lin losses }}
$$

$$
\frac{\partial \mathrm{Zm}}{\partial t}=+\underbrace{\left[F_{\mathrm{Zm}}\right]}_{\text {all grazing }}-\underbrace{\left[\mathrm{M} 1_{\mathrm{Zm}}\right]}_{\text {linearlosses }}-\underbrace{\left[\mathrm{M} 2_{\mathrm{Zm}}\right]}_{\text {non-linlosses }}
$$




$$
\begin{aligned}
& \frac{\partial \mathrm{D}}{\partial t}=+\underbrace{[\mathrm{M} 2 \mathrm{Pn}]}_{\text {non-diatomlosses }}+\underbrace{[\mathrm{M} 2 \mathrm{Z \mu}]}_{\mu \text { zoolosses }}+\underbrace{\left[\left(1-\mathrm{D} 1_{\text {frac }}\right) \cdot \mathrm{M} 2 \mathrm{Pd}\right.}_{\text {diatomlosses }}] \\
& +\underbrace{\left[\left(1-\mathrm{D} 2_{\text {frac }}\right) \cdot \mathrm{M} 2_{\mathrm{Zm}}\right]}_{\text {mzoolosses }}+\underbrace{\left[\left(1-\beta_{\mathrm{N}}\right) \cdot \mathrm{IN}_{\mathrm{Z \mu}}\right]}_{\mu \text { zoo egestion }} \\
& +\underbrace{\left[\left(1-\beta_{\mathrm{N}}\right) \cdot \mathrm{IN} \mathrm{Zm}_{\mathrm{m}}\right]}_{\text {mzooegestion }}-\underbrace{\left[\mathrm{G} \mu_{\mathrm{D}}\right]}_{\mu \text { zoograze }}-\underbrace{[\mathrm{Gm} \mathrm{D}]}_{\text {mzoograze }} \\
& -\underbrace{\left[\mathrm{M}_{\mathrm{D}}\right]}_{\text {remin }}-\underbrace{\left[w_{\mathrm{g}} \cdot \frac{\partial \mathrm{D}}{\partial z}\right]}_{\text {sinking }}
\end{aligned}
$$

$$
\begin{aligned}
& \frac{\partial \mathrm{D}_{\mathrm{C}}}{\partial t}=+\underbrace{\left[\theta_{\mathrm{Pn}} \cdot \mathrm{M} 2_{\mathrm{Pn}}\right]}_{\text {non-diatomlosses }}+\underbrace{\left[\theta_{\mathrm{Z \mu}} \cdot \mathrm{M} 2_{\mathrm{Z \mu}}\right]}_{\mu \mathrm{zoolosses}} \\
& +\underbrace{\left[\theta_{\mathrm{Pd}} \cdot\left(1-\mathrm{D} 1_{\mathrm{frac}}\right) \cdot \mathrm{M} 2_{\mathrm{Pd}}\right]}_{\text {diatomlosses }}+\underbrace{\left[\theta_{\mathrm{Zm}} \cdot\left(1-\mathrm{D} 2_{\mathrm{frac}}\right) \cdot \mathrm{M} 2_{\mathrm{Zm}}\right]}_{\text {mzoolosses }} \\
& +\underbrace{\left[\left(1-\beta_{\mathrm{C}}\right) \cdot \mathrm{IC}_{\mathrm{Z \mu}}\right]}_{\mu z o o \text { egestion }}+\underbrace{\left[\left(1-\beta_{\mathrm{C}}\right) \cdot \mathrm{IC}_{\mathrm{Zm}}\right]}_{\text {mzoo egestion }}-\underbrace{\left[\mathrm{G} \mu_{\mathrm{Dc}}\right]}_{\mu z o o \text { graze }} \\
& -\underbrace{\left[\mathrm{Gm}_{\mathrm{Dc}}\right]}_{\text {mzoograze }}-\underbrace{\left[\mathrm{M}_{\mathrm{Dc}}\right]}_{\text {remin }}-\underbrace{\left[w_{\mathrm{g}} \cdot \frac{\partial \mathrm{D}_{\mathrm{C}}}{\partial z}\right]}_{\text {sinking }}
\end{aligned}
$$

$$
\begin{aligned}
& \frac{\partial \mathrm{N}}{\partial t}=-\underbrace{\left[\mathrm{PP}_{\mathrm{Pn}} \cdot \mathrm{Pn}\right]}_{\text {non-diatom PP }}-\underbrace{\left[\mathrm{PP} \mathrm{Pd}_{\mathrm{Pd}} \cdot \mathrm{Pd}\right]}_{\text {diatom PP }}+\underbrace{\left[\phi \cdot\left(\mathrm{G} \mu_{\mathrm{Pn}}+\mathrm{G} \mu_{\mathrm{D}}\right)\right]}_{\mu \text { zoo messy feeding }} \\
& +\underbrace{\left[\phi \cdot\left(\mathrm{Gm}_{\mathrm{Pn}}+\mathrm{Gm}_{\mathrm{Pd}}+\mathrm{Gm}_{\mathrm{Z \mu}}+\mathrm{Gm}_{\mathrm{D}}\right)\right]} \\
& \text { mzoo messy feeding } \\
& +\underbrace{\left[E_{\mathrm{Z \mu}}\right]}_{\mu z \text { oexcretion }}+\underbrace{\left[E_{\mathrm{Zm}}\right]}_{\text {mzooexcretion }}+\underbrace{\left[\mathrm{M} 1_{\mathrm{Pn}}\right]}_{\text {non-diatomlosses }}+\underbrace{\left[\mathrm{M} 1_{\mathrm{Pd}}\right]}_{\text {diatomlosses }} \\
& +\underbrace{\left[\mathrm{M} 1_{\mathrm{Zu}}\right]}_{\text {uzoolosses }}+\underbrace{\left[\mathrm{M} 1_{\mathrm{Zm}}\right]}_{\text {mzoolosses }}+\underbrace{\left[\mathrm{M}_{\mathrm{D}}\right]}_{\text {remin }}+\underbrace{\left[\mathrm{LD} \mathrm{D}_{\mathrm{N}}(k)\right]}_{\text {fast N remin }}+\underbrace{\left[\mathrm{BF}_{\mathrm{N}}\right]}_{\text {benthic remin }}
\end{aligned}
$$$$
\begin{aligned}
\frac{\partial \mathrm{S}}{\partial t} & =-\underbrace{\left[\mathrm{PP}_{\mathrm{Pd}_{\mathrm{Si}}} \cdot \mathrm{Pd} \mathrm{Pd}_{\mathrm{Si}}\right]}_{\text {diatomPP }}+\underbrace{\left[\mathrm{M}_{\left.\mathrm{Pd}_{\mathrm{Si}}\right]}\right]}_{\text {linear losses }}+\underbrace{\left[\left(1-\mathrm{D} 1_{\text {frac }}\right) \cdot \mathrm{M} 2_{\mathrm{Pd}_{\mathrm{Si}}}\right]}_{\text {non-lin.losses }} \\
& +\underbrace{\left[\mathrm{DS} \mathrm{Sd}_{\mathrm{Si}}\right]}_{\text {dissolution }}+\underbrace{\left[\left(1-\mathrm{D} 2_{\mathrm{frac}}\right) \cdot \mathrm{Gm}_{\mathrm{Pd}_{\mathrm{Si}}}\right]}_{\text {mzoo graze }} \\
& +\underbrace{\left[\mathrm{L} D_{\mathrm{Si}}(k)\right]}_{\text {fast Sidetritus diss }}+\underbrace{\left[\mathrm{BF} F_{\mathrm{Si}}\right]}_{\text {benthic diss }}
\end{aligned}
$$

$$
\begin{aligned}
\frac{\partial \mathrm{F}}{\partial t}= & -\underbrace{\left[R_{\mathrm{Fe}} \cdot \frac{\partial \mathrm{N}}{\partial t}\right]}_{\text {coupled to } \mathrm{N}}+\underbrace{\left[F_{\text {atmos }}\right]}_{\text {aeolian }}+\underbrace{\left[F_{\text {benth }}\right]}_{\text {sediments }} \\
& -\underbrace{\left[F_{\text {scavenge }}\right]}_{\text {scavenging }}+\underbrace{\left[\mathrm{BF}_{\mathrm{Fe}}\right]}_{\text {benthic remin }}
\end{aligned}
$$

$$
\begin{aligned}
& \frac{\partial \mathrm{DIC}}{\partial t}=-\underbrace{\left[\theta_{\mathrm{Pn}} \cdot \mathrm{PP} \mathrm{Pn}_{\mathrm{Pn}} \cdot \mathrm{Pn}\right]}_{\text {non-diatom PP }}-\underbrace{\left[\theta_{\mathrm{Pd}} \cdot \mathrm{PP}_{\mathrm{Pd}} \cdot \mathrm{Pd}\right]}_{\text {diatomPP }}+\underbrace{\left[\phi \cdot \theta_{\mathrm{Pn}} \cdot \mathrm{G} \mu_{\mathrm{Pn}}\right]}_{\mu \text { zoo messy feeding, } \mathrm{Pn}} \\
& +\underbrace{\left[\phi \cdot \mathrm{G} \mu_{\mathrm{Dc}}\right]}+\underbrace{\left[\phi \cdot \theta_{\mathrm{Pn}} \cdot \mathrm{Gm}_{\mathrm{Pn}}\right]}+\underbrace{\left[\phi \cdot \theta_{\mathrm{Pd}} \cdot \mathrm{Gm}_{\mathrm{Pd}}\right]} \\
& \mu \text { zoomessy feeding, Dc mzoomessyfeeding, Pn mzoomessyfeeding, Pd } \\
& +\underbrace{\left[\phi \cdot \theta_{\mathrm{Z \mu}} \cdot \mathrm{Gm}_{\mathrm{Z \mu}}\right]}+\underbrace{\left[\phi \cdot \mathrm{Gm}_{\mathrm{Dc}}\right]}+\underbrace{\left[R_{\mathrm{Z} \mu}\right]} \\
& \text { mzoomessyfeeding, } \mathrm{Z} \mu \text { mzoomessyfeeding, Dc } \mu \underbrace{\text { pzoorespiration }} \\
& +\underbrace{\left[R_{\mathrm{Zm}}\right]}_{\text {mzoorespiration }}+\underbrace{\left[\theta_{\mathrm{Pn}} \cdot \mathrm{M} 1_{\mathrm{Pn}}\right]}_{\text {non-diatomlosses }}+\underbrace{\left[\theta_{\mathrm{Pd}} \cdot \mathrm{M} 1_{\mathrm{Pd}}\right]}_{\text {diatomlosses }}+\underbrace{\left[\theta_{\mathrm{Z \mu}} \cdot \mathrm{M} 1_{\mathrm{Z \mu}}\right]}_{\mu \text { zzoolosses }} \\
& +\underbrace{\left[\theta_{\mathrm{Zm}} \cdot \mathrm{M} 1_{\mathrm{Zm}}\right]}_{\text {mzoolosses }}+\underbrace{\left[\mathrm{M}_{\mathrm{Dc}}\right]}_{\text {remin }}+\underbrace{\left[\mathrm{LD}_{\mathrm{C}}(k)\right]}_{\text {fast Cremin }}-\underbrace{\left[\mathrm{FD}_{\mathrm{CaCO}_{3}}\right]}_{\mathrm{CaCO}_{3} \text { production }} \\
& +\underbrace{\left[\mathrm{LD}_{\mathrm{CaCO}_{3}}(k)\right]}_{\mathrm{CaCO}_{3} \text { diss }}+\underbrace{\left[\mathrm{BF}_{\mathrm{C}}\right]}_{\text {benthic remin }}+\underbrace{\left[\mathrm{ASF}_{\mathrm{CO}_{2}}\right]}_{\text {air-seagas exchange }}
\end{aligned}
$$

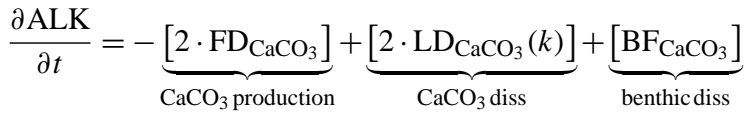$$
\frac{\partial \mathrm{O}_{2}}{\partial t}=+\underbrace{\left[\theta_{\text {nit }} \cdot \mathrm{PP} \mathrm{Pn}_{n} \cdot \mathrm{Pn}\right]}_{\text {non-diatomPP }}+\underbrace{\left[\theta_{\text {nit }} \cdot \mathrm{PP}_{\mathrm{Pd}} \cdot \mathrm{Pd}\right]}_{\text {diatom PP }}-\underbrace{\left[\theta_{\text {nit }} \cdot \phi \cdot \mathrm{G} \mu_{\mathrm{Pn}}\right]}_{\mu \text { zoomessyfeeding, Pn }}
$$$$
-\left[\theta_{\text {nit }} \cdot \phi \cdot \mathrm{G}_{\mathrm{D}}\right]-\underbrace{\left[\theta_{\text {nit }} \cdot \phi \cdot \mathrm{Gm}_{\mathrm{Pn}}\right]}-\underbrace{\left[\theta_{\text {nit }} \cdot \phi \cdot \mathrm{Gm}_{\mathrm{Pd}}\right]}
$$

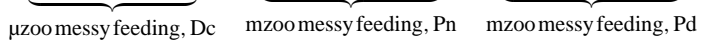$$
-\underbrace{\left[\theta_{\text {nit }} \cdot \phi \cdot \mathrm{Gm}_{\mathrm{Z} \mu}\right]}_{\text {mzoo messy feeding, Zu }}-\underbrace{\left[\theta_{\text {nit }} \cdot \phi \cdot \mathrm{Gm}_{\mathrm{D}}\right]}_{\text {mzoomessy feeding, Dc }}-\underbrace{\left[\theta_{\text {nit }} \cdot E_{\mathrm{Z} \mu}\right]}_{\mu \text { zooexcretion }}
$$$$
-\underbrace{\left[\theta_{\mathrm{nit}} \cdot E_{\mathrm{Zm}}\right]}-\underbrace{\left[\theta_{\mathrm{nit}} \cdot \mathrm{M} 1_{\mathrm{Pn}}\right]}-\underbrace{\left[\theta_{\mathrm{nit}} \cdot \mathrm{M} 1_{\mathrm{Pd}}\right]}
$$$$
\text { mzooexcretion non-diatomlosses }
$$$$
-\underbrace{\left[\theta_{\text {nit }} \cdot \mathrm{M} 1_{\mathrm{Z \mu}}\right]}_{\mu \text { zoolosses }}-\underbrace{\left[\theta_{\text {nit }} \cdot \mathrm{M} 1_{\mathrm{Zm}}\right]}_{\text {mzoolosses }}-\underbrace{\left[\theta_{\text {nit }} \cdot \mathrm{M}_{\mathrm{D}}\right]}_{\text {remin }}
$$$$
-\underbrace{\left[\theta_{\text {nit }} \cdot \mathrm{LD}_{\mathrm{N}}(k)\right]}_{\text {fast N remin }}+\underbrace{\left[\theta_{\text {rem }} \cdot \theta_{\mathrm{Pn}} \cdot \mathrm{PP}_{\mathrm{Pn}} \cdot \mathrm{Pn}\right]}_{\text {non-diatom PP }}+\underbrace{\left[\theta_{\text {rem }} \cdot \theta_{\mathrm{Pd}} \cdot \mathrm{PP}_{\mathrm{Pd}} \cdot \mathrm{Pd}\right]}_{\text {diatom PP }}
$$

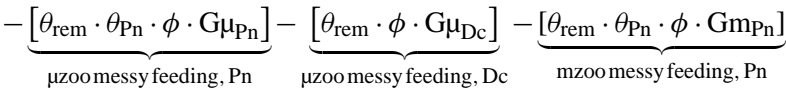$$
-\underbrace{\left[\theta_{\mathrm{rem}} \cdot \theta_{\mathrm{Pd}} \cdot \phi \cdot \mathrm{Gm}_{\mathrm{Pd}}\right]}_{\text {mzoo messy feeding, Pd }}-\underbrace{\left[\theta_{\mathrm{rem}} \cdot \theta_{\mathrm{Z} \mu} \cdot \phi \cdot \mathrm{Gm}_{\mathrm{Z} \mu}\right]}_{\text {mzoo messy feeding, } \mathrm{Z} \mu}
$$$$
-\underbrace{\left[\theta_{\mathrm{rem}} \cdot \phi \cdot \mathrm{Gm}_{\mathrm{Dc}}\right]}-\underbrace{\left[\theta_{\mathrm{rem}} \cdot R_{\mathrm{Z \mu}}\right]}-\underbrace{\left[\theta_{\mathrm{rem}} \cdot R_{\mathrm{Zm}}\right]}
$$$$
\text { mzoomessyfeeding, } \mathrm{Dc} \quad \underbrace{}_{\mu z 0 o \text { respiration }} \text { mzoorespiration }
$$$$
-\underbrace{\left[\theta_{\mathrm{rem}} \cdot \theta_{\mathrm{Pn}} \cdot \mathrm{M} 1_{\mathrm{Pn}}\right]}_{\text {non-diatom losses }}-\underbrace{\left[\theta_{\mathrm{rem}} \cdot \theta_{\mathrm{Pd}} \cdot \mathrm{M} 1_{\mathrm{Pd}}\right]}_{\text {diatomlosses }}-\underbrace{\left[\theta_{\mathrm{rem}} \cdot \theta_{\mathrm{Z} \mu} \cdot \mathrm{M} 1_{\mathrm{Z \mu}}\right]}_{\mu \text { zoo losses }}
$$$$
-\underbrace{\left[\theta_{\text {rem }} \cdot \theta_{\mathrm{Zm}} \cdot \mathbf{M} 1_{\mathrm{Zm}}\right]}_{\text {mzoolosses }}-\underbrace{\left[\theta_{\text {rem }} \cdot \mathbf{M}_{\mathrm{Dc}}\right]}_{\text {remin }}-\underbrace{\left[\theta_{\text {rem }} \cdot \mathrm{LD}_{\mathrm{C}}(k)\right]}_{\text {fast Cremin }}
$$$$
-\underbrace{\left[\theta_{\text {nit }} \cdot \mathrm{BF}_{\mathrm{N}}\right]}_{\text {benthic remin }}-\underbrace{\left[\theta_{\text {rem }} \cdot \mathrm{BF}_{\mathrm{C}}\right]}_{\text {benthic remin }}+\underbrace{\left[\mathrm{ASF}_{\mathrm{O}_{2}}\right]}_{\text {air-seagas exchange }}
$$

The above equations are applied throughout the domain of the physical ocean model, without regard to horizontal or vertical position. This approach is inherited from MEDUSA-1.0 but differs from that of some other models (Popova et al., 
2006) where different equations are applied in different volumes of the ocean to account, for instance, for photic and aphotic zones. Note that terms such as air-sea gas exchange, aeolian dust deposition and fluxes from the benthic submodel (see below) obviously only apply in ocean grid cells that are in contact with either the atmosphere or the benthos.

$$
\begin{aligned}
& \frac{\mathrm{dB}}{\mathrm{d} t}=+\underbrace{\left[w_{\mathrm{g}} \cdot \frac{\partial \mathrm{D}_{\mathrm{N}}}{\partial z}\right]}_{\text {slow N deposit }}+\underbrace{\left[T_{\mathrm{N}}(z)\right]}_{\text {fast Ndeposit }}-\underbrace{\left[\lambda_{\mathrm{N}} \cdot \mathrm{B}_{\mathrm{N}}\right]}_{\text {benthicNremin }} \\
& \frac{\mathrm{dB}_{\mathrm{Si}}}{\mathrm{d} t}=+\underbrace{\left[T_{\mathrm{Si}}(z)\right]}_{\text {fast }}-\underbrace{\left[\lambda_{\mathrm{Si}} \cdot \mathrm{B}_{\mathrm{Si}}\right]}_{\text {benthic }{ }_{\mathrm{Sidiss}}} \\
& \frac{\mathrm{dB} \mathrm{C}}{\mathrm{d} t}=+\underbrace{\left[w_{\mathrm{g}} \cdot \frac{\partial \mathrm{D}_{\mathrm{C}}}{\partial z}\right]}_{\text {slow Cdeposit }}+\underbrace{\left[T_{\mathrm{C}}(z)\right]}_{\text {fastCdeposit }}-\underbrace{\left[\lambda_{\mathrm{C}} \cdot \mathrm{B}_{\mathrm{C}}\right]}_{\text {benthic Cremin }} \\
& \frac{\mathrm{dB}_{\mathrm{Ca}}}{\mathrm{d} t}=+\underbrace{\left[T_{\mathrm{Ca}}(z)\right]}_{\text {fast deposit }}-\underbrace{\left[\lambda_{\mathrm{Ca}} \cdot \mathrm{B}_{\mathrm{Ca}}\right]}_{\text {benthic Cadiss }}
\end{aligned}
$$

Differential equations (16)-(19) describe the storage and release of biogenic material at the base of each water column in the model. Material enters these reservoirs as slow- and fast-sinking detritus, and is remineralised to DIN, iron, silicic acid, DIC and alkalinity. As with the rest of MEDUS A-2.0, iron is coupled via fixed stoichiometry to the nitrogen cycle and so is handled implicitly. Note that there is no horizontal communication between the benthic reservoirs in MedusA-2.0. Since release of material from the benthic reservoirs occurs at fixed specific rates, the above equations are complete.

\subsection{Interaction functional forms}

The following sections expand on the terms that appear above in MedusA-2.0's differential equations. Although MEDUSA-2.0 includes a number of new state variables as well as several additional biogeochemical processes, it largely overlaps MEDUSA-1.0 with regard to the form and parameterization of shared processes. As such, and since this manuscript aims to provide a complete and standalone description of MEDUSA-2.0, there is repetition with the previously published description of MEDUSA-1.0. Parameter definitions and values are listed in Sect. 2.4.

\subsubsection{Non-diatom limitation and growth}

$\theta_{\mathrm{Pn}}^{\mathrm{Chl}}=\frac{\mathrm{Chl}_{\mathrm{Pn}} \cdot \xi}{\mathrm{Pn}}$

$\hat{\alpha}_{\mathrm{Pn}}=\alpha_{\mathrm{Pn}} \cdot \theta_{\mathrm{Pn}}^{\mathrm{Chl}}$

$\theta_{\mathrm{Pn}}^{\mathrm{Chl}}$ is the scaled chlorophyll to biomass ratio, while $\hat{\alpha}_{\mathrm{Pn}}$ scales the initial slope of the photosynthesis-irradiance $(P-I)$ curve, $\alpha_{\mathrm{Pn}}$, by this ratio so that phytoplankton with a high chlorophyll content have an elevated response to irradiance.

$V_{\mathrm{Pn}^{T}}=V_{\mathrm{Pn}} \cdot 1.066^{T}$

This term calculates maximum phytoplankton growth rate as an exponential function of temperature, $T$, and base growth rate at $0^{\circ} \mathrm{C}$ (Eppley, 1972).

$J_{\mathrm{Pn}}=\frac{V_{\mathrm{Pn}^{T}} \cdot \hat{\alpha}_{\mathrm{Pn}} \cdot I}{\left(V_{\mathrm{Pn}^{T}}^{2}+\hat{\alpha}_{\mathrm{Pn}}^{2} \cdot I^{2}\right)^{1 / 2}}$

Given the (chlorophyll-related) initial slope of the $P-I$ curve and (temperature-related) maximum phytoplankton growth rate, this function calculates realised growth rate given local irradiance, $I\left(\mathrm{~W} \mathrm{~m}^{-2}\right)$.

$$
\begin{aligned}
Q_{\mathrm{N}, \mathrm{Pn}} & =\frac{\mathrm{N}}{k_{\mathrm{N}, \mathrm{Pn}}+\mathrm{N}} \\
Q_{\mathrm{Fe}, \mathrm{Pn}} & =\frac{\mathrm{F}}{k_{\mathrm{Fe}, \mathrm{Pn}}+\mathrm{F}}
\end{aligned}
$$

Nutrient limitation of phytoplankton growth is specified here via standard, hyperbolic Michaelis-Menten terms that use ambient nutrient concentrations and parameters for the concentration at which phytoplankton growth is half its theoretical maximum.

$\mathrm{PP}_{\mathrm{Pn}}=J_{\mathrm{Pn}} \cdot Q_{\mathrm{N}, \mathrm{Pn}} \cdot Q_{\mathrm{Fe}, \mathrm{Pn}}$

Light- and nutrient-limitation factors are brought together in a multiplicative term that determines nutrient uptake and, via Redfield coupling, primary production. Yool et al. (2011) investigated the significance of an alternative Liebig law of the minimum scheme for multiple nutrient limitation, and use of this approach is permitted in MEDUSA-2.0 via a switch, jliebig.

MEDUSA-2.0 uses a light attenuation submodel derived from the simpler LOBSTER model (Levy et al., 2001). This splits photosynthetically available radiation (PAR) into two wavebands ("red" and "green-blue") that are attenuated separately by seawater and by phytoplankton chlorophyll (i.e. not biomass) from both modelled groups. As such, the model includes self-shading by phytoplankton within the water column. Irradiance above, $I$, is the sum of these two components of PAR.

\subsubsection{Diatom limitation and growth}

Diatom phytoplankton growth terms are identical to those of non-diatom phytoplankton. However, because of their obligate requirement for silicon, diatom growth is additionally coupled to the availability of this nutrient, and a submodel of silicon uptake and diatom growth is used to represent these processes (Mongin et al., 2006). This places constraints on growth and nutrient uptake based upon the $\mathrm{Si}: \mathrm{N}$ ratio of the 
modelled diatom cells, but allows a degree of plasticity in this ratio depending upon ambient growth conditions.

$$
\begin{aligned}
\theta_{\mathrm{Pd}}^{\mathrm{Chl}} & =\frac{\mathrm{Ch} l_{\mathrm{Pd}} \cdot \xi}{\mathrm{Pd}} \\
\hat{\alpha}_{\mathrm{Pd}} & =\alpha_{\mathrm{Pd}} \cdot \theta_{\mathrm{Pd}}^{\mathrm{Chl}} \\
V_{\mathrm{Pd}} T & =V_{\mathrm{Pd}} \cdot 1.066^{T} \\
J_{\mathrm{Pd}} & =\frac{V_{\mathrm{Pd}^{T}} \cdot \hat{\alpha}_{\mathrm{Pd}} \cdot I}{\left(V_{\mathrm{Pd}^{T}}^{2}+\hat{\alpha}_{\mathrm{Pd}}^{2} \cdot I^{2}\right)^{1 / 2}} \\
Q_{\mathrm{N}, \mathrm{Pd}} & =\frac{\mathrm{N}}{k_{\mathrm{N}, \mathrm{Pd}}+\mathrm{N}} \\
Q_{\mathrm{Si}} & =\frac{\mathrm{S}}{k_{\mathrm{Si}}+\mathrm{S}} \\
Q_{\mathrm{Fe}, \mathrm{Pd}} & =\frac{\mathrm{F}}{k_{\mathrm{Fe}, \mathrm{Pd}}+\mathrm{F}}
\end{aligned}
$$

As noted above, the growth of diatom phytoplankton is additionally limited by the availability of the macronutrient silicic acid.

$$
\begin{aligned}
& R_{\mathrm{Si}: \mathrm{N}}=\frac{\mathrm{Pd}_{\mathrm{Si}}}{\mathrm{Pd}} \\
& R_{\mathrm{N}: \mathrm{Si}}=\frac{\mathrm{Pd}}{\mathrm{Pd}_{\mathrm{Si}}} .
\end{aligned}
$$

Silicon is largely used by diatom phytoplankton in the construction of their cell walls, or frustules, which can vary significantly in their ornamentation (e.g. spines, girdle bands; Martin-Jézéquel et al., 2000) depending upon silicon availability. As a result, model diatoms have a degree of plasticity in their requirement for silicon, necessitating a separate state variable, $\mathrm{Pd}_{\mathrm{Si}}$, and centred around the stoichiometric ratios, $R_{\mathrm{Si}: \mathrm{N}}$ and $R_{\mathrm{N}: \mathrm{Si}}$.

if $R_{\mathrm{Si}: \mathrm{N}} \leq R_{\mathrm{Si}: \mathrm{N}}^{0}$ then,

$\mathrm{PP}_{\mathrm{Pd}}=0$

else if $R_{\mathrm{Si}: \mathrm{N}}^{0}<R_{\mathrm{Si}: \mathrm{N}}<\left(3 \cdot R_{\mathrm{Si}: \mathrm{N}}^{0}\right)$ then,

$\mathrm{PP}_{\mathrm{Pd}}=\left(J_{\mathrm{Pd}} \cdot Q_{\mathrm{N}, \mathrm{Pd}} \cdot Q_{\mathrm{Fe}, \mathrm{Pd}}\right) \cdot\left(U_{\infty} \cdot \frac{R_{\mathrm{Si}: \mathrm{N}}-R_{\mathrm{Si}: \mathrm{N}}^{0}}{R_{\mathrm{Si}: \mathrm{N}}}\right)$

else if $R_{\mathrm{Si}: \mathrm{N}} \geq\left(3 \cdot R_{\mathrm{Si}: \mathrm{N}}^{0}\right)$ then,

$\mathrm{PP}_{\mathrm{Pd}}=\left(J_{\mathrm{Pd}} \cdot Q_{\mathrm{N}, \mathrm{Pd}} \cdot Q_{\mathrm{Fe}, \mathrm{Pd}}\right)$

In the above equations, $U_{\infty}$ is the hypothetical growth ratio at an infinite ambient $\mathrm{Si}: \mathrm{N}$ ratio, and the uptake of nitrogen (and iron) by diatom cells, $\mathrm{PP}_{\mathrm{Pd}}$, is governed by the $\mathrm{Si}: \mathrm{N}$ ratio. If this falls below a critical value, $R_{\mathrm{Si}: \mathrm{N}}^{0}$, diatom cells are unable to complete their cell division cycle and growth stops (Martin-Jézéquel et al., 2000). At values above this minimum ratio growth is scaled by a factor of the $\mathrm{Si}$ : $\mathrm{N}$ ratio, and above 3 times this ratio, growth in diatom biomass is unimpeded.

if $R_{\mathrm{Si}: \mathrm{N}}<\left(3 \cdot R_{\mathrm{Si}: \mathrm{N}}^{0}\right)^{-1}$ then,

$\operatorname{PP}_{\mathrm{Pd}_{\mathrm{Si}}}=\left(J_{\mathrm{Pd}} \cdot Q_{\mathrm{Si}}\right)$

else if $\left(3 \cdot R_{\mathrm{Si}: \mathrm{N}}^{0}\right)^{-1} \leq R_{\mathrm{Si}: \mathrm{N}}<\left(R_{\mathrm{Si}: \mathrm{N}}^{0}\right)^{-1}$ then,

$\mathrm{PP}_{\mathrm{Pd}_{\mathrm{Si}}}=\left(J_{\mathrm{Pd}} \cdot Q_{\mathrm{Si}}\right) \cdot\left(U_{\infty} \cdot \frac{R_{\mathrm{N}: \mathrm{Si}}-R_{\mathrm{N}: \mathrm{Si}}^{0}}{R_{\mathrm{N}: \mathrm{Si}}}\right)$

else if $R_{\mathrm{Si}: \mathrm{N}} \geq\left(R_{\mathrm{Si}: \mathrm{N}}^{0}\right)^{-1}$ then,

$\mathrm{PP}_{\mathrm{Pd}_{\mathrm{Si}}}=0$

Silicon uptake, $\mathrm{PP}_{\mathrm{Pd}_{\mathrm{Si}}}$, occurs at the maximum rate permitted by light and silicon availability whenever the $\mathrm{Si}: \mathrm{N}$ ratio is below a critical threshold, $\left(3 \cdot R_{\mathrm{Si}: \mathrm{N}}^{0}\right)^{-1}$. Above this ratio, silicon uptake is linearly decreased to another threshold value, $\left(R_{\mathrm{Si}: \mathrm{N}}^{0}\right)^{-1}$, above which no silicon is taken up by diatom cells - though diatom biomass, Pd, can still increase (and, of course, alter the $\mathrm{Si}: \mathrm{N}$ ratio). Figure 2 illustrates these equations by showing uptake of nitrogen and silicon by diatoms across a range of biomass $\mathrm{Si}: \mathrm{N}$ ratios.

\subsubsection{Chlorophyll growth scaling factors}

As noted already, both phytoplankton groups have separate chlorophyll state variables in addition to those of nitrogen biomass. These allow modelled phytoplankton to alter their chlorophyll content dynamically under different light regimes (e.g. in response to season and depth). The following terms for these processes are taken from Taylor et al. (1997).

$$
\begin{aligned}
& R_{\mathrm{Pn}}=\frac{\theta_{\mathrm{max}, \mathrm{Pn}}^{\mathrm{Ch}}}{\theta_{\mathrm{Pn}}^{\mathrm{Chl}}} \cdot \frac{\mathrm{PP}_{\mathrm{Pn}}}{\hat{\alpha}_{\mathrm{Pn}} \cdot I} \\
& R_{\mathrm{Pd}}=\frac{\theta_{\mathrm{max}, \mathrm{Pd}}^{\mathrm{Chl}}}{\theta_{\mathrm{Pd}}^{\mathrm{Chl}}} \cdot \frac{\mathrm{PP}_{\mathrm{Pd}}}{\hat{\alpha}_{\mathrm{Pd}} \cdot I}
\end{aligned}
$$

\subsubsection{Microzooplankton grazing}

As part of the size-structuring of MEDUSA, microzooplankton graze on smaller non-diatom phytoplankton and on particles of slow-sinking detritus. The ingestion function that balances the availability of these prey items with the preference microzooplankton have for them is drawn from the classic model of Fasham et al. (1990).

$G \mu_{\mathrm{X}}=\frac{g_{\mu} \cdot p_{\mu \mathrm{X}} \cdot \mathrm{X}^{2} \cdot \mathrm{Z} \mu}{k_{\mu}^{2}+p_{\mu \mathrm{Pn}} \cdot \mathrm{Pn}^{2}+p_{\mu \mathrm{D}} \cdot \mathrm{D}^{2}}$

In the above, $\mathrm{X}$ is $\mathrm{Pn}$ or $\mathrm{D}$.

The above term is repeated for each separate prey item consumed by microzooplankton. The term is based around a sigmoid function in which the "substrate" is composed of the sum of the prey items scaled by the preference that microzooplankton have for them. It is assumed here that microzooplankton prefer non-diatom phytoplankton over detritus 

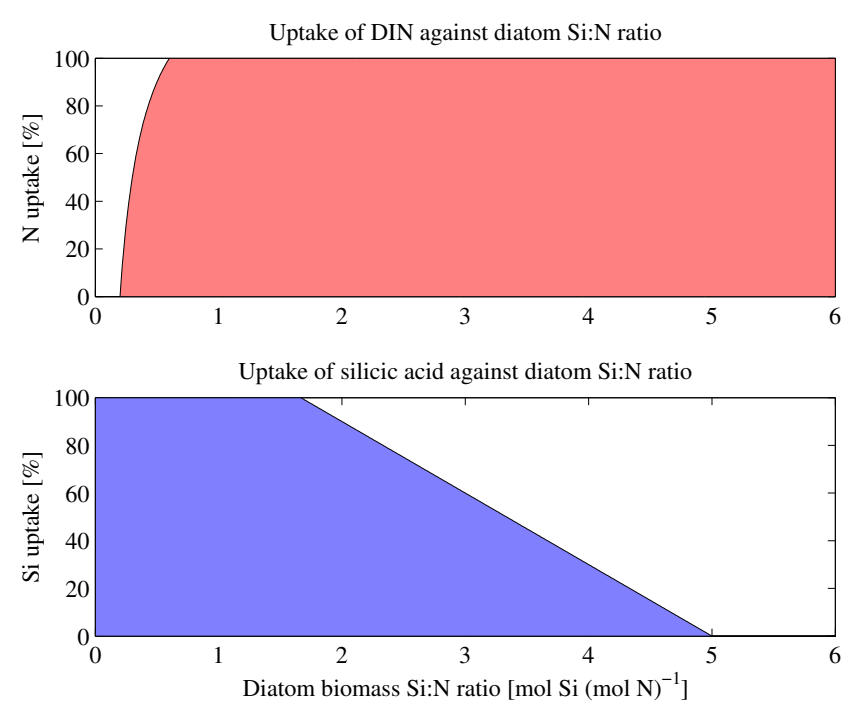

Fig. 2. Diatom uptake of nitrogen (top) and silicon (bottom) against the $\mathrm{Si}$ : $\mathrm{N}$ ratio of diatom biomass.

since they represent a higher quality food item.

$\mathrm{IN}_{\mathrm{Z \mu}}=(1-\phi) \cdot\left(G \mu_{\mathrm{Pn}}+G \mu_{\mathrm{D}}\right)$
$\mathrm{IC}_{\mathrm{Z \mu}}=(1-\phi) \cdot\left(\theta_{\mathrm{Pn}} \cdot G \mu_{\mathrm{Pn}}+\theta_{\mathrm{D}} \cdot G \mu_{\mathrm{D}}\right)$

Here, the separate quantities of nitrogen, $\mathrm{IN}_{Z \mu}$, and carbon, $\mathrm{IC}_{\mathrm{Z} \mu}$, ingested by microzooplankton are summed. Parameter $\phi$ relates to grazing inefficiency, so-called "messy feeding", that returns a fraction of the grazed material back to dissolved nutrient. For the material actually ingested, the resulting $\mathrm{C}: \mathrm{N}$ ratio, $\theta_{\mathrm{F} \mu}$, can be calculated.

$\theta_{\mathrm{F} \mu}=\frac{\mathrm{IC}_{\mathrm{Z} \mu}}{\mathrm{IN}_{\mathrm{Z} \mu}}$

Since grazed material may have a different $\mathrm{C}: \mathrm{N}$ ratio than that required for microzooplankton growth, the assimilation and metabolism submodel of Anderson and Pondaven (2003) is incorporated here to balance growth, excretion and respiration. The $\mathrm{C}: \mathrm{N}$ ratio of ingested food calculated above is then compared to the ideal ratio preferred by microzooplankton, $\theta_{\mathrm{F} \mu}^{*}$. This makes use of the $\mathrm{C}: \mathrm{N}$ ratio of microzooplankton biomass, $\theta_{\mathrm{Z} \mu}$, the assimilation efficiencies of nitrogen, $\beta_{\mathrm{N}}$, and carbon, $\beta_{\mathrm{C}}$, as well as the carbon growth efficiency, $k_{\mathrm{C}}$, of microzooplankton. Unlike in MEDUSA-1.0, where an implicit treatment of carbon required all $\mathrm{C}: \mathrm{N}$ ratios to be identical, here $\theta_{\mathrm{Z} \mu}$ adopts a lower value more consistent with that of zooplankton.

$\theta_{\mathrm{F} \mu}^{*}=\frac{\beta_{\mathrm{N}} \cdot \theta_{\mathrm{Z} \mu}}{\beta_{\mathrm{C}} \cdot k_{\mathrm{C}}}$

Either $\mathrm{C}$ or $\mathrm{N}$ limits production depending on whether $\theta_{\mathrm{F} \mu}$ is greater or lower than $\theta_{\mathrm{F} \mu}^{*}$, with any excess carbon respired, and any excess nitrogen excreted. Respiration, $R_{Z \mu}$, growth, $F_{\mathrm{Z} \mu}$, and excretion, $E_{\mathrm{Z} \mu}$, are calculated as follows.

$R_{\mathrm{Z} \mu}=\left(\beta_{\mathrm{C}} \cdot \mathrm{IC}_{\mathrm{Z \mu}}\right)-\left(\theta_{\mathrm{Z} \mu} \cdot F_{\mathrm{Z} \mu}\right)$

if $\theta_{\mathrm{F} \mu}>\theta_{\mathrm{F} \mu}^{*}$ then $\mathrm{N}$ is limiting and

$F_{\mathrm{Z} \mu}=\beta_{\mathrm{N}} \cdot \mathrm{IN}_{\mathrm{Z} \mu}$

$E_{\mathrm{Z} \mu}=0$

else if $\theta_{\mathrm{F} \mu}<\theta_{\mathrm{F} \mu}^{*}$ then $\mathrm{C}$ is limiting and

$F_{\mathrm{Z} \mu}=\frac{\beta_{\mathrm{C}} \cdot k_{\mathrm{C}} \cdot \mathrm{IC}_{\mathrm{Z} \mu}}{\theta_{\mathrm{Z} \mu}}$

$E_{\mathrm{Z} \mu}=\mathrm{IC}_{\mathrm{Z} \mu} \cdot\left(\frac{\beta_{\mathrm{N}}}{\theta_{\mathrm{F} \mu}}-\frac{\beta_{\mathrm{C}} \cdot k_{\mathrm{C}}}{\theta_{\mathrm{Z} \mu}}\right)$

Figure 3 of Yool et al. (2011) shows the relative partitioning of carbon and nitrogen grazed by zooplankton depending upon food $\mathrm{C}: \mathrm{N}$ ratio. In MedusA-1.0, the flux of $\mathrm{C}$ produced by zooplankton respiration was simply diagnostic, since the biogeochemical cycle of $\mathrm{C}$ was not resolved. Here, the loss of $\mathrm{C}$ through respiration is explicitly balanced by an increase in DIC in Eq. (13).

\subsubsection{Mesozooplankton grazing}

Mesozooplankton grazing follows that of microzooplankton with the exception that mesozooplankton have a broader range of prey items: non-diatoms, diatoms, microzooplankton and slow-sinking detritus. Because of this longer list of prey items, Eq. (55) below is used to simplify the presentation of mesozooplankton grazing. Note that, though mesozooplankton do not utilise grazed silicon from diatoms, Eq. (56) is included below to account for the grazing-induced loss of diatom silicon. For simplicity, parameters $\phi, \beta_{\mathrm{N}}, \beta_{\mathrm{C}}$, and $k_{\mathrm{C}}$ are identical to those used for microzooplankton.

$G m_{\mathrm{X}}=\frac{g_{m} \cdot p_{m \mathrm{X}} \cdot \mathrm{X}^{2} \cdot \mathrm{Zm}}{k_{m}^{2}+F_{m}}$

where $\mathrm{X}$ is $\mathrm{Pn}, \mathrm{Pd}, \mathrm{Z} \mu$ or $\mathrm{D}$.

$$
\begin{aligned}
& F_{m}=\left(p_{m \mathrm{Pn}} \cdot \mathrm{Pn}^{2}\right)+\left(p_{m \mathrm{Pd}} \cdot \mathrm{Pd}^{2}\right)+\left(p_{m Z \mu} \cdot \mathrm{Z} \mu^{2}\right)+\left(p_{m \mathrm{D}} \cdot \mathrm{D}^{2}\right) \\
& G m_{\mathrm{Pd} \mathrm{Si}}=R_{\mathrm{Si}: \mathrm{N}} \cdot G m_{\mathrm{Pd}} \\
& \mathrm{IN}_{\mathrm{Zm}}=(1-\phi) \cdot\left(G m_{\mathrm{Pd}}+G m_{\mathrm{Pn}}+G m_{\mathrm{Z} \mu}+G m_{\mathrm{Pd}}\right) \\
& \mathrm{IC}_{\mathrm{Zm}}=(1-\phi) \cdot\left(\left(\theta_{\mathrm{Pd}} \cdot G m_{\mathrm{Pd}}\right)+\left(\theta_{\mathrm{Pn}} \cdot G m_{\mathrm{Pn}}\right)\right. \\
& \left.\quad+\left(\theta_{\mathrm{Z} \mu} \cdot G m_{\mathrm{Z} \mu}\right)+\left(\theta_{\mathrm{D}} \cdot G m_{\mathrm{D}}\right)\right) \\
& \theta_{\mathrm{Fm}}=\frac{\mathrm{IC}_{\mathrm{Zm}}}{\mathrm{IN}_{\mathrm{Zm}}}
\end{aligned}
$$




$$
\begin{aligned}
& \theta_{\mathrm{Fm}}^{*}=\frac{\beta_{\mathrm{N}} \cdot \theta_{\mathrm{Zm}}}{\beta_{\mathrm{C}} \cdot k_{\mathrm{C}}} \\
& R_{\mathrm{Zm}}=\left(\beta_{\mathrm{C}} \cdot \mathrm{IC}_{\mathrm{Zm}}\right)-\left(\theta_{\mathrm{Zm}} \cdot F_{\mathrm{Zm}}\right) \\
& \text { if } \theta_{\mathrm{Fm}}>\theta_{\mathrm{Fm}}^{*} \text { then } \mathrm{N} \text { is limiting and } \\
& F_{\mathrm{Zm}}=\beta_{\mathrm{N}} \cdot \mathrm{IN} \mathrm{Z}_{\mathrm{Zm}} \\
& E_{\mathrm{Zm}}=0
\end{aligned}
$$

else if $\theta_{\mathrm{Fm}}<\theta_{\mathrm{Fm}}^{*}$ then $\mathrm{C}$ is limiting and

$$
\begin{aligned}
& F_{\mathrm{Zm}}=\frac{\beta_{\mathrm{C}} \cdot k_{\mathrm{C}} \cdot \mathrm{IC}_{\mathrm{Zm}}}{\theta_{\mathrm{Zm}}} \\
& E_{\mathrm{Zm}}=\mathrm{IC}_{\mathrm{Zm}} \cdot\left(\frac{\beta_{\mathrm{N}}}{\theta_{\mathrm{Fm}}}-\frac{\beta_{\mathrm{C}} \cdot k_{\mathrm{C}}}{\theta_{\mathrm{Zm}}}\right)
\end{aligned}
$$

Note that grazing by both types of zooplankton in MEdusA-2.0 is not a function of temperature, in contrast with a number of other studies (e.g. Schartau and Oschlies, 2003; Chen et al., 2012). This decision largely reflects the source of the grazing submodel used here, (Anderson and Pondaven, 2003), as well as the likely computational cost of recalibrating this submodel to include temperaturedependence. Nonetheless, model studies such as that of Taucher and Oschlies (2011) illustrate that the response of plankton ecosystems to future climate warming can be more complex than that typically simulated (e.g. Steinacher et al., 2010). As such, this represents an important aspect for the future development of MEDUSA-2.0.

\subsubsection{Plankton loss terms}

In addition to losses due to grazing, all four living components of the plankton model incur smaller, secondary losses due to other processes.

$$
\begin{aligned}
\mathrm{M} 1_{\mathrm{Pn}} & =\mu_{1, \mathrm{Pn}} \cdot \mathrm{Pn} \\
\mathrm{M} 1_{\mathrm{Pd}} & =\mu_{1, \mathrm{Pd}} \cdot \mathrm{Pd} \\
\mathrm{M} 1_{\mathrm{Pd}_{\mathrm{Si}}} & =R_{\mathrm{Si}} \cdot \mathrm{N} \cdot \mathrm{M} 1_{\mathrm{Pd}} \\
\mathrm{M} 1_{\mathrm{Z} \mu} & =\mu_{1, \mathrm{Z} \mu} \cdot \mathrm{Z} \mu \\
\mathrm{M} 1_{\mathrm{Zm}} & =\mu_{1, \mathrm{Zm}} \cdot \mathrm{Zm}
\end{aligned}
$$

The above functions are density-independent loss terms for processes such as metabolism that occur without reference to abundance (i.e. the absolute loss scales linearly with abundance).

$$
\begin{aligned}
\mathrm{M} 2_{\mathrm{Pn}} & =\mu_{2, \mathrm{Pn}} \cdot \frac{\mathrm{Pn}}{k_{\mathrm{Pn}}+\mathrm{Pn}} \cdot \mathrm{Pn} \\
\mathrm{M} 2_{\mathrm{Pd}} & =\mu_{2, \mathrm{Pd}} \cdot \frac{\mathrm{Pd}}{k_{\mathrm{Pd}}+\mathrm{Pd}} \cdot \mathrm{Pd} \\
\mathrm{M} 2_{\mathrm{Pd}} & =R_{\mathrm{Si}: \mathrm{N}} \cdot \mathrm{M} 2_{\mathrm{Pd}} \\
\mathrm{M} 2_{\mathrm{Z} \mu} & =\mu_{2, \mathrm{Z} \mu} \cdot \frac{\mathrm{Z} \mu}{k_{\mathrm{Z} \mu}+\mathrm{Z} \mu} \cdot \mathrm{Z} \mu \\
\mathrm{M} 2_{\mathrm{Zm}} & =\mu_{2, \mathrm{Zm}} \cdot \frac{\mathrm{Zm}}{k_{\mathrm{Zm}}+\mathrm{Zm}} \cdot \mathrm{Zm}
\end{aligned}
$$

The above functions are density-dependent loss terms for processes that occur at rates that depend upon plankton abundance (i.e. the absolute loss disproportionately increases with abundance). These include those such as disease (e.g. viruses), intra-trophic trophic "cannibalism" and predation by implicit, higher trophic level actors. By default, densitydependent losses are represented using a hyperbolic function of plankton concentration (Fasham, 1993), although switches in the model code (Table 6) permit linear, quadratic and sigmoid functions. The best choice of a form for a mortality function is unclear, but can have significant consequences for models (e.g. Steele and Henderson, 1992; Edwards and Yool, 2000; Anderson et al., 2010). As such, Yool et al. (2011) investigated alternative functions for this mortality term. While the simplest form examined - linear mortality - had significant (and unrealistic) impacts on the behaviour of Medus A-1.0, the differences between simulations using quadratic, hyperbolic (as here) and sigmoid forms was much more minor, and MEDUSA-2.0 retains the same default as MedusA-1.0.

\subsubsection{Miscellaneous losses}

As silicic acid occurs at undersaturated concentrations throughout the modern ocean (Yool and Tyrrell, 2003), the silicon component of diatom phytoplankton is additionally vulnerable to dissolution. This is represented here by a simple linear loss rate (Mongin et al., 2006).

$\mathrm{DS}_{\mathrm{Pd}_{\mathrm{Si}}}=\mathrm{Diss} \cdot \mathrm{Pd}_{\mathrm{Si}}$

Remineralisation of slow-sinking detrital particles to dissolved inorganic pools occurs at rates dependent on ambient temperature.

$$
\begin{aligned}
\mathrm{M}_{\mathrm{D}} & =\mu_{\mathrm{D}} \cdot 1.066^{T} \cdot \mathrm{D} \\
\mathrm{M}_{\mathrm{Dc}} & =\mu_{\mathrm{Dc}} \cdot 1.066^{T} \cdot \mathrm{D}_{\mathrm{C}}
\end{aligned}
$$

\subsubsection{Iron supply and removal}

Following the submodel of Dutkiewicz et al. (2005), iron is added to the ocean by aeolian deposition of iron-carrying dust at the surface, and removed throughout its volume by scavenging.

$F_{\text {atmos }}=$ spatially variable rate

The field of iron deposition used in MEdusA-1.0 has been updated for MEDUSA-2.0 to take advantage of a newer climatology, and now makes use of the "present-day" field produced by Mahowald (2005). Figure 3 shows a map of annual average iron deposition. However, as with MEDUSA-1.0, aeolian iron solubility was adjusted such that the total addition of dissolved iron to the open ocean by dust was the same as that of Dutkiewicz et al. (2005).

$F_{\text {benthos }}=$ spatially variable rate 

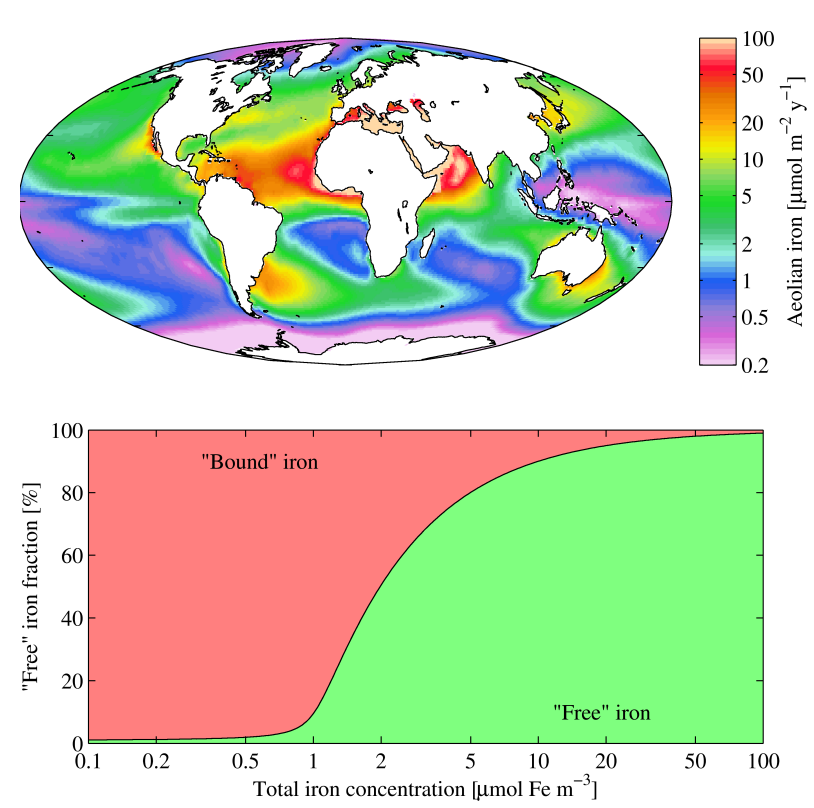

Fig. 3. The top panel shows mean annual aeolian iron input to the ocean (i.e. the quantity of iron that dissolves into seawater from deposited dust). The input is shown on a logarithmic scale in units of $\mu \mathrm{molm}^{-2} \mathrm{yr}^{-1}$, and integrated input is $2.564 \mathrm{GmolFe} \mathrm{yr}^{-1}$. The bottom panel shows the fractionation of total iron between "free" and ligand-bound forms across a logarithmic range of total iron concentrations.

A further difference with MedusA-1.0 lies in the inclusion of a benthic source of dissolved iron. Such a supply route is already known for iron, most noticeably around islands and other areas of shallow water in regions that are otherwise depleted in iron (e.g. the Crozet Archipelago in the Southern Ocean; Pollard et al., 2009), and some existing models already include it (e.g. Moore et al., 2004). Here, a flux of iron is added to ocean cells immediately above the seafloor wherever the water column is shallower than $500 \mathrm{~m}$. There is considerable uncertainty in the addition rate of iron to the ocean by this route (Moore et al., 2004), and here the rate has been chosen such that aeolian and benthic supply routes are of approximately similar magnitude.

$F_{\text {free }}=F-F_{\text {ligand }}$

Medusa's iron state variable, $F$, represents total iron, and this is assumed to occur in two fractions: "free", $F_{\text {free}}$; and that bound to organic ligands, $F_{\text {ligand }}$ (Gledhill and van den Berg, 1994). In the ocean, it is estimated that more than $97 \%$ of total iron is complexed with ligands (Boye et al., 2003).

$$
\begin{aligned}
F_{\text {ligand }} & =L_{\text {total }}-L_{\text {free }} \\
L_{\text {free }} & =0.5 \cdot \frac{\left(F_{1}+\sqrt{F_{2}}\right)}{k_{\mathrm{FeL}}} \\
F_{1} & =k_{\mathrm{FeL}} \cdot\left(L_{\mathrm{total}}-F\right)-1 \\
F_{2} & =\max \left(F_{1}^{2}+\left(4 \cdot k_{\mathrm{FeL}} \cdot L_{\mathrm{total}}\right), 0\right)
\end{aligned}
$$

The complexation reactions between iron species and ligands occur rapidly, and it is assumed here that they reach equilibrium in a shorter period than the model time step (Rose and Waite, 2003). In the equations above, $L_{\text {total }}$ is the total ligand concentration of seawater, and is assumed to be globally constant; $k_{\mathrm{FeL}}$ is the ligand binding strength. Given these equations and parameters, Fig. 3 illustrates the resulting partition between "free" and bound iron over a range of total iron concentrations.

$F_{\text {scavenge }}=k_{\text {scav }} \cdot F_{\text {free }}$

Scavenging of iron occurs at a fixed linear rate, $k_{\text {scav }}$, throughout the full volume of the ocean, but is assumed to only remove "free" iron, $F_{\text {free }}$.

\subsubsection{Fast detritus production}

Sinking detrital material in MedusA-2.0 occurs in two forms:

- Small particles that are assumed to sink slowly and are modelled explicitly (as D and $\mathrm{D}_{\mathrm{C}}$ ); these particles remineralise at a temperature-dependent rate and are a food item of both micro- and mesozooplankton.

- Large particles that are assumed to sink quickly and whose attenuation down the water column is modelled implicitly; these particles remineralise exponentially with depth and are not available as a food item.

As in MedusA-1.0, fast-sinking detrital particles are remineralised down the water column using a variant of the socalled ballasting hypothesis (Armstrong et al., 2002). This scheme posits a relationship between organic material and associated - and protective - biominerals. As the description in Yool et al. (2011) includes extensive treatment of the scheme used in MEDUSA-1.0, here we give a summary overview and focus on the differences in MEDUSA-2.0.

In the first instance, the components of fast-sinking detrital particles are produced by a series of ecosystem processes. Organic material $(\mathrm{N}, \mathrm{Fe}, \mathrm{C})$ is derived from losses from diatoms and mesozooplankton, the larger components of the plankton. Note that, as with other processes, iron is again coupled to nitrogen via a fixed $\mathrm{Fe}: \mathrm{N}$ ratio.

Equations 87-91 below relate to the total quantities of fastsinking detrital components, $T_{\mathrm{X}}$, being transferred downwards between model levels - that is, increasing values of model grid index $k$. The equations express the amount of material entering, $k$, and exiting, $k+1$, a given model layer and the processes that act as sources ("production") and sinks ("remineralisation") for these quantities. Later 
equations describe these sink, or loss, terms, $\mathrm{LD}_{\mathrm{X}}$.

$$
\begin{aligned}
& T_{\mathrm{N}}(k+1)=\underbrace{T_{\mathrm{N}}(k)}_{\text {FDN from above }}-\underbrace{\mathrm{LD}_{\mathrm{N}}}_{\text {FD remineralisation }} \\
& +\underbrace{\left(\left(\mathrm{D} 1_{\mathrm{frac}} \cdot \mathrm{M} 2_{\mathrm{Pd}}\right)+\left(\mathrm{D} 2_{\mathrm{frac}} \cdot \mathrm{M} 2_{\mathrm{Zm}}\right)\right) \cdot \delta z(k)}_{\text {FD production }} \\
& T_{\mathrm{Fe}}(k+1)=\underbrace{T_{\mathrm{Fe}}(k)}_{\text {FD Fe from above }}-\underbrace{\mathrm{LD}_{\mathrm{Fe}}}_{\text {FD remineralisation }} \\
& +\underbrace{\left(\left(R_{\mathrm{Fe}} \cdot \mathrm{D} 1_{\mathrm{frac}} \cdot \mathrm{M} 2_{\mathrm{Pd}}\right)+\left(R_{\mathrm{Fe}} \cdot \mathrm{D} 2_{\mathrm{frac}} \cdot \mathrm{M} 2_{\mathrm{Zm}}\right)\right) \cdot \delta z(k)}_{\text {FD production }} \\
& T_{\mathrm{C}}(k+1)=\underbrace{T_{\mathrm{C}}(k)}_{\text {FDCfrom above }}-\underbrace{\mathrm{LD}_{\mathrm{C}}}_{\text {FD remineralisation }} \\
& +\underbrace{\left(\left(\theta_{\mathrm{Pd}} \cdot \mathrm{D} 1_{\mathrm{frac}} \cdot \mathrm{M} 2_{\mathrm{Pd}}\right)+\left(\theta_{\mathrm{Zm}} \cdot \mathrm{D} 2_{\mathrm{frac}} \cdot \mathrm{M} 2_{\mathrm{Zm}}\right)\right) \cdot \delta z(k)}_{\text {FD production }}
\end{aligned}
$$

Inorganic biogenic opal ( $\mathrm{Si}$ ) is derived directly (via cell mortality) or indirectly (as a product of mesozooplankton grazing) from diatom phytoplankton. In MedusA-1.0, the fraction of grazed opal that became associated with fastsinking detritus was the same as the fraction of mesozooplankton losses that were similarly channelled, D $2_{\text {frac }}$. Here, a new parameter, $\mathrm{D} 3_{\text {frac }}$, has been introduced to allow the separate specification of this transfer efficiency.

$$
\begin{aligned}
& T_{\mathrm{Si}}(k+1)=\underbrace{T_{\mathrm{Si}}(k)}_{\text {FDSifrom above }}-\underbrace{\mathrm{LD}_{\mathrm{Si}}}_{\text {FD dissolution }} \\
& +\underbrace{\left(\left(\mathrm{D} 1_{\text {frac }} \cdot \mathrm{M} 2_{\mathrm{Pd}_{\mathrm{Si}}}\right)+\left(\mathrm{D} 3_{\text {frac }} \cdot G m_{\mathrm{Pd}_{\mathrm{Si}}}\right)\right) \cdot \delta z(k)}_{\text {FD production }}
\end{aligned}
$$

Calcium carbonate, $\mathrm{CaCO}_{3}$, is also an important biomineral in the ballast hypothesis, but its production is not modelled explicitly in either version of MEDUSA. This decision to omit calcification in MEDUSA stems from the diversity (phylogenetic and trophic) of organisms that manufacture $\mathrm{CaCO}_{3}$ and the uncertainty in the ecological factors that regulate it, as is evidenced by the wide range of approaches used to model it (e.g. Tyrrell and Taylor, 1996; Moore et al., 2002; Gehlen et al., 2007; Zahariev et al., 2008; Yool et al., 2010). Instead, MEDUSA adopts an empirical approach in which the only calcification explicitly considered is that associated with sinking material; $\mathrm{CaCO}_{3}$ that is synthesised and dissolved without significant vertical movement is considered tangential.

$$
\begin{aligned}
& T_{\mathrm{CaCO}_{3}}(k+1)=\underbrace{}_{\mathrm{FDCaCO}} \text { from above } \\
& T_{\mathrm{CaCO}_{3}(k)}-\underbrace{\mathrm{LD}_{\mathrm{CaCO}_{3}}}_{\text {FDdissolution }} \\
& +\underbrace{\left(\left(\theta_{\mathrm{Pd}} \cdot \mathrm{D} 1_{\text {frac }} \cdot \mathrm{M} 22_{\mathrm{Pd}}\right)+\left(\theta_{\mathrm{Zm}} \cdot \mathrm{D} 2_{\text {frac }} \cdot \mathrm{M} 2_{\mathrm{Zm}}\right)\right) \cdot \delta z(k) \cdot \mathrm{fo}\left(\Omega_{\text {calcite }}\right)}_{\text {FD production }}
\end{aligned}
$$

Following Dunne et al. (2007), MEDus A-1.0 used a simple triangular function of latitude, fc(lat), to calculate the relative quantity of $\mathrm{CaCO}_{3}$ associated with fast-sinking detrital particles, the so-called "rain ratio" (highest values at the equator and lowest values at the poles). MEDUSA-2.0 retains this functionality as an option, but introduces a further option that instead calculates associated $\mathrm{CaCO}_{3}$ as a function, fo $\left(\Omega_{\text {calcite }}\right)$, of the ambient saturation state of the $\mathrm{CaCO}_{3}$ polymorph calcite.

fo $\left(\Omega_{\text {calcite }}\right)=\left(\Omega_{\text {calcite }}-1\right)^{\eta} \cdot r_{0}$

This is based on the formulation of Ridgwell et al. (2007), and uses the concentrations of calcium (seawater average; scaled by salinity) and carbonate (calculated from DIC) ions

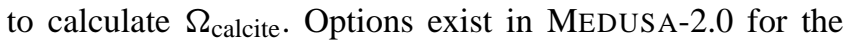
rain ratio to be based on $\Omega_{\text {calcite }}$ at the ocean surface or at the local position within its interior (via switch jrratio; see Table 6). Parameter $r_{0}$ has been scaled in MEDUSA-2.0 so that total production of $\mathrm{CaCO}_{3}$ using Eq. (92) approximately matches that in MEDUSA-1.0 (see later). Note that in the real ocean a second polymorph of $\mathrm{CaCO}_{3}$ is also produced, aragonite, but for simplicity calculations are performed as if all $\mathrm{CaCO}_{3}$ in MEDUSA-2.0 is the more stable polymorph, calcite (though the saturation state of aragonite, $\Omega_{\text {aragonite, }}$ is calculated as a diagnostic variable).

\subsubsection{Fast detritus remineralisation}

The ballast hypothesis of Armstrong et al. (2002) posits that a fraction of the sinking organic material is quantitatively associated with sinking inorganic material (here calcium carbonate and biogenic silica), and that this provides "protection" for the organic matter, allowing it to penetrate deeper into the water column than might otherwise be expected. Follow-up work by Klaas and Archer (2002) derived a parameterization of the hypothesis based on a global data set of sediment trap measurements, and this latter study has subsequently been used as the basis for other work. Its implementation by Dunne et al. (2007) was that adopted by MEDUSA-1.0, and this has been retained by MEDUSA-2.0.

By way of summary, the fast-sinking detrital flux of organic carbon is proportioned into so-called "protected", $\mathrm{TC}_{\text {protect }}=\left(\mathrm{TC}_{\mathrm{bSi}}+\mathrm{TC}_{\mathrm{bCaCO}}\right)$, and "excess", $\mathrm{TC}_{\text {excess }}$, portions as follows.

$$
\begin{aligned}
\mathrm{TC}_{\mathrm{bSi}} & =T_{\mathrm{Si}}(k) \cdot \frac{\mathrm{M}_{\mathrm{Si}}}{\mathrm{M}_{\mathrm{org}}} \cdot f_{\mathrm{Si}} \\
\mathrm{TC}_{\mathrm{bCaCO}_{3}} & =T_{\mathrm{CaCO}_{3}}(k) \cdot \frac{\mathrm{M}_{\mathrm{CaCO}_{3}}}{\mathrm{M}_{\mathrm{org}}} \cdot f_{\mathrm{CaCO}_{3}} \\
\mathrm{TC}_{\text {protect }} & =\left(\mathrm{TC}_{\mathrm{bSi}}+\mathrm{TC}_{\mathrm{bCa}}\right) \\
\mathrm{TC}_{\text {excess }} & =T_{\mathrm{C}}(k)-\mathrm{TC}_{\text {protect }}
\end{aligned}
$$

Where $\mathrm{M}_{\mathrm{Si}}$ and $\mathrm{M}_{\mathrm{CaCO}_{3}}$ convert molar silicon and calcium carbonate ballast into mass equivalents that can then be used with mass-based organic carbon protection ratios $f_{\mathrm{Si}}$ and $f_{\mathrm{CaCO}_{3}}$. The "protected" fraction passes through unscathed to the next level down the water column, while the "excess" fraction is attenuated across a particular level, with a corresponding release of inorganic carbon. Not all "excess" 
carbon is remineralised in a given level, and the surviving portion, $\mathrm{TC}_{\text {survive }}$, is calculated as follows.

$\mathrm{TC}_{\text {survive }}=\mathrm{TC}_{\text {excess }} \cdot \exp \left(-\frac{\delta z(k)}{d_{\text {excess }}}\right)$

Leaving aside that added through production (see Eq. 89), the quantity of fast detritus reaching the next model layer, $T_{\mathrm{C}}(k+1)$, is then as follows.

$T_{\mathrm{C}}(k+1)=\mathrm{TC}_{\text {protect }}+\mathrm{TC}_{\text {survive }}$

The flux of remineralised carbon to level $k$ is then simply as shown below.

$\mathrm{LD}_{\mathrm{C}}(k)=\frac{\mathrm{TC}_{\text {excess }}-\mathrm{TC}_{\text {survive }}}{\delta z(k)}$

The remineralisation fluxes of nitrogen and iron follow that of carbon, with the same fraction of sinking material "protected" by ballasting minerals. By contrast, the sinking fluxes of both biogenic silica, $T_{\mathrm{Si}}(k)$, and calcium carbonate, $T_{\mathrm{CaCO}_{3}}(k)$, attenuate with depth independently of organic carbon.

In the case of biogenic silica, this attenuation occurs at all depths because it is globally undersaturated with respect to ambient silicic acid concentrations. The equations governing sinking biogenic silica and its dissolution are as follows.

$$
\begin{gathered}
T_{\mathrm{Si}}(k+1)=T_{\mathrm{Si}}(k) \cdot \exp \left(-\frac{\delta z(k)}{d_{\mathrm{Si}}}\right) \\
\mathrm{LD}_{\mathrm{Si}}(k)=\frac{T_{\mathrm{Si}}(k)-T_{\mathrm{Si}}(k+1)}{\delta z(k)}
\end{gathered}
$$

Unlike biogenic silica, $\mathrm{CaCO}_{3}$ is generally not soluble in surface waters because of supersaturating concentrations of the carbonate ion. However, at depth, specifically below the lysocline, concentrations become undersaturating and dissolution can occur.

if $z(k)<$ lysocline(lat, lon)

$T_{\mathrm{CaCO}_{3}}(k+1)=T_{\mathrm{CaCO}_{3}}(k) \cdot \exp \left(-\frac{\delta z(k)}{d_{\mathrm{CaCO}_{3}}}\right)$

else

$T_{\mathrm{CaCO}_{3}}(k+1)=T_{\mathrm{CaCO}_{3}}(k)$

In MedusA-1.0, the depth of the lysocline, lysocline(lat, lon), was precalculated using physical and biogeochemical fields from the World Ocean Atlas and GLODAP climatologies (Locarnini et al., 2010; Antonov et al., 2010; Key et al., 2004). Here, the inclusion of DIC and alkalinity, as well as a carbonate chemistry submodel, allows MEDUSA-2.0 to calculate the saturation state of $\mathrm{CO}_{3}^{2-}$ at all depths, and to use this to determine the point in each water column at which biogenic $\mathrm{CaCO}_{3}$ will begin to dissolve. The dissolution flux calcium carbonate is then simply as follows.

$\mathrm{LD}_{\mathrm{CaCO}_{3}}(k)=\frac{T_{\mathrm{CaCO}_{3}}(k)-T_{\mathrm{CaCO}_{3}}(k+1)}{\delta z(k)}$
Figure 20 (see later) shows the depth of the simulated lysocline.

\subsubsection{Computation}

The structure of MEDusA is such that the production of particles of fast-sinking detritus has a variable vertical distribution that depends upon location-specific details in plankton dynamics. Consequently, production and remineralisation of fast-sinking particles occur in parallel down the water column, unlike the situation in the source model for this part of MedusA, Dunne et al. (2007). As described previously in Yool et al. (2011), the computation of the distribution and fate of fast-sinking detritus is performed layer-bylayer down the water column. All fast-sinking detritus produced within one layer is exported to the next layer, together with the fast-sinking detritus from preceding layers that is not remineralised within that one layer. MEDUSA then iterates this process down the water column to the seafloor, at which point all fast-sinking detritus has either been remineralised or is transferred to the benthic reservoirs. The entire procedure is implicit and occurs within a model time step. As such, the fast-sinking detritus component of MEDUSA unlike the slow-sinking component - does not explicitly consider detrital sinking speeds or remineralisation rates, but instead operates in an e-folding length scale approach akin to the canonical empirical export model of Martin et al. (1987).

Additional explanation of the fast-sinking detritus scheme can be found in commentary within the model source code that accompanies this document.

\subsubsection{Alternative models}

Separate from the ballast model, MedusA-2.0 includes a code switch, jexport, to permit the use of two alternative remineralisation schemes for the organic components of fastsinking detritus: the classic Martin et al. (1987) curve; and the variant developed by Henson et al. (2012). Both models attenuate organic material using the same power relationship shown below.

$F_{\mathrm{C}}(z)=F_{\mathrm{C}}(100) \cdot\left(\frac{z}{100}\right)^{b}$

Parameterized using the limited data that was available at the time, the Martin et al. (1987) curve uses a fixed value of -0.858 for parameter $b$ in Eq. (105). Using a more modern data set of thorium-derived POC export, Henson et al. (2012) developed a variant scheme in which parameter $b$ is instead a function of local surface temperature.

$b=-1.06+(0.024 \cdot T)$

In the work described here, only the ballast scheme is formally used, though the significance of these (and, potentially, other) schemes will be the subject of future work. 


\subsubsection{Air-sea gas exchange}

MedusA-2.0 includes gas exchange for two modelled constituents, $\mathrm{O}_{2}$ and $\mathrm{CO}_{2}$. In the case of $\mathrm{O}_{2}$, the scheme developed by Najjar and Orr (1999) for the OCMIP-2 project is used. In this, the saturation concentration of $\mathrm{O}_{2}$ is calculated based on local temperature and salinity, and this is used in conjunction with ocean surface $\mathrm{O}_{2}$ concentration and wind speed (via standard gas transfer calculations) to calculate airsea exchange.

The case of $\mathrm{CO}_{2}$ is complicated by the intricacies of carbonate chemistry, which necessitates the iterative calculation of surface ocean $\mathrm{pH}$ to determine surface $\mathrm{H}_{2} \mathrm{CO}_{3}$ concentration. As with $\mathrm{O}_{2}$, this is then combined with atmospheric $p \mathrm{CO}_{2}$ and wind speed to calculate the air-sea exchange of $\mathrm{CO}_{2}$. The numerical scheme used here is that published by Blackford et al. (2007) (and utilised in Artoli et al., 2012). Alongside air-sea exchange, this scheme calculates other carbonate chemistry properties that are utilised by MEDUSA-2.0, such

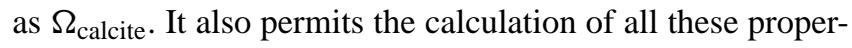
ties at arbitrary depths down the water column, and is used in Medus A-2.0 to determine the location of the CCD.

Surface gas exchange calculations are performed at every model timestep. Carbonate chemistry calculations are only performed for the full water column on a monthly timescale to reduce computational burden.

\subsubsection{Oxygen cycle}

Since its cycle is tightly coupled to that of nitrogen and carbon, the differential equation for dissolved oxygen, Eq. (15), contains a large number of terms. However, these are largely replicated from other differential equations, and scaled by the appropriate stoichiometric ratio, $\theta_{\text {nit }}$ or $\theta_{\text {rem }}$. The oxygen stoichiometry used here follows that of Yool et al. (2010), and is ultimately derived from one of the range of estimates put forward by Anderson (1995) to account for the production by phytoplankton of a suite of organic molecules (including lipids, proteins and nucleic acids) in addition to carbohydrates, $\left(\mathrm{CH}_{2} \mathrm{O}\right)_{\mathrm{n}}$. The resulting $\mathrm{C}: \mathrm{N}: \mathrm{O}_{2}$ stoichiometry of organic matter production is as follows.

$$
\begin{aligned}
& 106 \mathrm{CO}_{2}+16 \mathrm{HNO}_{3}+78 \mathrm{H}_{2} \mathrm{O}+\text { light } \\
& \Rightarrow\left(\mathrm{C}_{106} \mathrm{H}_{124} \mathrm{O}_{36}\right)\left(\mathrm{NH}_{3}\right)_{16}+151 \mathrm{O}_{2}
\end{aligned}
$$

The remineralisation of organic matter in MEDUSA-2.0 is assumed to be be precise reverse of this. This translates to a $\mathrm{C}: \mathrm{N}: \mathrm{O}_{2}$ ratio of $106: 16:-151$ for the organic matter produced, and effectively assumes that primary production is fuelled by nitrate, as well as the complete nitrification of organic nitrogen back to nitrate during remineralisation. In addition to suggesting a reduced $\mathrm{H}$ and $\mathrm{O}$ content of organic material relative to conventional carbohydrate synthesis, $106: 16:-138$, it also results in an increased production of $\mathrm{O}_{2}$ per mol of fixed carbon. For reference, using similar assumptions to those above, organic matter production using ammonia, and remineralisation back to the same, would have a corresponding $\mathrm{C}: \mathrm{N}: \mathrm{O}_{2}$ stoichiometry of $106: 16:-119$.

To facilitate accounting given variable $\mathrm{C}: \mathrm{N}$ ratios across MedusA-2.0, the terms listed in Eq. (15) (and the model code) separate oxygen production and consumption according to whether nitrogen or carbon are being remineralised by a particular process. Given the above stoichiometry, this gives a $\mathrm{O}_{2}: \mathrm{N}$ ratio for $\theta_{\text {nit }}$ of $2: 1(=2.0)$, and a $\mathrm{O}_{2}: \mathrm{C}$ ratio for $\theta_{\text {rem }}$ of $119: 106(\simeq 1.1226)$.

Note that, following Najjar and Orr (1999), dissolved oxygen is consumed down to a minimum concentration, $\mathrm{O}_{\min }$, below which remineralisation can still take place (using unspecified and unmodelled oxidants) but without consuming oxygen.

\subsubsection{Alkalinity cycle}

The partial differential equation for alkalinity, Eq. (14), has only three terms: one for $\mathrm{CaCO}_{3}$ production, and one each for pelagic and benthic dissolution. As described previously, the production of $\mathrm{CaCO}_{3}$ is a function of the production of fast-sinking detritus and ambient $\Omega_{\text {calcite. Dissolution occurs }}$ below the calculated CCD (see Fig. 20) and at the seafloor regardless of CCD depth, in order to prevent drift in pelagic alkalinity inventory. This simplicity reflects the aim, in both MedusA-1.0 and MedusA-2.0, of representing the dominant driver of alkalinity distributions, the so-called "hard tissues" component of the biological pump (cf. Najjar and Orr, 1999). A result of this approach is the omission from consideration of secondary processes that would require a more complex treatment (cf. Wolf-Gladrow et al., 2007; Paulmier et al., 2009). For instance, as noted above, bulk DIN is considered in MEDUSA-2.0 rather than separate nitrate and ammonia (as well as other species), the differing use (and remineralisation) of which impacts proton consumption and production and, thus, distribution of alkalinity. Similarly, the inclusion of explicit calcifiers with variable abundance, and potentially dynamic calcification, would require a more complex alkalinity cycle. However, the restricted set of actors and processes selected for inclusion in the current version of MEdus a limit the need for a more sophisticated submodel.

\subsubsection{Miscellaneous}

In MedusA-1.0, the same Redfield $\mathrm{C}: \mathrm{N}$ ratio of 6.625 was assumed for both phytoplankton and zooplankton so that the pool of detritus was fed $\mathrm{C}$ and $\mathrm{N}$ at the same ratio regardless of the source. With the inclusion of a separate detrital carbon pool, $\mathrm{D}_{\mathrm{C}}$, these ratios no longer need to be identical, and both micro- and mesozooplankton are assumed to have a lower $\mathrm{C}: \mathrm{N}$ ratio, 5.625 (Anderson and Pondaven, 2003).

\subsection{Parameter values}

Tables 1-6 list model parameters, a brief description of each, and their respective units and default values. For ease of use, 
Table 1. Phytoplankton growth parameters.

\begin{tabular}{|c|c|c|}
\hline$\xi$ & $\begin{array}{l}\mathrm{C}: \mathrm{N} \text { conversion factor } \\
\mathrm{molN}(\mathrm{gC})^{-1}\end{array}$ & 0.01257 \\
\hline$\alpha_{\mathrm{Pn}}, \alpha_{\mathrm{Pd}}$ & $\begin{array}{l}\text { chl-specific initial slope of } P-I \text { curve } \\
\mathrm{gC}(\mathrm{gchl})^{-1}\left(\mathrm{~W} \mathrm{~m}^{-2}\right)^{-1} \mathrm{~d}^{-1}\end{array}$ & $15.0,11.25$ \\
\hline$V_{\mathrm{Pn}}, V_{\mathrm{Pd}}$ & $\begin{array}{l}\text { maximum phytoplankton growth rate } \\
\mathrm{d}^{-1}\end{array}$ & $0.53,0.50$ \\
\hline$\theta_{\max , \mathrm{Pn}}^{\mathrm{Chl}}, \theta_{\max , \mathrm{Pd}}^{\mathrm{Chl}}$ & $\begin{array}{l}\operatorname{maximum} \mathrm{Chl}: \mathrm{C} \text { ratio } \\
\mathrm{gchl}(\mathrm{gC})^{-1}\end{array}$ & $0.05,0.05$ \\
\hline$R_{\mathrm{Si}: \mathrm{N}}^{0}$ & $\begin{array}{l}\text { minimum diatom } \mathrm{Si}: \mathrm{N} \text { ratio } \\
\operatorname{mol} \mathrm{Si}(\mathrm{molN})^{-1}\end{array}$ & 0.2 \\
\hline$R_{\mathrm{N}: \mathrm{Si}}^{0}$ & $\begin{array}{l}\operatorname{minimum} \text { diatom } \mathrm{N}: \text { Si ratio } \\
\operatorname{molN}(\mathrm{molSi})^{-1}\end{array}$ & 0.2 \\
\hline$U_{\infty}$ & $\begin{array}{l}\text { hypothetical growth ratio at } \infty \mathrm{Si}: \mathrm{N} \text { ratio } \\
-\end{array}$ & 1.5 \\
\hline$k_{\mathrm{N}, \mathrm{Pn}}, k_{\mathrm{N}, \mathrm{Pd}}$ & $\begin{array}{l}\mathrm{N} \text { nutrient uptake half-saturation constants } \\
\mathrm{mmolNm}^{-3}\end{array}$ & $0.50,0.75$ \\
\hline$k_{\mathrm{Si}}$ & $\begin{array}{l}\text { Si nutrient uptake half-saturation constant } \\
\mathrm{mmolSim}^{-3}\end{array}$ & 3.00 \\
\hline$k_{\mathrm{Fe}, \mathrm{Pn}}, k_{\mathrm{Fe}, \mathrm{Pd}}$ & $\begin{array}{l}\text { Fe nutrient uptake half-saturation constants } \\
\mu \mathrm{molFe} \mathrm{m}\end{array}$ & $0.33,0.67$ \\
\hline
\end{tabular}

the ordering of parameters closely reflects their appearance in the namelist.trc.sms file in which they are specified (see Appendix A and accompanying model code).

Almost all parameter values in MEDUSA-2.0 are identical to those from MEDUSA-1.0, though there are a small number of minor changes, and several additional parameters that relate to new state variables. Regarding parameters with reassigned values, the diatom half-saturation concentration for silicic acid uptake, $k_{\mathrm{Si}}$, has been increased $(0.75 \rightarrow 3.0)$ to a value more congruent with studies such as Fasham et al. (2006). Small detritus sinking velocity, $w_{\mathrm{g}}$, has been slightly decreased $(3.0 \rightarrow 2.5)$ to favour shallower remineralisation and near-surface nutrient retention. Reflecting the addition of the carbon cycle, the assimilation efficiencies of both zooplankton types are now specified separately for the nitrogen (0.77) and carbon (0.64) ingested during grazing (from Medus A-1.0's common value of 0.69; Anderson and Pondaven, 2003). New parameters include a separate remineralisation rate for detrital carbon, a series of oxygen stoichiometry parameters, a minimum concentration for dissolved oxygen consumption, and a series of remineralisation/dissolution rate parameters for the benthic reservoirs.

In addition to the parameters above, MEDUSA-2.0 includes a number of control parameters that allow the model to switch between different functional forms for a small number of processes. These appear in namelist.trc.sms and are listed in Table 6. As noted above, the control parameters available in MEDUSA-1.0 have been augmented by several new options including export submodel, jexport, rain ratio calculation, jrratio and $\mathrm{CCD}$ calculation, jocalccd.
Table 2. Zooplankton grazing parameters.

\begin{tabular}{llc}
\hline$g_{\mu}, g_{m}$ & $\begin{array}{l}\text { maximum zooplankton grazing rate } \\
\mathrm{d}^{-1}\end{array}$ & $2.0,0.5$ \\
$k_{\mu}, k_{m}$ & $\begin{array}{l}\text { zooplankton grazing half-saturation constants } \\
\text { mmol } \mathrm{Nm}^{-3}\end{array}$ & $0.8,0.3$ \\
& zooplankton grazing inefficiency & 0.20 \\
& - & \\
$\beta_{\mathrm{N}}$ & zooplankton N assimilation efficiency & 0.77 \\
& - & 0.64 \\
$\beta_{\mathrm{C}}$ & zooplankton C assimilation efficiency & 0.80 \\
& - & \\
$k_{\mathrm{C}}$ & zooplankton net C growth efficiency & $0.75,0.25$ \\
$p_{\mu \mathrm{Pn}}, p_{\mu \mathrm{D}}$ & - & \\
& - & $0.15,0.35$ \\
$p_{m \mathrm{Pn}}, p_{m \mathrm{Pd}}$, & mesozooplankton grazing preferences \\
$p_{m \mathrm{Z} \mu}, p_{m \mathrm{D}}$ & - & $0.35,0.15$ \\
\hline
\end{tabular}

Table 3. Plankton and detritus loss parameters.

\begin{tabular}{llc}
\hline$\mu_{1, \mathrm{Pn}}, \mu_{1, \mathrm{Pd}}$ & $\begin{array}{l}\text { phytoplankton loss rates } \\
\mathrm{d}^{-1}\end{array}$ & $0.02,0.02$ \\
$\mu_{1, \mathrm{Z} \mu}, \mu_{1, \mathrm{Zm}}$ & $\begin{array}{l}\text { zooplankton loss rates } \\
\mathrm{d}^{-1}\end{array}$ & $0.02,0.02$ \\
$\mu_{2, \mathrm{Pn}}, \mu_{2, \mathrm{Pd}}$ & $\begin{array}{l}\text { phytoplankton maximum loss rates } \\
\mathrm{d}^{-1}\end{array}$ & $0.1,0.1$ \\
$k_{\mathrm{Z} \mu}, k_{\mathrm{Zm}}$ & $\begin{array}{l}\text { phytoplankton loss half-saturation constants } \\
\text { mmol N }{ }^{-3}\end{array}$ & $0.5,0.5$ \\
$\mu_{2, \mathrm{Z} \mu}, \mu_{2, \mathrm{Zm}}$ & $\begin{array}{l}\text { zooplankton maximum loss rates } \\
\mathrm{d}^{-1}\end{array}$ & $0.1,0.2$ \\
$k_{\mathrm{Z} \mu}, k_{\mathrm{Zm}}$ & $\begin{array}{l}\text { zooplankton loss half-saturation constants } \\
\text { mmol Nm }\end{array}$ & $0.5,0.75$ \\
$\mu_{\mathrm{D}}$ & $\begin{array}{l}\text { detrital N remineralisation rate } \\
\mathrm{d}^{-1}\end{array}$ & 0.0158 \\
$\mu_{\mathrm{D}}$ & $\begin{array}{l}\text { detrital C remineralisation rate } \\
\mathrm{d}^{-1}\end{array}$ & 0.0127 \\
\hline
\end{tabular}

\section{Default simulation}

The following section describes a simulation and evaluation of MEDUSA-2.0 using the default equations, functional forms and parameter values described previously. Evaluation is performed against observational data, but also with MEDUSA-1.0 itself.

Both NEMO and MEDUSA-2.0 were initialised at the timepoint of midnight on 1 January 1860 . This is a standard point in HadGEM2-ES simulations for CMIP5. The model was then run out to 30 December 2005. Note that this is the final day of the year in the 360 day calendar of the atmospheric forcing used here.

\subsection{Physical model}

The underlying physical model used in this simulation is version 3.2 of NEMO (Madec, 2008). This is comprised of an ocean general circulation model, OPA9 (Madec et al., 
1998; Madec, 2008), coupled with a sea-ice model, Louvainla-Neuve Ice Model version 2 (LIM2; Timmermann et al., 2005). This physical framework is configured at approximately $1^{\circ} \times 1^{\circ}$ horizontal resolution $(292 \times 362$ grid points $)$, with a focusing of resolution around the equator to improve the representation of equatorial upwelling. Vertical space is divided into 64 levels, which increase in thickness with depth, from approximately $6 \mathrm{~m}$ at the surface to $250 \mathrm{~m}$ at $6000 \mathrm{~m}$. To improve the representation of deep water circulation, partial level thicknesses are used in the specification of bottom topography. Vertical mixing is parameterized using the turbulent kinetic energy (TKE) scheme of Gaspar et al. (1990), with modifications by Madec (2008).

The sea-ice submodel used here, LIM2, is based upon viscous-plastic ice rheology (Hibler, 1979) and three layer (two layers of sea ice, one layer of snow) thermodynamics (Semtner, 1976), with a number of updated physical processes (see Timmermann et al., 2005; and references therein). Model sea ice is coupled to the ocean every 5 ocean timesteps through the non-linear quadratic drag law of the shear between sea ice and ocean surface velocity (Timmermann et al., 2005). Freshwater exchange between the ocean and sea ice is calculated from precipitation and ice formation/melting (Fichefet and Morales Maqueda, 1997), where sea-ice salinity is assumed to be 4 psu and rain/snow are assumed fresh. The heat flux between the sea ice and ocean is proportional to the departure in temperature from salinity-dependent freezing point and the friction velocity at the ice-ocean interface. Solar radiation can penetrate sea ice not covered by snow, and is dissipated by brine pockets within the ice where it increases latent heat storage (Fichefet and Morales Maqueda, 1997).

In Yool et al. (2011), NEMO was forced at the ocean surface for the period 1966-2005 using DFS4.1 fields developed by the European DRAKKAR collaboration (DRAKKAR Group, 2007). As MEDUSA-2.0 includes the ocean's carbon cycle, and since this is currently undergoing secular change driven by increasing atmospheric concentrations of $\mathrm{CO}_{2}$, simulations running over a longer period of time are necessary. There are a number of approaches to achieve this including, for instance, the use of a climatological average or "normal year" (e.g. Najjar et al., 2007), or the repeated cycling of historical forcing (e.g. Yool et al., 2010). These have the advantage of using actual observationally derived forcing, but also assume that the recent past from which they are derived is representative of earlier periods of time (in spite of ongoing climate change). An alternative approach is to utilise forcing derived from either atmospheric models or coupled ocean-atmosphere models. These are routinely run in long duration simulations that span pre-industrial or pre-20th century periods when there was comparatively little change in climate or the carbon cycle. They also offer the opportunity to forecast biogeochemical cycles into the future with a significantly different climate from that of the present-day.
Table 4. Miscellaneous parameters.

\begin{tabular}{|c|c|c|}
\hline$\theta_{\mathrm{Pn}}, \theta_{\mathrm{Pd}}$ & $\begin{array}{l}\text { phytoplankton } \mathrm{C}: \mathrm{N} \text { ratio } \\
\operatorname{mol} \mathrm{C}(\mathrm{mol} \mathrm{N})^{-1}\end{array}$ & 6.625 \\
\hline$\theta_{\mathrm{Z} \mu}, \theta_{\mathrm{Zm}}$ & $\begin{array}{l}\text { zooplankton } \mathrm{C}: \mathrm{N} \text { ratio } \\
\operatorname{mol~} \mathrm{C}(\mathrm{mol} \mathrm{N})^{-1}\end{array}$ & 5.625 \\
\hline$\theta_{\mathrm{D}}$ & $\begin{array}{l}\text { detritus } \mathrm{C}: \mathrm{N} \text { ratio } \\
\mathrm{mol} \mathrm{C}(\mathrm{mol} \mathrm{N})^{-1}\end{array}$ & 6.625 \\
\hline$R_{\mathrm{Fe}}$ & $\begin{array}{l}\text { phytoplankton } \mathrm{Fe}: \mathrm{N} \text { uptake ratio } \\
\mu \mathrm{mol} \mathrm{Fe}(\mathrm{mol} \mathrm{N})^{-1} \mathrm{~m}\end{array}$ & 30.0 \\
\hline$L_{\text {total }}$ & $\begin{array}{l}\text { total ligand concentration } \\
\mu \mathrm{mol} \mathrm{m}\end{array}$ & 1.0 \\
\hline$k_{\mathrm{FeL}}$ & dissociation constant for $(\mathrm{Fe}+$ ligand $)$ & 100.0 \\
\hline$k_{\text {scav }}$ & $\begin{array}{l}\text { scavenging rate of "free" Fe } \\
\mathrm{d}^{-1}\end{array}$ & 0.001 \\
\hline Diss & $\begin{array}{l}\text { diatom frustule dissolution rate } \\
\mathrm{d}^{-1}\end{array}$ & 0.006 \\
\hline$w_{\mathrm{g}}$ & $\begin{array}{l}\text { detrital sinking rate } \\
\mathrm{m} \mathrm{d}^{-1}\end{array}$ & 2.5 \\
\hline$\theta_{\text {nit }}$ & $\begin{array}{l}\mathrm{O}_{2} \text { consumption by } \mathrm{N} \text { remineralisation } \\
\mathrm{mol} \mathrm{O}_{2}(\mathrm{~mol} \mathrm{~N})^{-1}\end{array}$ & 2.0 \\
\hline$\theta_{\text {rem }}$ & $\begin{array}{l}\mathrm{O}_{2} \text { consumption by } \mathrm{C} \text { remineralisation } \\
\mathrm{mol} \mathrm{O}_{2}(\mathrm{~mol} \mathrm{C})^{-1}\end{array}$ & 1.1226 \\
\hline $\mathrm{O}_{\min }$ & $\begin{array}{l}\text { minimum } \mathrm{O}_{2} \text { concentration } \\
\mathrm{mmol} \mathrm{O}_{2} \mathrm{~m}^{-3}\end{array}$ & 4.0 \\
\hline
\end{tabular}

Here, NEMO is forced following this latter approach, using output from a simulation of the HadGEM2-ES Earth system model run by the UK Meteorological Office (UKMO). HadGEM2-ES is a development of the physical climate model, HadGEM1 (Johns et al., 2006), that includes representations of the terrestrial and oceanic carbon cycles, atmospheric chemistry and aerosols (Collins et al., 2011). The HadGEM2-ES simulation used here, identifier AJKKH, was performed as part of the UKMO's input (Jones et al., 2011) to the Coupled Model Intercomparison Project 5 (CMIP5) and Assessment Report 5 (AR5) of the Intergovernmental Panel on Climate Change (IPCC). Operationally, HadGEM2-ES output was processed into the same forcing fields as that provided by the DFS4.1 forcing previously used with MedusA-1.0. The frequency of the output fields also matched that of DFS4.1, namely monthly for precipitation (rain, snow, runoff), daily for radiation (downwelling shortand long-wave) and 6-hourly for the turbulent variables (air temperature, humidity and wind velocities). Note that the reference height of forcing in HadGEM2-ES differs from that of DFS4.1, but that NEMO's bulk formulae allow this height to readily be changed to accommodate HadGEM2-ES.

For maximum congruence with the surface forcing, temperature and salinity fields are initialised here using output from HadGEM2-ES valid for the same time as the forcing. 
Table 5. Fast detritus submodel parameters.

\begin{tabular}{|c|c|c|}
\hline $\mathrm{D} 1_{\text {frac }}$ & fast detritus fraction of diatom losses & 0.33 \\
\hline $\mathrm{D} 2_{\mathrm{frac}}$ & $\begin{array}{l}\text { fast detritus fraction of mesozooplankton losses } \\
-\end{array}$ & 1.00 \\
\hline$D 3_{\text {frac }}$ & $\begin{array}{l}\text { fast detritus fraction of mesozooplankton grazing } \\
-\end{array}$ & 0.80 \\
\hline$r_{0}$ & $\begin{array}{l}\mathrm{CaCO}_{3} \text { : POC: export rain ratio scalar } \\
\text { Ridgwell et al. (2007) } \\
\text { - }\end{array}$ & 0.026 \\
\hline$\eta$ & $\begin{array}{l}\text { thermodynamic calcification rate power } \\
\text { Ridgwell et al. (2007) } \\
\text { - }\end{array}$ & 0.81 \\
\hline $\mathrm{M}_{\mathrm{org}}$ & $\begin{array}{l}\text { organic carbon mass : mole ratio, } \mathrm{C} \\
\mathrm{g}(\mathrm{mol} \mathrm{C})^{-1}\end{array}$ & 12.011 \\
\hline $\mathrm{M}_{\mathrm{CaCO}_{3}}$ & $\begin{array}{l}\text { calcium carbonate mass : mole ratio, } \mathrm{CaCO}_{3} \\
\mathrm{~g}(\mathrm{~mol} \mathrm{C})^{-1}\end{array}$ & 100.086 \\
\hline $\mathrm{M}_{\mathrm{Si}}$ & $\begin{array}{l}\text { biogenic } \mathrm{Si} \text { mass : mole ratio, } \mathrm{SiO}_{2} \\
\mathrm{~g}(\mathrm{~mol} \mathrm{Si})^{-1}\end{array}$ & 60.084 \\
\hline$f_{\mathrm{CaCO}_{3}}$ & $\begin{array}{l}\text { calcium carbonate protection ratio } \\
\mathrm{gC}\left(\mathrm{g} \mathrm{C}^{-1}\right.\end{array}$ & 0.070 \\
\hline$f_{\mathrm{Si}}$ & $\begin{array}{l}\text { biogenic Si protection ratio } \\
\mathrm{gC}\left(\mathrm{g} \mathrm{Si}^{-1}\right.\end{array}$ & 0.026 \\
\hline$d_{\text {excess }}$ & $\begin{array}{l}\text { excess organic carbon dissolution length scale } \\
\mathrm{m}\end{array}$ & 188 \\
\hline$d_{\mathrm{CaCO}_{3}}$ & $\begin{array}{l}\text { calcium carbonate dissolution length scale } \\
\mathrm{m}\end{array}$ & 3500 \\
\hline$d_{\mathrm{Si}}$ & $\begin{array}{l}\text { biogenic Si dissolution length scale } \\
\mathrm{m}\end{array}$ & 2000 \\
\hline$\lambda_{\mathrm{N}}$ & $\begin{array}{l}\text { benthic } \mathrm{N} \text { remineralisation rate } \\
\mathrm{d}^{-1}\end{array}$ & 0.05 \\
\hline$\lambda_{\mathrm{Si}}$ & $\begin{array}{l}\text { benthic Si dissolution rate } \\
\mathrm{d}^{-1}\end{array}$ & 0.01 \\
\hline$\lambda_{\mathrm{C}}$ & $\begin{array}{l}\text { benthic } \mathrm{C} \text { remineralisation rate } \\
\mathrm{d}^{-1}\end{array}$ & 0.05 \\
\hline$\lambda_{\mathrm{Ca}}$ & $\begin{array}{l}\text { benthic } \mathrm{CaCO}_{3} \text { dissolution rate } \\
\mathrm{d}^{-1}\end{array}$ & 0.01 \\
\hline
\end{tabular}

To prevent excessive drift, sea surface salinity (SSS) is relaxed towards that derived from HadGEM2-ES. Unlike simulations under DFS4.1, where an invariant monthly mean climatology of SSS values is used, here the SSS target consists of a monthly time series running across the forcing period. The relaxation timescale is approximately 30 days for the open ocean, and 12 days under sea ice. The freshwater budget is also monitored for imbalances between integrated downward and upward fluxes, and a correction term applied between years (i.e. an imbalance in year $\mathrm{X}$ is corrected for in year $X+1)$.

Further details concerning physical model configuration can be found in Barnier et al. (2006), Penduff et al. (2007) and Penduff et al. (2010), but note that these describe higher resolution instances of NEMO.

\subsection{Biogeochemistry}

MEdUSA-2.0's fields of DIN, silicic acid and oxygen were initialised using January values from the World Ocean Atlas 2009 (Garcia et al., 2010a, b). Similarly to MEDUSA-1.0, total iron was initialised using an iron field derived from a longduration simulation of a lower resolution GCM (Parekh et al., 2005; Dutkiewicz et al., 2005). DIC and alkalinity were initialised using a modified form of the GLODAP climatology (Key et al., 2004). It was assumed that GLODAP's preindustrial DIC field is approximately valid for the 1860 start of this simulation, though this approach has known issues concerning the ocean's anthropogenic $\mathrm{CO}_{2}$ inventory in 1860 (e.g. Yool et al., 2010).

The GLODAP fields used here required modification to account for large regional lacunae including the Arctic Ocean, the Caribbean Sea, the Mediterranean Sea and the Malay Archipelago. These were filled through an approach utilising multiple linear regression (MLR) together with the more complete WOA 2009 fields of temperature (Locarnini et al., 2010), salinity (Antonov et al., 2010), DIN, phosphate, silicic acid and oxygen. For each missing region, values of these tracers in immediately adjacent areas were used to construct a unique MLR. The calculated MLR was then used to fill the lacuna using field values from the WOA 2009. As biogeochemical tracers frequently show strong vertical gradients, separate MLRs were constructed for a series of intervals down the water column $(0-50,50-100,100-200,200$ $500,500-1000,1000-2000$, below $2000 \mathrm{~m}$ ). This procedure was used first with alkalinity, and then the resulting alkalinity field was added to the list of input fields for the construction of MLRs to fill DIC lacunae. While extrapolating in this fashion is likely to introduce some spurious values, particularly where WOA 2009 fields are already uncertain (e.g. the Arctic Ocean), it resulted in fields of DIC and alkalinity that appeared more credible than extrapolation by simple floodfilling was able to achieve.

All other model tracers (plankton and detritus) were initialised to arbitrary small values. Benthic reservoirs of nutrients, carbon and $\mathrm{CaCO}_{3}$ were set to zero. Note that, unlike in MEDusA-1.0, no coastal relaxation fluxes were applied to nutrients (N, $\mathrm{Si}$ ) in MEdus A-2.0. This change reflects both the switch to forcing periods outside the "present-day", and the finding in Yool et al. (2011) that this relaxation scheme did not universally emulate the riverine addition of nutrients as originally intended.

\section{Results}

In this section, a selection of model results are presented with the aim of providing an overview of MEDUSA-2.0's performance. In the first instance, model outputs that can be compared to observational fields are presented. These are followed by Taylor diagrams that aim to provide a quantitative 
Table 6. MedusA-2.0 switches.

\begin{tabular}{|c|c|}
\hline jphy & $\begin{array}{l}\text { switches phytoplankton maximum growth between temperature independence }(=0) \text { and de- } \\
\text { pendence }(=1) \text {; the default is jphy }=1\end{array}$ \\
\hline jmpn & $\begin{array}{l}\text { switches non-diatom phytoplankton density-dependent mortality between linear }(=1) \text {, } \\
\text { quadratic }(=2) \text {, hyperbolic }(=3) \text { and sigmoid }(=4) \text { forms; the default is jmpn }=3\end{array}$ \\
\hline jmpd & as jmpn but for diatom phytoplankton \\
\hline jmzmi & as jmpn but for microzooplankton \\
\hline jmzme & as jmpn but for mesozooplankton \\
\hline jmd & as jphy but for detrital remineralisation; the default is $\mathrm{jmd}=1$ \\
\hline jliebig & $\begin{array}{l}\text { switches between multiplicative }(=0) \text { and Liebig }(=1) \text { phytoplankton nutrient limitation; the } \\
\text { default is } j l i \text { ebig }=0\end{array}$ \\
\hline jexport & $\begin{array}{l}\text { switches between ballast }(=1) \text {, Martin et al. }(1987)(=2) \text { and Henson et al. }(2011)(=3) \\
\text { export submodels; the default is jexport }=1\end{array}$ \\
\hline jrratio & $\begin{array}{l}\text { switches between MEDUSA-1.0 }(=0) \text {, surface } \Omega_{\text {calcite }}(=1) \text { and local } \Omega_{\text {calcite }}(=2) \mathrm{CaCO}_{3} \\
\text { production; the default is jrratio }=2\end{array}$ \\
\hline jocalccd & $\begin{array}{l}\text { switches between specified lysocline }\left(=0 \text {; MEDUSA-1.0) and one calculated from } \Omega_{\text {calcite }}\right. \\
(=1) \text {; the default is jocalccd }=1\end{array}$ \\
\hline
\end{tabular}

evaluation of performance (cf. space and time). Next, model fields of interesting but unmeasured (or unmeasurable) properties are shown to illuminate notable aspects of MEDUSA-2.0. To illustrate the model's stability and drift, some plots of the time evolution of MEDUSA-2.0 are shown. This format of presentation and analysis is generally repetitive of that for MEDUSA-1.0 as described in Yool et al. (2011). However, since the simulation of MEDUSA-2.0 here is of considerably longer duration than than analysed for MEDUSA-1.0 (146 yr versus $41 \mathrm{yr}$ ), the results are of particular interest because they permit evaluation of the model's longer-term behaviour and stability. To extend the utility of this analysis, it concludes with an intercomparison of MEDUSA-2.0 with a selection of CMIP5 models.

Observational fields used in comparison with MEDUSA-2.0 are comprised of WOA 2009 nutrients (Garcia et al., 2010b), SeaWiFS chlorophyll (O'Reilly et al., 1998), estimated primary production (Behrenfeld and Falkowski, 1997; Carr et al., 2006; Westberry et al., 2008), GLODAP carbon and alkalinity (Key et al., 2004) and air-sea $\mathrm{CO}_{2}$ exchange (Takahashi et al., 2009). Because of its biogeochemical importance, and the diversity in estimates of it, observational primary production is drawn here from three empirical models: VGPM (Behrenfeld and Falkowski, 1997); Eppley-VGPM (Carr et al., 2006); and CbPM (Westberry et al., 2008). The observational fields of chlorophyll and productivity used here represent averages over the same $5 \mathrm{yr}$ period from 2000 to 2004 inclusive, and this same period is used throughout the following analysis as a standard interval except where noted.

The philosophy behind selecting these fields for the purpose of model validation has several facets. Firstly, they are ocean properties that have been observed at the global scale that MEDUSA-2.0 is simulated at. In the case of surface chlorophyll, this is now estimated by remote sensing at a fine spatial scale on a continuous basis. Dissolved tracers are much less well-sampled, but coverage has still been sufficient for high quality climatologies of each to be assembled. Secondly, they generally represent quantities that are believed to be the foundation of biological oceanography. Nutrient distributions, for instance, play a critical role in structuring ocean communities in both space and time, while primary production is the overwhelming route by which energy-rich organic carbon enters the marine food web. Thirdly, their measurement is well-defined and open to relatively little ambiguity. Properties that are more directly related to biological entities or processes can be more difficult to measure in the field, and more difficult to marry with model "equivalents". That said, synoptic estimates of primary production - a property examined here - still carry relatively high uncertainty, as evidenced by the range in estimates produced from the same inputs. Finally, and this is in part a corollary of the above, they are properties which, if modelled poorly, can cast legitimate doubt over the utility of a biogeochemical model as a whole. Models will always have discrepancies with observations, but any systematic failure to capture at least qualitative aspects of these quantities in particular will strongly suggest model weakness.

Note that, as well as from these geographically synoptic fields, MEDUSA-2.0 is also compared with more sparse observations of modelled quantities such as zooplankton and with globally integrated estimates of quantities such as biogenic opal production. 

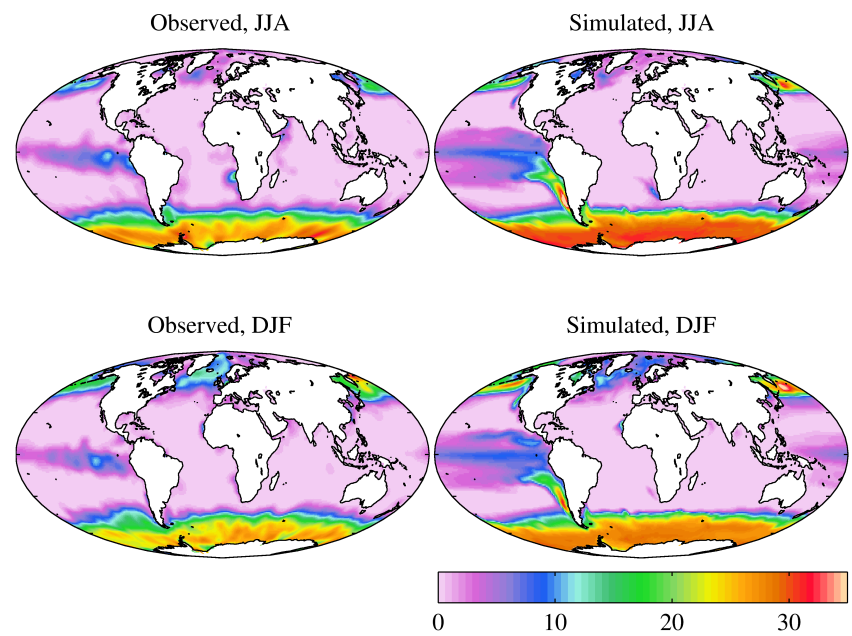

Fig. 4. Observational (World Ocean Atlas, 2009; left) and simulated (right) surface dissolved inorganic nitrogen for northern summer (June-July-August; top) and northern winter (December-JanuaryFebruary; bottom). Concentrations in $\mathrm{mmolm}^{-3}$. In passing, note that in this and subsequent geographical plots, the Mollweide equal area projection has been preferred in order that ocean regions are presented without undue emphasis.

\subsection{Validation}

Figures 4 and 5 compare MEdusA-2.0's performance in representing, respectively, surface concentrations of the macronutrients DIN and silicic acid (note that here, and subsequently, "surface concentration" refers to concentration within the uppermost model level, 0.00-6.06 m). In the case of DIN, MEDUSA-2.0 shows generally good agreement in the Northern Hemisphere, but with noticeably higher concentrations in both equatorial upwelling regions and in the Southern Ocean. A similarly strong Southern Ocean bias was found with MEDUSA-1.0, though equatorial waters there showed a slight bias in the opposite direction. Silicic acid concentrations are very similar between both MEDUSA versions, and show the very same patterns of bias. Most noticeably, markedly elevated Southern Ocean concentrations, uniformly too-low equatorial concentrations, and concentrations in the Northern Pacific lower than those observed in this HNLC region. Figures 6 and 7 show corresponding, basinaveraged Hovmöller diagrams of DIN and silicic acid for the Atlantic and Pacific Oceans.

Focusing on the deep ocean, Figs. 8 and 9 show zonally averaged sections of DIN and silicic acid down the Atlantic and Pacific basins (the Atlantic includes the Arctic Ocean; both basin sections include the Southern Ocean). In both cases, most large-scale structure has persisted in MEdusA-2.0 across the run duration. However, there are some important differences, of which the Southern Ocean is the most extreme. In this region, excessive ventilation acts to homogenise horizontal and vertical gradients, most notice-
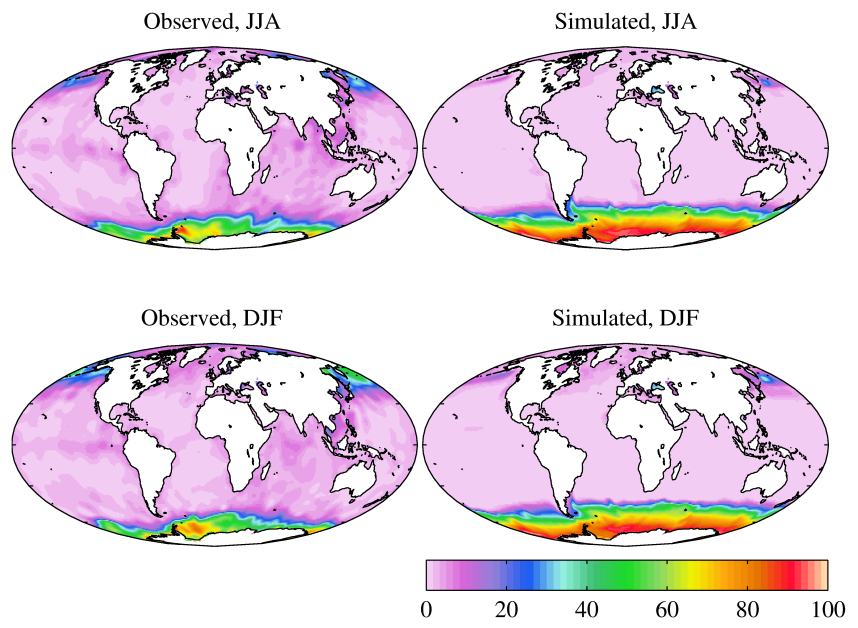

Fig. 5. Observational (World Ocean Atlas, 2009; left) and simulated (right) surface silicic acid for northern summer (June-July-August; top) and northern winter (December-January-February; bottom). Concentrations in $\mathrm{mmol} \mathrm{m} \mathrm{m}^{-3}$.
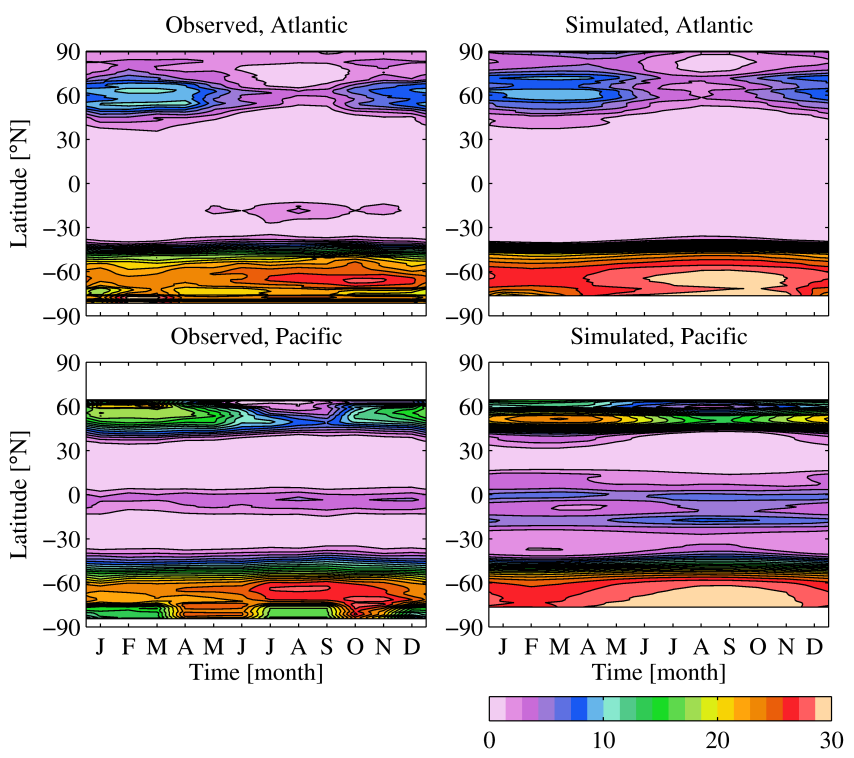

Fig. 6. Hovmöller diagrams of observational (World Ocean Atlas, 2009; left) and simulated (right) monthly surface dissolved inorganic nitrogen, averaged zonally for the Atlantic (top) and Pacific (bottom) basins. Concentrations in $\mathrm{mmolN}^{-3}$.

ably those of silicic acid. A similar problem in the Southern Ocean was noted by Yool et al. (2011) and ascribed to a deficiency in NEMO, but the problem here is somewhat worse and that this may stem from the change in surface forcing.

An examination of the large-scale circulation of the run finds that the Antarctic Circumpolar Current (ACC) is significantly stronger $(220 \mathrm{~Sv})$ in this simulation compared to that used with MEDUSA-1.0 (160 Sv), and toward the high end of other models (CMIP5 range of 90-264 Sv; Meijers et al., 2012). This is associated with stronger Antarctic Bottom 

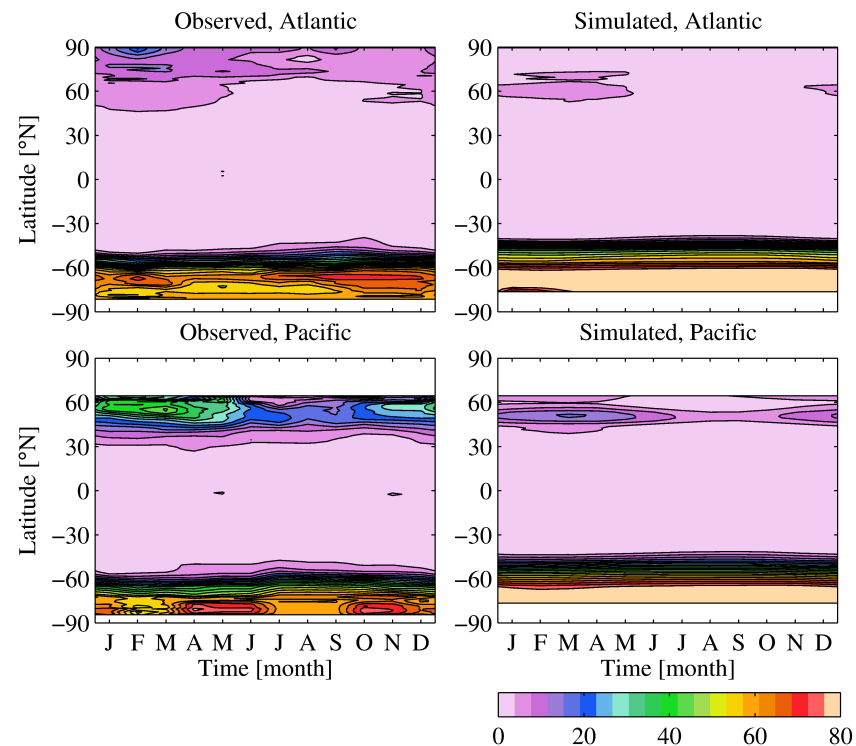

Fig. 7. Hovmöller diagrams of observational (World Ocean Atlas, 2009; left) and simulated (right) monthly surface silicic acid, averaged zonally for the Atlantic (top) and Pacific (bottom) basins. Concentrations in $\mathrm{mmolSim}^{-3}$.
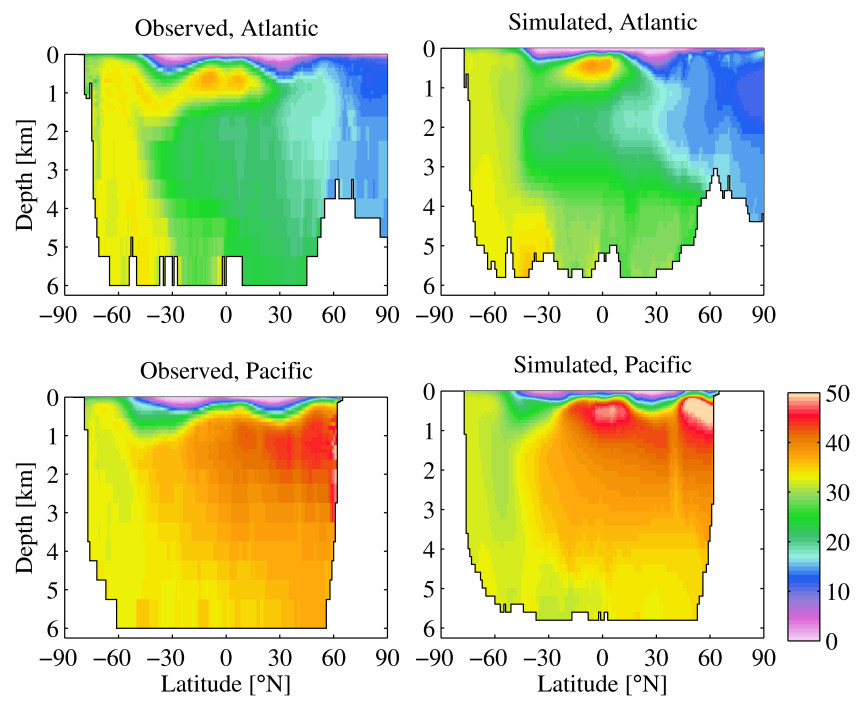

Fig. 8. Intercomparison of observational (left) and model (right) fields of zonally averaged dissolved inorganic nitrogen for the Atlantic (top) and Pacific (bottom) basins. Concentrations in $\mathrm{mmolNm} \mathrm{m}^{-3}$.

Water (AABW) formation around Antarctica, and leads to enhanced ventilation of the deep Atlantic and Pacific basins. In turn, this tends to erode deep gradients in nutrients that can be seen in the WOA (2009) panels of Figs. 8 and 9 but which are much weaker in the corresponding MEDUSA-2.0 panels. This enhanced ventilation is even clearer in the case of dissolved oxygen, Fig. 26, where strong vertical gradients in the Southern Ocean are strongly eroded in MEDUSA-2.0
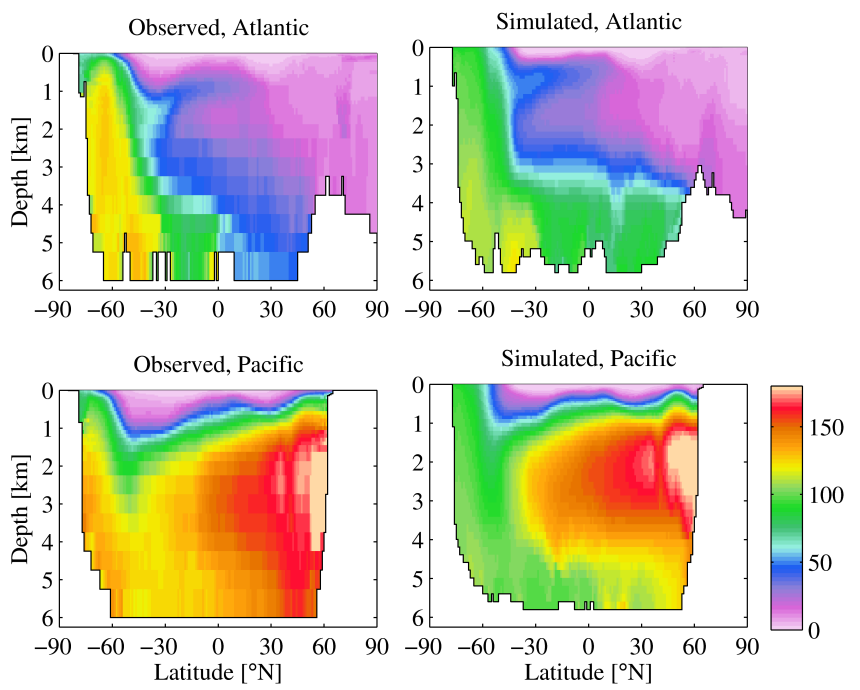

Fig. 9. Intercomparison of observational (left) and model (right) fields of zonally averaged silicic acid for the Atlantic (top) and $\mathrm{Pa}-$ cific (bottom) basins. Concentrations in $\mathrm{mmol} \mathrm{Sim}^{-3}$.

(and similarly for DIC and alkalinity; Figs. 17 and 18). However, as noted above, much of the zonal structure in the rest of the World Ocean is maintained, even in the case of dissolved oxygen. So while an improved circulation state would certainly be preferred, the impacts for MEDUSA-2.0 of NEMO's "robust" Southern Ocean ventilation are somewhat restricted.

Leaving aside these significant circulation-driven changes in tracer distributions, the section-averages of Figs. 8 and 26 indicate that MEDUSA-2.0 itself may also be a source of model-observation discrepancy. In both the real and modelled oceans, the remineralisation of sinking detrital material results in concentrations of DIN being generally elevated with depth, while those of dissolved oxygen broadly decline. However, in the case of MEDUSA-2.0, the highest DIN concentrations, and lowest oxygen concentrations, occur at noticeably shallower depths than in the WOA (2009). This is most pronounced in the Pacific panels of Figs. 8 and 26, but this mismatch is also apparent in the Atlantic panels. While deficiencies in circulation will also play a role, the remineralisation of sinking detrital material at depths that are too shallow plays a part. There are a number of parameters in MEdUSA-2.0 that may be implicated in this including the remineralisation rate of slow-sinking detrital particles, $\mu_{\mathrm{D}}$, the corresponding sinking velocity, $w_{\mathrm{g}}$, and the remineralisation length scale of fast-sinking detritus, $d_{\text {excess }}$. Ironically, one of these parameters, $w_{\mathrm{g}}$, was changed from its MEDUSA-1.0 value to improve model behaviour, and was altered in exactly the direction that would cause the current mismatch. Note, however, that the convolution of biogeochemical processes and circulation (as well as the long spinup periods required to detect model-observation mismatch) prevents a clean separation or quantitative evaluation of the cause or causes of discrepancies such as this. 

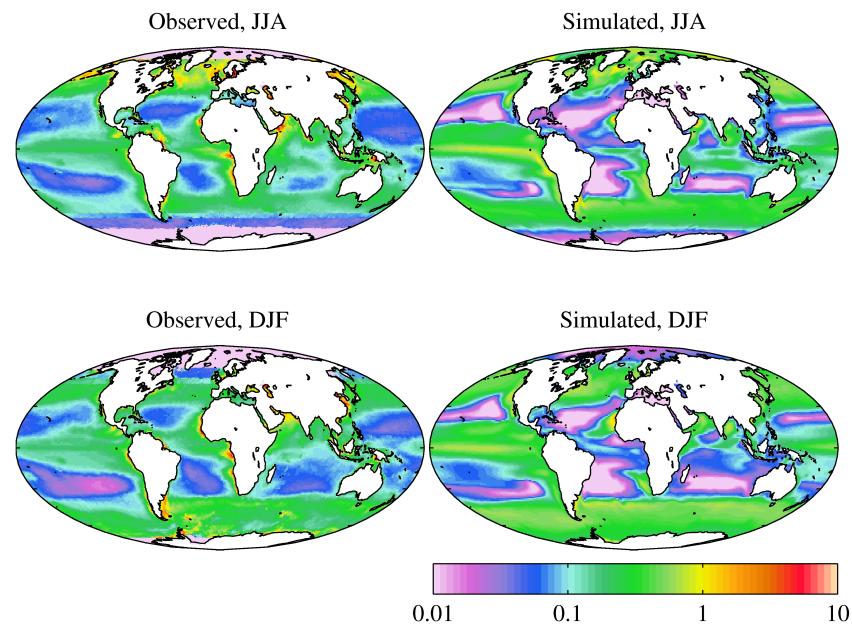

Fig. 10. Observational (SeaWiFS; left) and simulated (right) surface chlorophyll for northern summer (June-July-August; top) and northern winter (December-January-February; bottom). Concentrations in $\mathrm{mgchl} \mathrm{m}^{-3}$.

Returning to the surface ocean, Figs. 10 and 11 compare MEDUSA-2.0's simulated total chlorophyll (non-diatom plus diatom) to corresponding SeaWiFS fields (note that a logarithmic colour scale is used to best represent the large range in ocean colour). Not uncommonly for ocean models, and similarly to MEDUSA-1.0, the representation of chlorophyll exhibits significant discrepancies with observations. MEdUSA-2.0 shows much less pronounced seasonality, particularly at higher latitudes in the Northern Hemisphere, and spatial boundaries that are significantly more sharply defined and consistently lower "background" chlorophyll concentrations in the ocean gyres. While the latter regions are not productive areas of the ocean, they represent a significant fraction of its total area. This was also noted with MEdus A-1.0, and speculatively attributed to the assumption of geographically invariant nutrient kinetics. This prevents model phytoplankton from adapting to oligotrophic conditions when, in the real world, nutrient uptake kinetics are more plastic (e.g. Smith et al., 2009). However, given the globally uniform parameterization of ecosystem actors in MEDUsA, it may be difficult to resolve this deficiency without more fundamental changes to the model framework. For instance, the addition of further phytoplankton types with parameter values more "at home" in oligotroph conditions.

Figures 12 and 13 compare MEDUSA's simulated total primary production (non-diatom plus diatom) to a simple average of the estimates of the VGPM, Eppley-VGPM and CbPM models. The average estimated production has been used here both to simplify intercomparison and because, while sharing inputs, the separate estimates disagree significantly with one another (to the extent that model-observation difference is comparable with the range of observational estimates; Fig. 48). In broad terms, MEDUSA-2.0 captures some
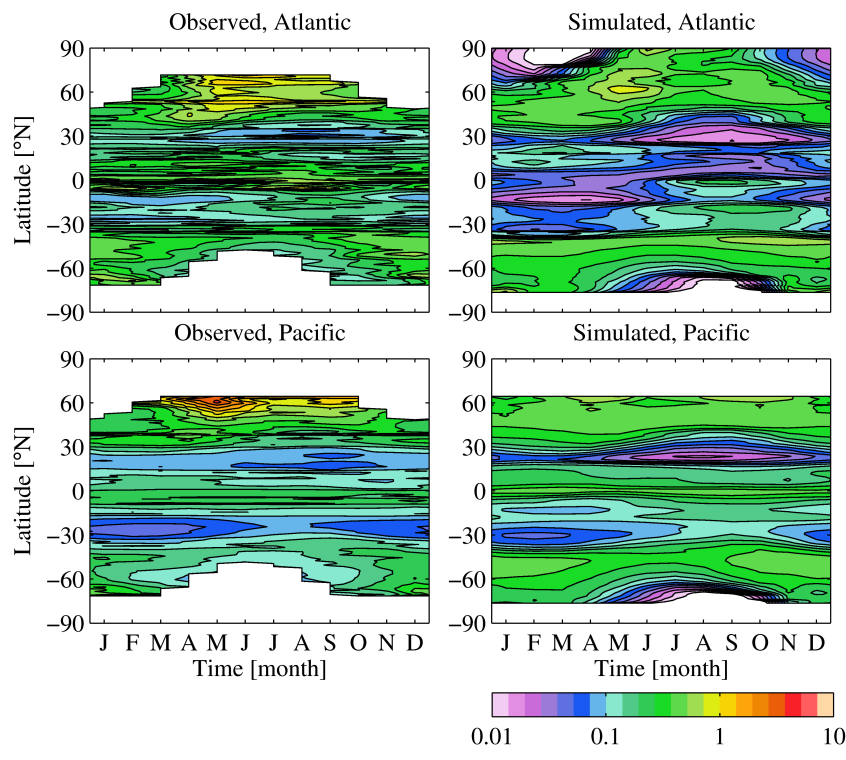

Fig. 11. Hovmöller diagrams of observational (SeaWiFS; left) and simulated (right) monthly surface chlorophyll, averaged zonally for the Atlantic (top) and Pacific (bottom) basins. Concentrations in $\mathrm{mgchlm}^{-3}$.
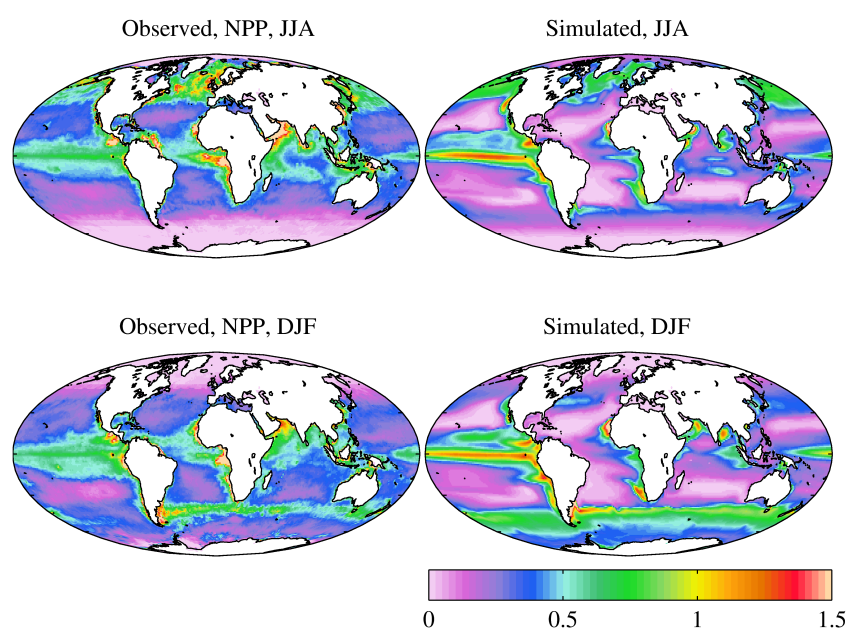

Fig. 12. Observational (left) and simulated (right) integrated primary production for northern summer (June-July-August; top) and northern winter (December-January-February; bottom). The observational field shown here is an average of the VGPM, EppleyVGPM and CbPM estimates. Production in $\mathrm{gCm}^{-2} \mathrm{~d}^{-1}$.

of the spatial and seasonal patterns in productivity, though it does show significant systematic differences as well. These include: consistently low subtropical gyre productivity; elevated productivity in iron-limited regions including the Southern Ocean, equatorial Pacific and (seasonally) North Pacific; and a weaker bloom across the North Atlantic. In terms of total oceanic primary production, MEDUSA-2.0 predicts $41.6 \mathrm{PgC} y r^{-1}$, a value slightly below the bottom of the 

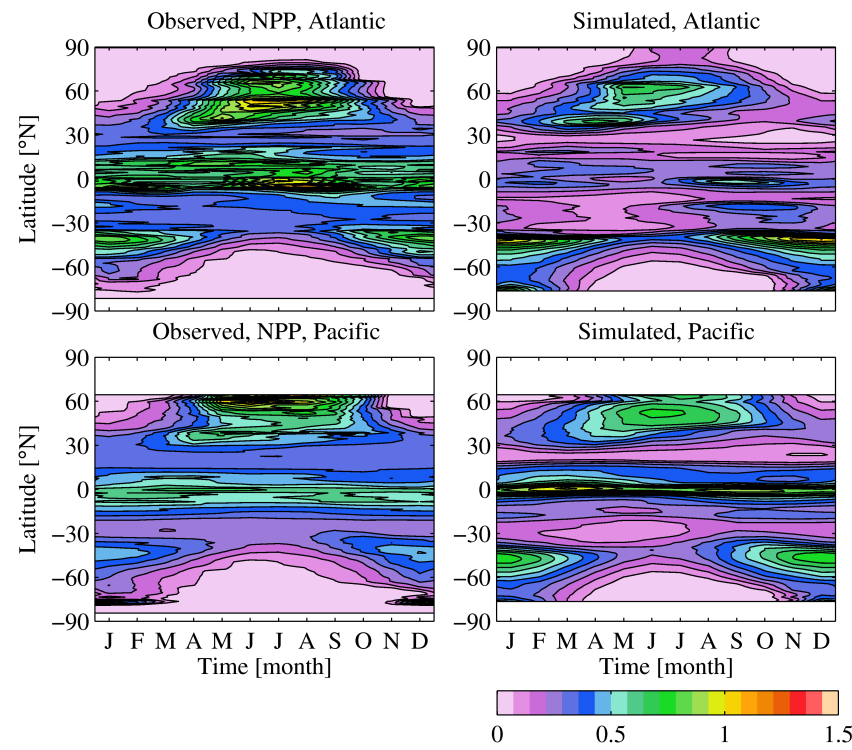

Fig. 13. Hovmöller diagrams of observational (left) and simulated (right) monthly integrated primary production, averaged zonally for the Atlantic (top) and Pacific (bottom) basins. Production in $\mathrm{gCm}^{-2} \mathrm{~d}^{-1}$

broad range of the observational estimates, 58.8, 60.4 and 46.3 $\mathrm{Pg} \mathrm{Cyr}^{-1}$ respectively (and below that of MEDUSA-1.0; 45.3 $\mathrm{PgC}^{-1}$ ).

Figures 14-15 show the corresponding model-observation comparisons using Taylor diagrams. These illustrate both the correlation between (circumference axis) and relative variability (radial axis) of model and observations. For each comparison two plots are shown. The first uses annually average fields, but separates the analysis between major ocean regions; the second uses globally average fields, but separates the analysis between months. In all cases, modelobservation agreement is greater the closer plotted data are to the red/black bullseye on the horizontal axis.

Similarly to MEDUSA-1.0, the best agreement occurs with nutrient fields, particularly DIN. While there remains significant scatter, MEDUSA-2.0 generally shows good correlation with World Ocean Atlas 2009 fields, and comparable magnitudes of variability. In the case of surface silicic acid, there is considerable variability between basins with the Pacific performing very poorly, and the Indian exhibiting significantly elevated variability. Much as with MEDUSA-1.0, agreement is still very weak in the case of chlorophyll, where the model both correlates poorly and shows much less variability than the observed SeaWiFS fields. Although estimated productivity is based on the same SeaWiFS chlorophyll fields, MEDUSA-2.0's agreement with the three productivity models is actually much greater, particularly the VGPM and CbPM models (results not shown), although correlations are still relatively weak.
Extending beyond MEDUSA-1.0, Fig. 16 compares MEDUSA-2.0's surface fields of 1990s average DIC and alkalinity concentration with those from the GLODAP climatology. As with preceding fields, there is broad agreement, but a number of notable differences. In the case of DIC, regions of high concentration are typically slightly higher $\left(<50 \mathrm{mmol} \mathrm{Cm}^{-3}\right)$ in MEDUS A-2.0, with the greatest difference occurring adjacent to Antarctica. In the case of alkalinity, the Southern Ocean again shows elevated concentrations caused by the increased ocean ventilation in this region mentioned earlier, but in the Pacific discrepancies are generally downwards. While, again, circulation deficiencies are in part responsible, excessive production in the Pacific, particularly in the equatorial region, is responsible for this discrepancy. In this region, MEDUSA-2.0's rain ratio formulation means that elevated primary production and export also drives a stronger export of $\mathrm{CaCO}_{3}$ - with lower surface alkalinity a principle result. As Fig. 19 shows, this general pattern of elevated DIC but decreased alkalinity also manifests in other surface properties. Here, modelled $\mathrm{pH}$ is globally lower than that estimated from GLODAP, with the result that $\Omega_{\text {calcite }}$ is also lower than that estimated, though insufficiently to significantly impact Eq. (92) and the rain ratio of export.

Following on from this, Fig. 20 shows a comparison of the observationally based lysocline (calculated from WOA and GLODAP fields) with that simulated by MEDUSA-2.0 for the 1990s (which corresponds to GLODAP's “presentday"). In both cases, the same carbonate chemistry routine used in MEDUSA-2.0 is used to calculate $\Omega_{\text {calcite, and the }}$ CCD shown is the shallowest depth at which $\Omega_{\text {calcite }}$ has a value below 1.0 (i.e. the first depth at which the concentration of $\mathrm{CO}_{3}^{2-}$ is undersaturated). While the two maps broadly agree in terms of overall pattern, there are several regions where there are significant differences and - globally averaged - modelled CCD is noticeably shallower, $2646 \mathrm{~m}$ compared to $2864 \mathrm{~m}$ from observations. The Arctic (model vs. observations: $1347 \mathrm{~m}$ vs. $1347 \mathrm{~m})$ and Indian $(3322 \mathrm{~m}$ vs. $3308 \mathrm{~m}$ ) basins have very close average CCDs, but the Southern (3318 m vs. 3166 m), Atlantic (3165 m vs. $3341 \mathrm{~m}$ ) and, especially, the Pacific (2008 m vs. $2482 \mathrm{~m}$ ) oceans show much larger discrepancies. Throughout much of the World Ocean, these differences are caused by relatively minor rearrangements of the vertical gradients of DIC and alkalinity by modelled circulation and biogeochemistry. In the case of the eastern Pacific, the large errors in CCD depth are a direct result of the excessively shallow remineralisation of sinking organic material previously identified in the zonal sections of dissolved inorganic nitrogen, carbon and, especially, oxygen (Figs. 8, 17 and 26). Between 150 and $1500 \mathrm{~m}$ depth, this region shows significantly elevated concentrations of DIC that depart markedly from observations, with the result that values of $\Omega_{\text {calcite }}$ drop below 1.0 much closer to the surface than in reality. Near-surface values of $\Omega_{\text {calcite }}$ are naturally less than 2.0 in this region, so model errors of this kind can easily impact CCD. They also, in part, reflect positive 

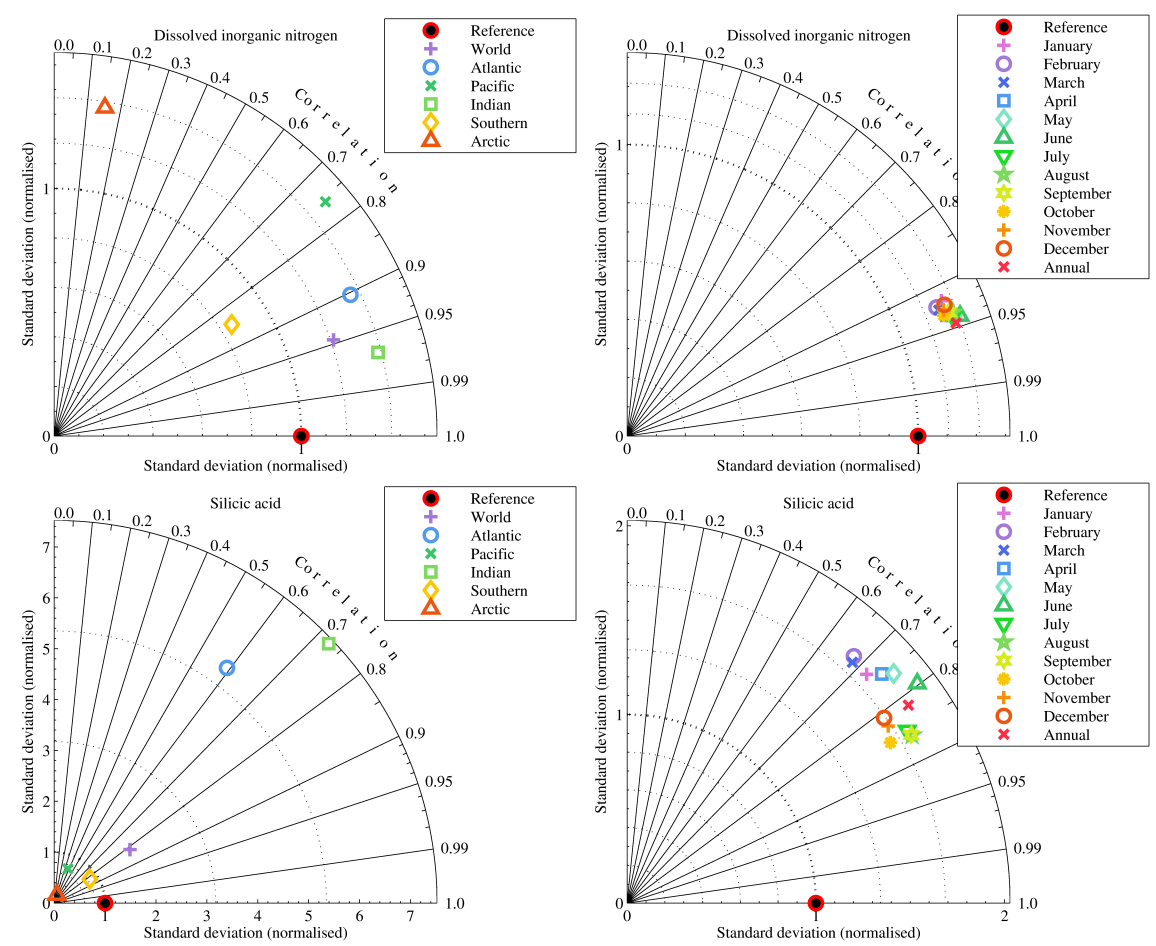

Fig. 14. Taylor diagrams of spatial (left) and temporal (right) model-observation comparisons for surface dissolved inorganic nitrogen (top) and silicic acid (bottom). In the leftmost panels, simulated annual means for different regions are compared to corresponding observational fields. In the rightmost panels, simulated global average means for different months are compared to corresponding observational fields.
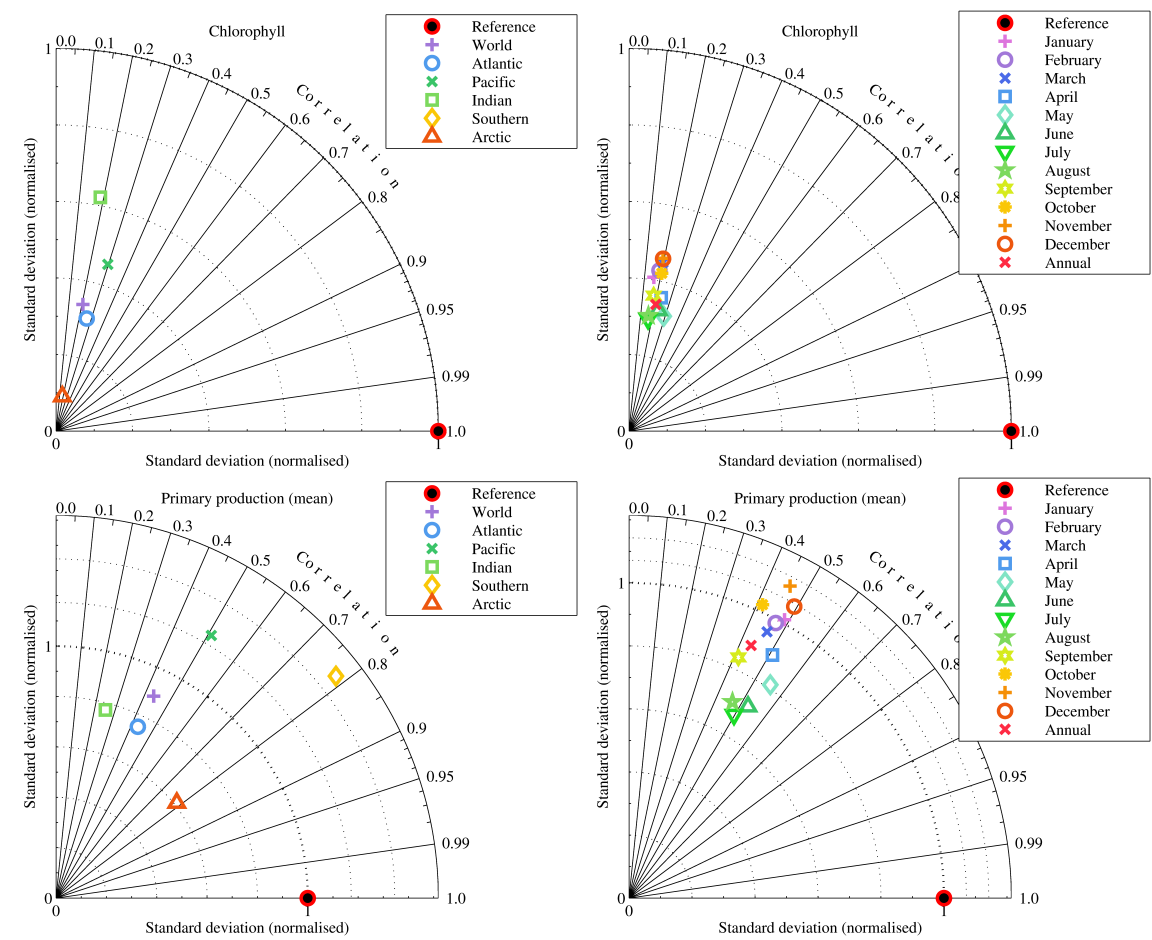

Fig. 15. Taylor diagrams of spatial (left) and temporal (right) model-observation comparisons for surface chlorophyll (top) and integrated primary production (bottom). In the leftmost panels, simulated annual means for different regions are compared to corresponding observational fields. In the rightmost panels, simulated global average means for different months are compared to corresponding observational fields. 

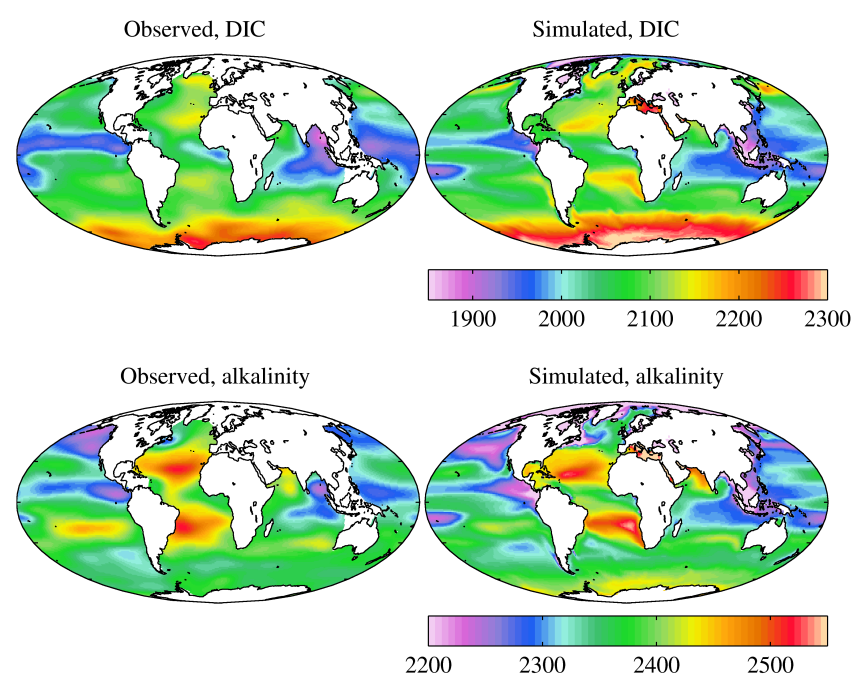

Fig. 16. Observational (GLODAP; left) and simulated (right) surface dissolved inorganic carbon (top; $\mathrm{mmol} \mathrm{Cm}^{-3}$ ) and surface alkalinity (bottom; meq $\mathrm{m}^{-3}$ ).
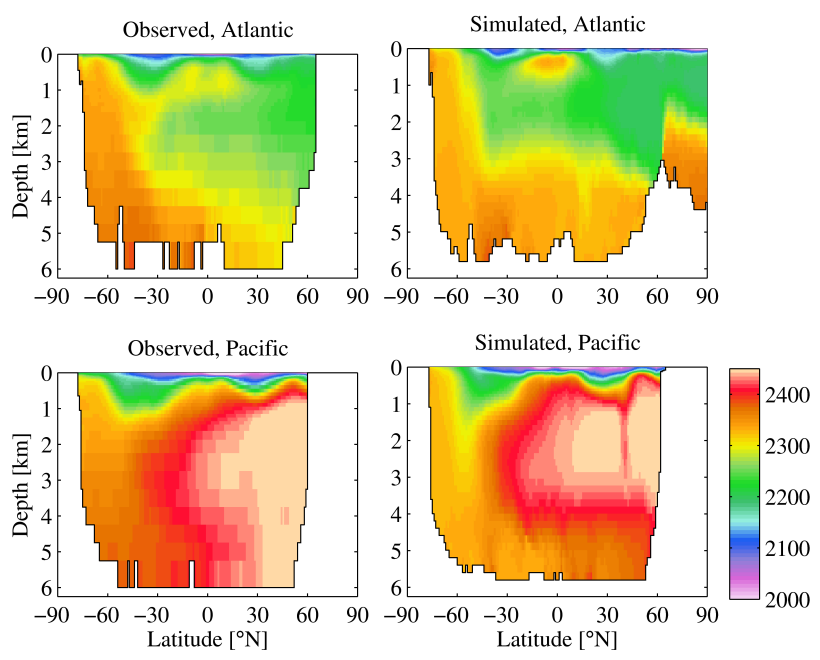

Fig. 17. Intercomparison of observational (left) and model (right) fields of zonally averaged dissolved inorganic carbon for the Atlantic (top) and Pacific (bottom) basins. Note that the GLODAP climatology has no values within the Arctic. Concentrations in $\mathrm{mmol} \mathrm{C} \mathrm{m}{ }^{-3}$.

feedback driven by the ballast submodel: too-shallow remineralisation increases near-surface DIC; this decreases local $\Omega_{\text {calcite; }}$ this shallows the depth at which $\mathrm{CaCO}_{3}$ dissolves; this decreases the "protection" offered to sinking organic material by ballast; and, in turn, this shoals remineralisation and increases near-surface DIC. It is difficult, however, to determine whether such feedback is the original cause of this error or merely a downstream consequence of some other problem with NEMO or MEDUSA-2.0 (e.g. physical circulation; biogeochemical parameter changes).
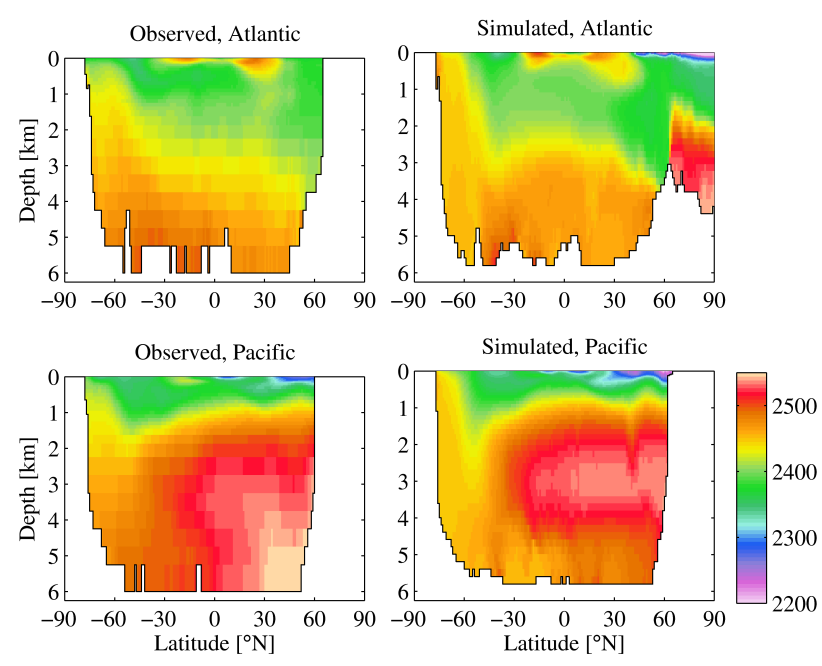

Fig. 18. Intercomparison of observational (left) and model (right) fields of zonally averaged alkalinity for the Atlantic (top) and $\mathrm{Pa}$ cific (bottom) basins. Note that the GLODAP climatology has no values within the Arctic. Concentrations in meq $\mathrm{m}^{-3}$.

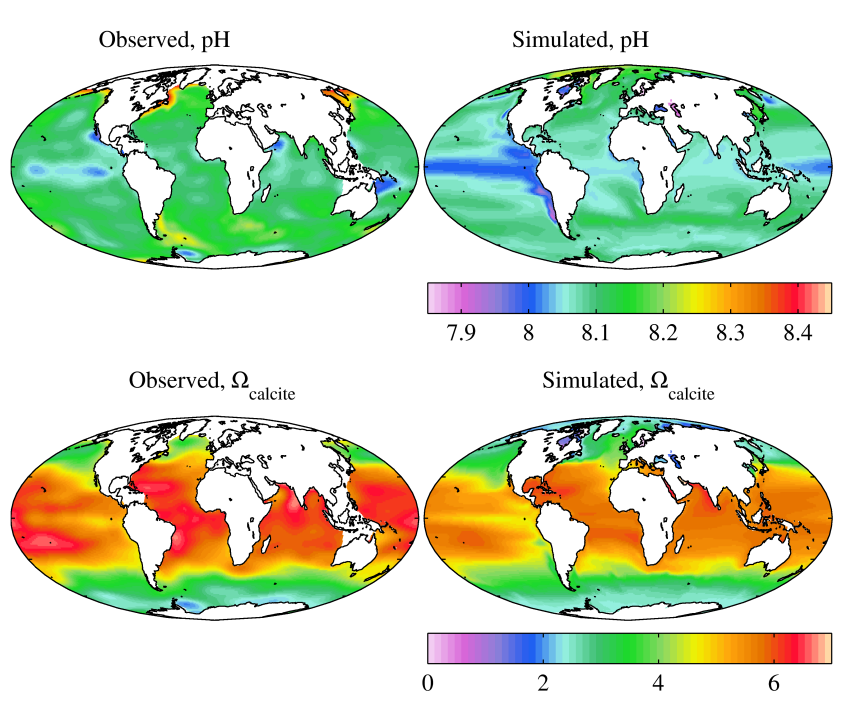

Fig. 19. Observational (GLODAP; left) and simulated (right) surface $\mathrm{pH}$ (top; -) and surface $\Omega_{\text {calcite }}$ (bottom; -).

Changing to the ocean carbon cycle's interaction with the atmosphere, Figs. 21-24 compare MEDUSA-2.0 to observationally derived fields of $\Delta p \mathrm{CO}_{2}$ and air-sea $\mathrm{CO}_{2}$ flux for year 2000 (Takahashi et al., 2009). The former is simply the localised difference between surface ocean $p \mathrm{CO}_{2}$ and that of the atmosphere (assumed a globally uniform but timevarying quantity in the model). The latter is an estimate of the actual net exchange of $\mathrm{CO}_{2}$ between the ocean and the atmosphere (where positive values indicate net air-to-sea flux), based on $\Delta p \mathrm{CO}_{2}$, air pressure, piston velocity and sea-ice concentration. 


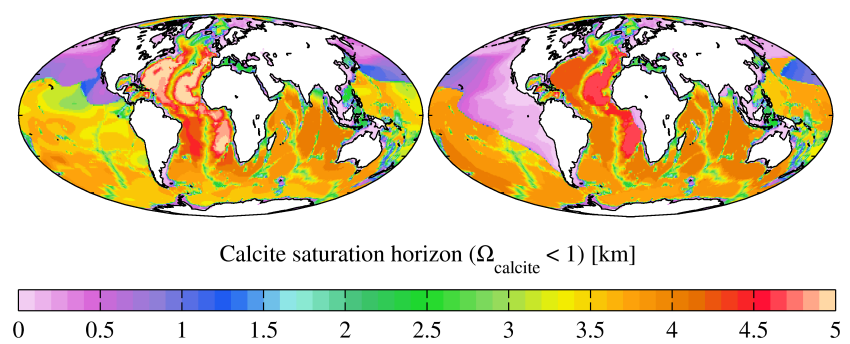

Fig. 20. Calcite compensation depth (CCD) as calculated from observations (left) and MEDUSA-2.0 (right). The CCD is defined here as the depth at which carbonate ion concentration falls below the local saturation concentration, that is, where $\Omega_{\text {calcite }}$ falls below a value of 1 .
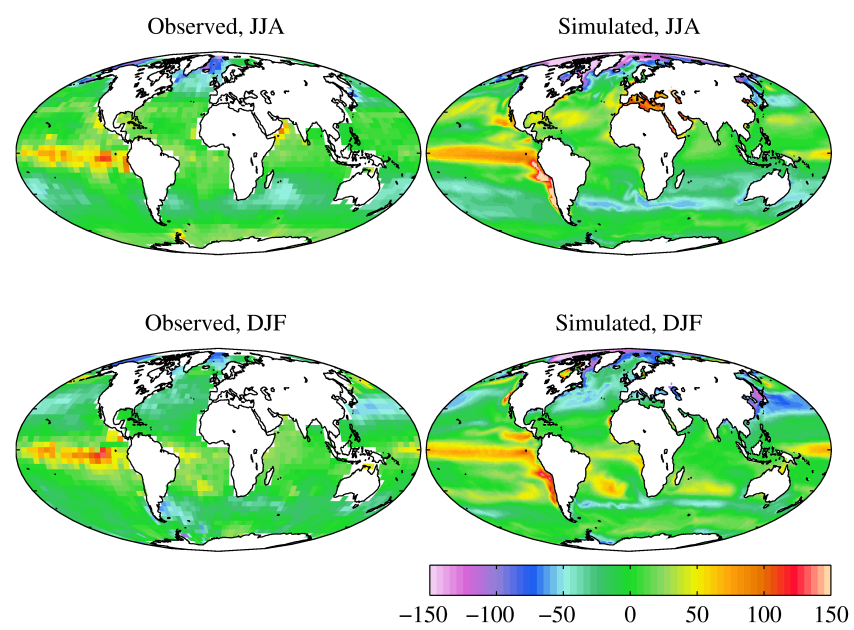

Fig. 21. Observational (Takahashi et al., 2009; left) and simulated (right) surface $\Delta p \mathrm{CO}_{2}$ for northern summer (June-July-August; top) and northern winter (December-January-February; bottom). $\Delta p \mathrm{CO}_{2}$ in $\mathrm{ppm}$.

With $\triangle p \mathrm{CO}_{2}$, MEDUSA-2.0 generally shows similar geographical patterns of excess or deficit. MedusA-2.0 tends to show somewhat exaggerated patterns with regions such as the northwest Pacific showing a stronger winter deficit, and others such as the Pacific upwelling showing a much stronger year-round excess. In contrast, and as Fig. 22 more clearly shows, MEDUSA-2.0 shows much weaker seasonality in the Southern Ocean, where estimated summer deficits and winter excesses are not well represented. Switching to Figs. 23 and 24, and the actual air-sea exchange of $\mathrm{CO}_{2}$, the situation is somewhat improved with MEDUSA-2.0's flux magnitudes more in agreement with those estimated. There are still, however, problems in the Southern Ocean, where the model misses periods of strong in- and out-gassing at the most southerly latitudes. Globally integrated, MEDUSA-2.0 estimates a net air-sea flux of $1.35 \mathrm{PgCyr}^{-1}$ compared to Takahashi et al. (2009)'s estimate of $1.42 \mathrm{PgCyr}^{-1}$. Note that Takahashi et al. (2009) believe that this direct estimate is
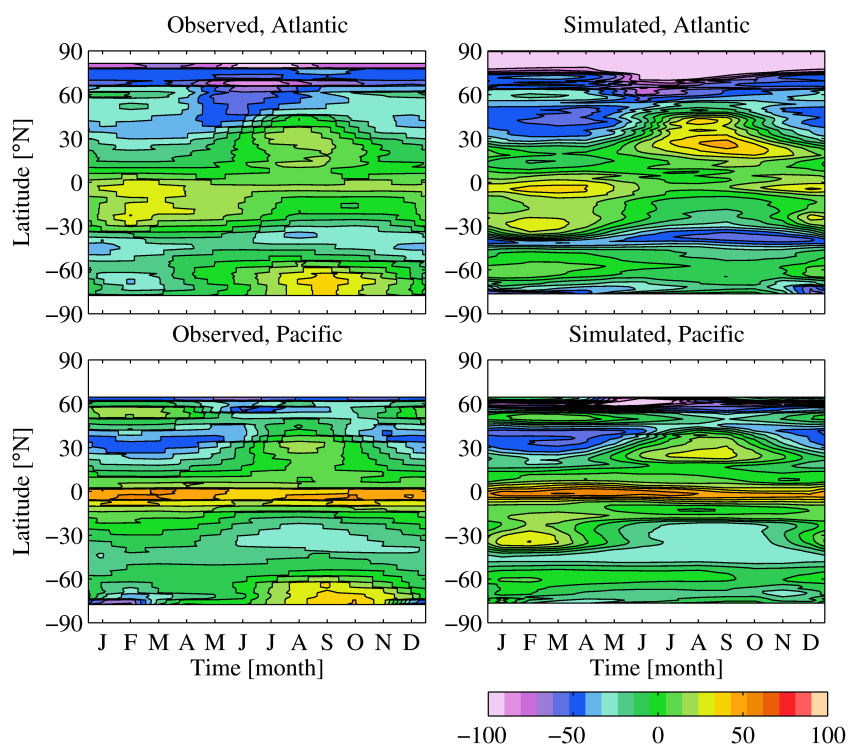

Fig. 22. Hovmöller diagrams of observational (Takahashi et al., 2009; left) and simulated (right) monthly $\Delta p \mathrm{CO}_{2}$, averaged zonally for the Atlantic (top) and Pacific (bottom) basins. $\Delta p \mathrm{CO}_{2}$ in ppm.
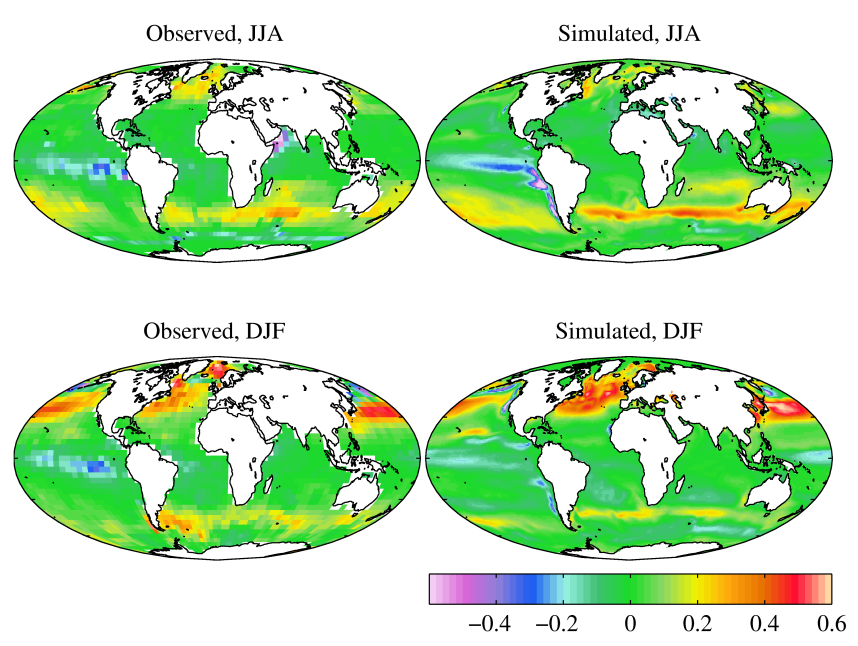

Fig. 23. Observational (Takahashi et al., 2009; left) and simulated (right) air-sea $\mathrm{CO}_{2}$ flux for northern summer (June-July-August; top) and northern winter (December-January-February; bottom). Air-sea $\mathrm{CO}_{2}$ flux in molC ${ }^{-2}$ month $^{-1}$.

probably an underestimate because of undersampling (which they suggest would increase it to $1.6 \mathrm{PgC} \mathrm{yr}^{-1}$ ).

MEDUSA-2.0 also exchanges oxygen with the atmosphere but, as Fig. 25 illustrates, its solubility is both greater than that of $\mathrm{CO}_{2}$ and is strongly temperature-dependent. As a result, though there are discrepancies in MEDUSA-2.0's prediction of surface dissolved oxygen concentrations, the modelled seasonal distributions are very similar. What differences there are occur in the over-ventilated Southern Ocean, and in areas where large-scale circulation produces strong sea 

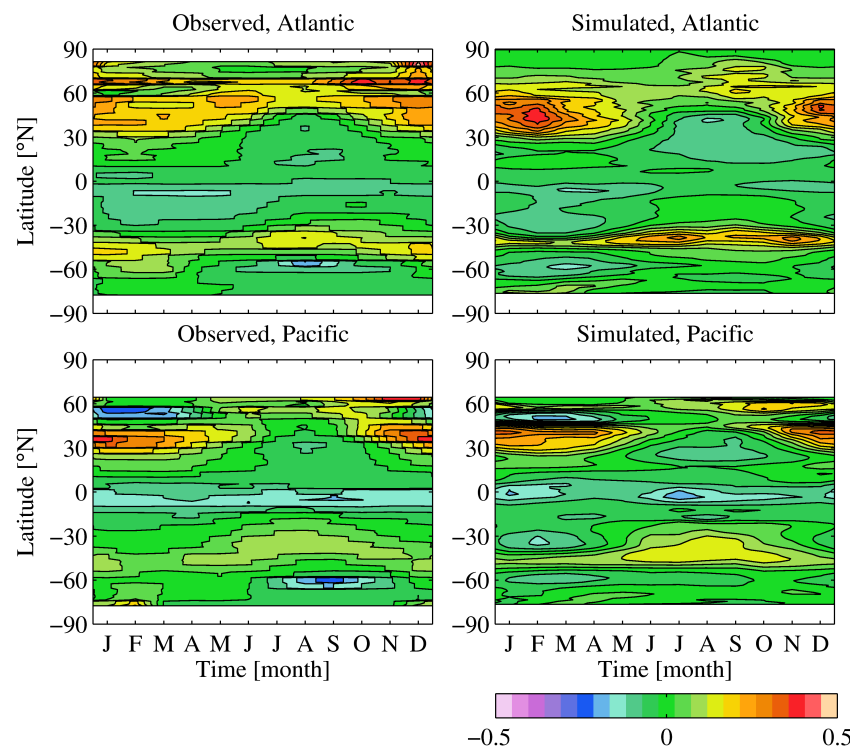

Fig. 24. Hovmöller diagrams of observational (Takahashi et al., 2009; left) and simulated (right) monthly air-sea $\mathrm{CO}_{2}$ flux, averaged zonally for the Atlantic (top) and Pacific (bottom) basins. Airsea $\mathrm{CO}_{2}$ flux in $\mathrm{molCm} \mathrm{Cm}^{-2}$ month $^{-1}$.

surface temperature features that are displaced in NEMO. For example, in the North Atlantic, where the position of the Gulf Stream determines SST gradients and, thus, those of surface dissolved oxygen. As previously noted, Fig. 26 shows larger discrepancies at depth, caused in part by circulation deficiencies (Southern Ocean; all depths) and partly by MEDUSA-2.0 itself (Pacific; midwater). In terms of ocean anoxia, suboxic regions $\left(<20 \mathrm{mmol} \mathrm{O}_{2} \mathrm{~m}^{-3}\right)$ occupy $13.1 \times 10^{6} \mathrm{~km}^{3}$ in the WOA but are more than double this in MEDUSA-2.0 at $30.4 \times 10^{6} \mathrm{~km}^{3}$.

Switching to ecosystem properties for which observations are less synoptic, Figs. 27-35 show seasonal and geographical plots for a range of model fields.

Figures 27 and 28 respectively show the split between surface biomass and integrated production for MEDUSA-2.0's two phytoplankton groups (shown on the same colour scales to facilitate intercomparison). Much as with MedusA-1.0, non-diatoms are dominant across most of the World Ocean, and particularly in the oligotrophic gyres, where diatom abundance and productivity is extremely low. However, diatom biomass can seasonally exceed that of the non-diatoms in regions such as the North Atlantic, and they still contribute modestly to total primary production $(15.9 \% ; 17.0 \%$ in terms of total nitrogen biomass). Observational estimates of this fraction at the global scale are rare. While a survey by Mann (1999) suggested 40-45\%, this is much greater than that estimated by either MEDUSA-2.0 or localised observations (13-34\%; Nelson and Brzezinski, 1997; Blain et al., 1997; Brzezinski et al., 1998).
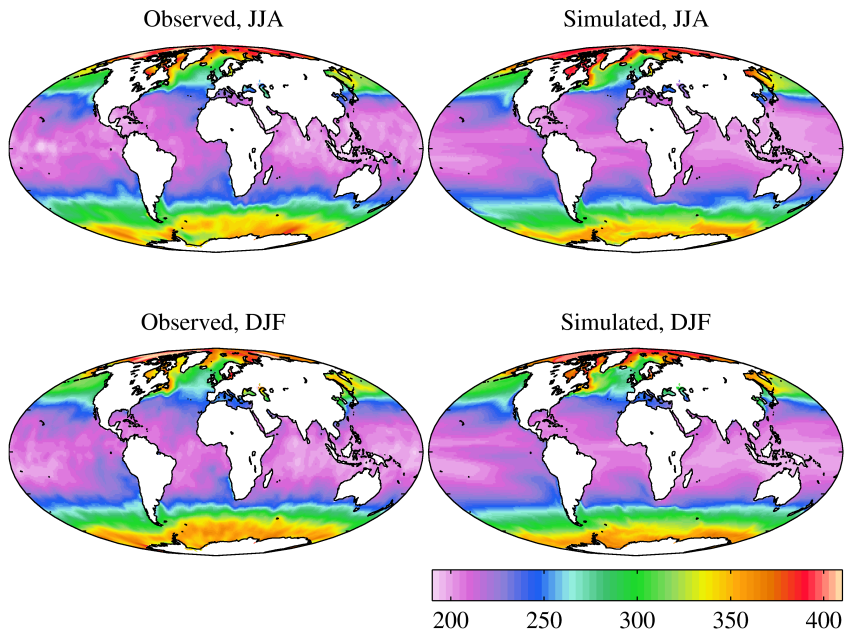

Fig. 25. Observational (World Ocean Atlas, 2009; left) and simulated (right) surface dissolved oxygen for northern summer (June-July-August; top) and northern winter (December-JanuaryFebruary; bottom). Concentrations in $\mathrm{mmolO}_{2} \mathrm{~m}^{-3}$.
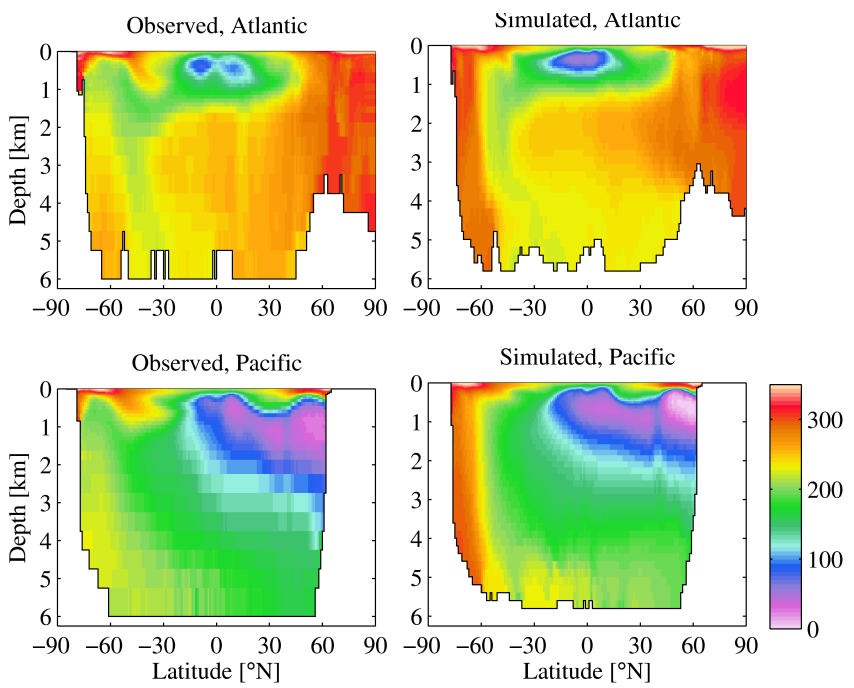

Fig. 26. Intercomparison of observational (left) and model (right) fields of zonally averaged dissolved oxygen for the Atlantic (top) and Pacific (bottom) basins. Concentrations in $\mathrm{mmolO}_{2} \mathrm{~m}^{-3}$.

The left panels of Fig. 29 show the fraction $(0-1)$ of total primary production that MEDUSA-2.0 predicts for the upper mixed layer, with the remainder occurring deeper in the water column, often in simulated deep chlorophyll (or productivity) maxima. In general, this fraction is lower in the summer, when nutrients are more limiting than light, and higher in the winter, when light limits production more. Patterns are less clear in the tropics and upwelling regions where the interplay of nutrient and light availability is more complex. In the case of northern latitudes, the ratio generally shifts between 0.5 and 1.0, but in the Southern Ocean the seasonal range is $0.7-1.0$, reflecting this basin's all-year macronutrient 

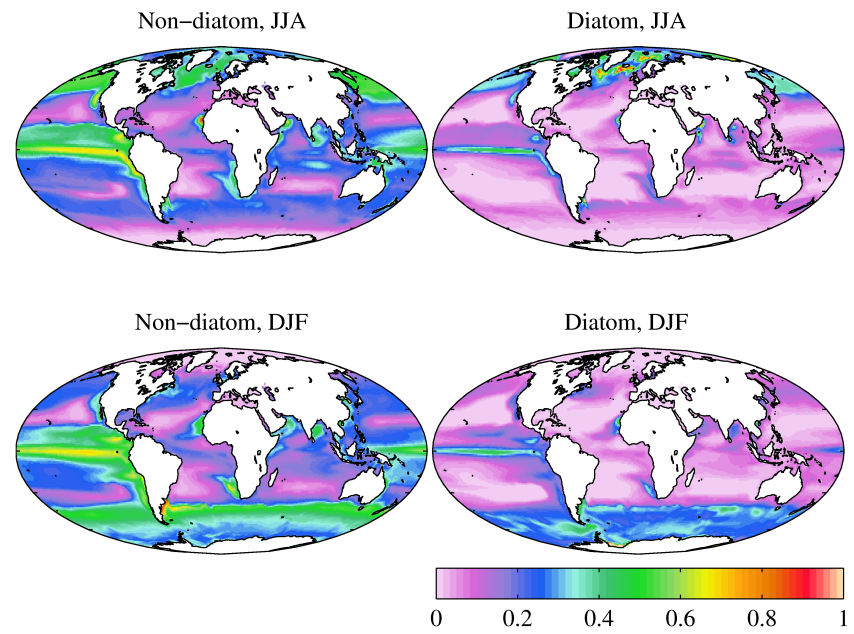

Fig. 27. Simulated surface non-diatom phytoplankton (left) and diatom phytoplankton (right) concentrations for northern summer (June-July-August; top) and northern winter (December-JanuaryFebruary; bottom). Concentrations in $\mathrm{mmol} \mathrm{m}^{-3}$.
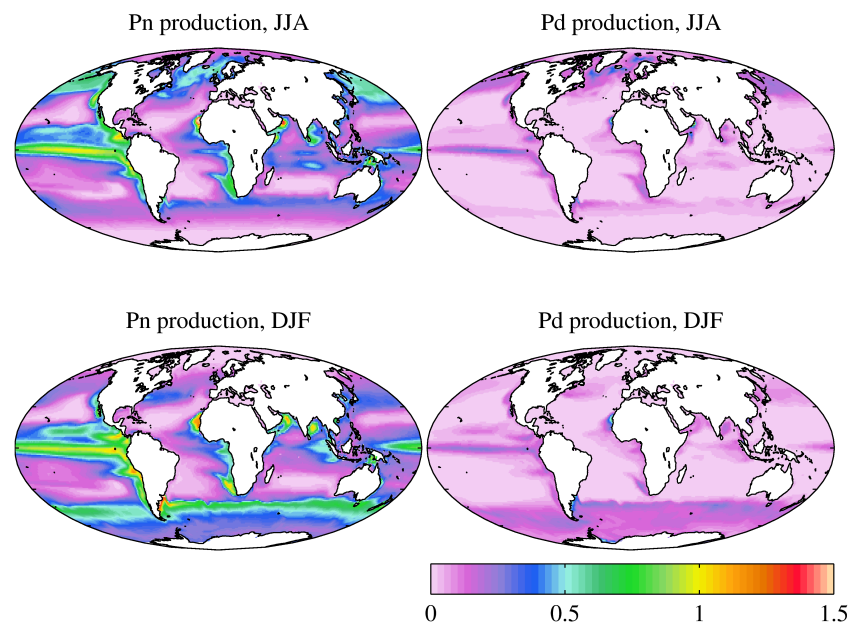

Fig. 28. Simulated non-diatom (left) and diatom (right) primary production for northern summer (June-July-August; top) and northern winter (December-January-February; bottom). Production in $\mathrm{gCm}^{-2} \mathrm{~d}^{-1}$.

availability. Integrating to the global scale, slightly more than two-thirds $(67.3 \%)$ of production occurs in the mixed layer in MEDUSA-2.0, and while there is geographical variation in this fraction between basins, the Southern Ocean is the most different at $85.8 \%$.

The right panels of Fig. 29 instead show ocean productivity from the perspective of the benthic communities that ultimately rely on them. The panels are shown on a $\log$ scale because the geographical variability of export production is compounded exponentially by variability in the seafloor depth that sinking material needs to reach. It shows strong seasonality at high latitudes and low seasonality in
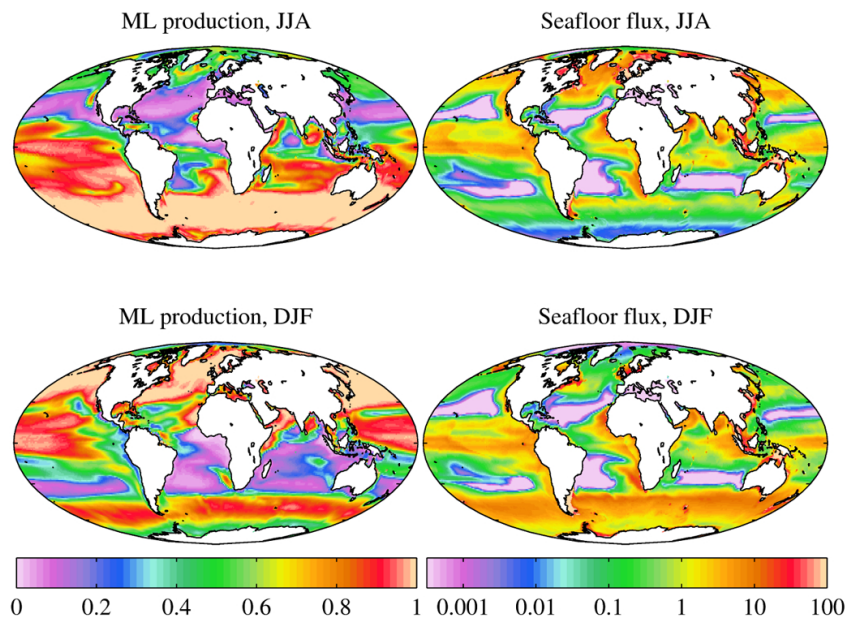

Fig. 29. Simulated mixed layer primary production fraction (left) and seafloor detrital flux (right) for northern summer (June-JulyAugust; top) and northern winter (December-January-February; bottom). Production fraction is dimensionless; seafloor detrital flux in $\mathrm{mg} \mathrm{Cm}^{-2} \mathrm{~d}^{-1}$, and shown on a logarithmic scale.

the tropics, with the actual magnitude of supply to the benthos strongly tied to seafloor depth (e.g. compare North Sea and Patagonian Shelf regions with adjacent deep water regions). Aside from this depth effect, the seafloor supply of organic material mirrors that of its source, primary production, and so discrepancies in the former (e.g. the excessive seafloor flux around Antarctica) are simply symptomatic of problems in the latter. Predictably, the seafloor distribution of organic material (results not shown) largely follows this input of sinking detrital matter. Globally integrated, MEDUSA-2.0 has an inventory of $62.27 \mathrm{MtC}$ of benthic organic carbon, with a $\mathrm{C}: \mathrm{N}$ ratio, $6.72: 1$, higher than that of surface plankton. This higher ratio is driven by the (marginally) preferential remineralisation of nitrogen in slow-sinking detritus. Dynamically, after an immediate spike following initialisation at zero, this total inventory is quickly approached (within $5 \mathrm{yr}$ ), and the long-term, interannual behaviour of this reservoir tracks that of overlying primary production (see later). The reservoirs of inorganic benthic material, silica and $\mathrm{CaCO}_{3}$, behave similarly, though with slightly greater stability since the modelled production of both of these biominerals has lower variability with time.

Following up on ocean productivity, Fig. 30 shows the patterns of limitation by nutrients for both modelled phytoplankton groups. The leftmost panels show overall phytoplankton growth limitation by nutrients (separate from light), while the rightmost panels indicate which nutrient provides the strongest limitation. In the case of diatoms, nitrogen and iron limitation are joined by silicon limitation. In broad outline, nitrogen is most limiting for both phytoplankton groups in oligotrophic gyres, while iron plays a more significant role in high latitude regions, particularly the Southern Ocean, 
and the equatorial Pacific. Note that, although iron is indicated as most-limiting in both the north Atlantic and Pacific, its impact is greater in the Pacific, particularly in the eastern region. For diatoms, the boundaries between regions of $\mathrm{N}$ - and Fe-limitation are typically where Si-limitation occurs, though in the North Atlantic in particular, the scarcity of silicon almost completely displaces iron stress. The geographical patterns in MEDUSA-2.0 generally parallel those of MEDUSA-1.0 (and other models; Moore et al., 2004), though the change in dust deposition forcing means that the equatorial Pacific experiences a greater degree of iron limitation. As this is one of the more productive regions in MEDusA, this iron-mediated change also decreases total oceanic primary production.

Switching from the production of organic material, Fig. 31 shows the seasonal production of the biominerals opal and $\mathrm{CaCO}_{3}$. As with the preceding plots, production of both is highly seasonal at high latitudes, and more constant at low latitudes. Because of the differential availability of silicic acid, opal production is highest in the North Pacific and Southern Ocean, higher even than that in the tropics, though the latter's annual constancy leads to greater overall production. Patterns of $\mathrm{CaCO}_{3}$ production - technically its export in MedusA-2.0 - are similarly seasonal, though the northern Atlantic and Pacific basins swap from the patterns shown with opal. However, within the northern reaches of both basins, opal and $\mathrm{CaCO}_{3}$ production show different, nonoverlapping geographical patterns. Global total opal production in Medus A-2.0 is $194 \mathrm{Tmol} \mathrm{Si} \mathrm{yr}^{-1}$, around $20 \%$ lower than that estimated by Tréguer et al. (1995) (and lower than that in MedusA-1.0). Total $\mathrm{CaCO}_{3}$ export in MedusA-2.0 is $0.41 \mathrm{PgCyr}^{-1}$, at the bottom end of the broad $0.4-1.8 \mathrm{PgCyr}^{-1}$ range estimated by Doney et al. (2009).

Switching again, this time to the consumption of organic material, Fig. 32 shows the seasonal distributions of surface concentrations of both zooplankton groups. Unsurprisingly, both show the same strong seasonality at high latitudes already seen. Though they have slower maximum growth and are less efficient at lower prey concentration, the wider range of available prey types provides a wider base for mesozooplankton and, coupled with their role as predator, makes them dominant in terms of biomass over microzooplankton. Figure 33 compares the spatio-temporal distribution of surface mesozooplankton in MEDUSA-2.0 with observational data from the COPEPOD database (O'Brien, 2005). Because of the relative scarcity of zooplankton data, annual means and seasonal zonal means are used. In general, though MEDUSA-2.0 has similar patterns of geographical distribution (which ultimately relate to those of phytoplankton), Fig. 33 shows that the model broadly overestimates abundance. This overestimation is greater at higher latitudes during summer months, and MEDUSA-2.0 underestimates winter abundance at the same latitudes. Noticeably,
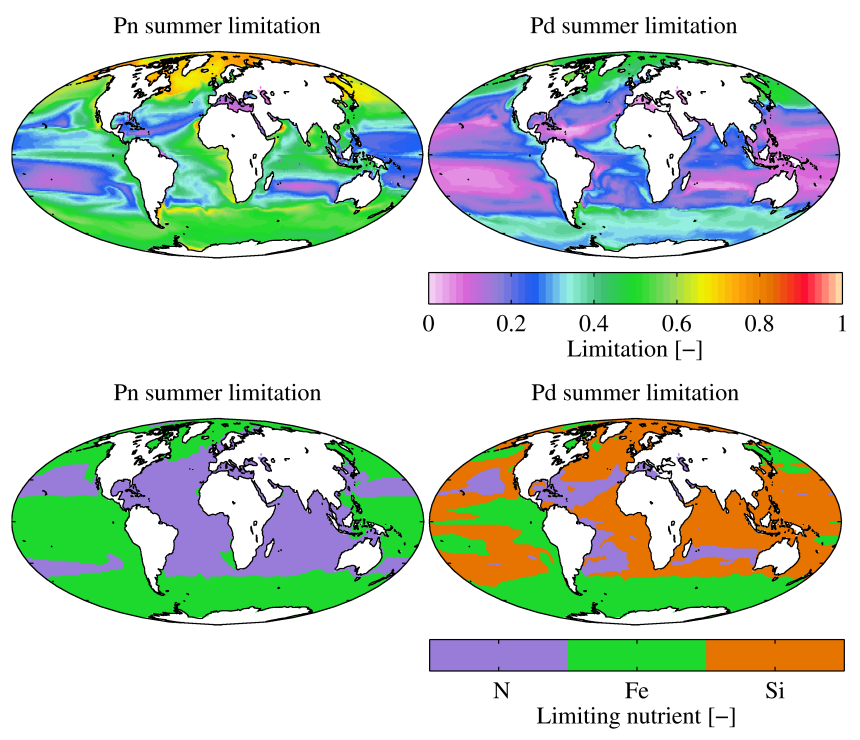

Fig. 30. Simulated summertime average non-diatom (top) and diatom (bottom) integrated nutrient limitation (left) and most-limiting nutrient (right). Limitation is weighted by biomass and integrated for the full water column. Limitation is dimensionless.
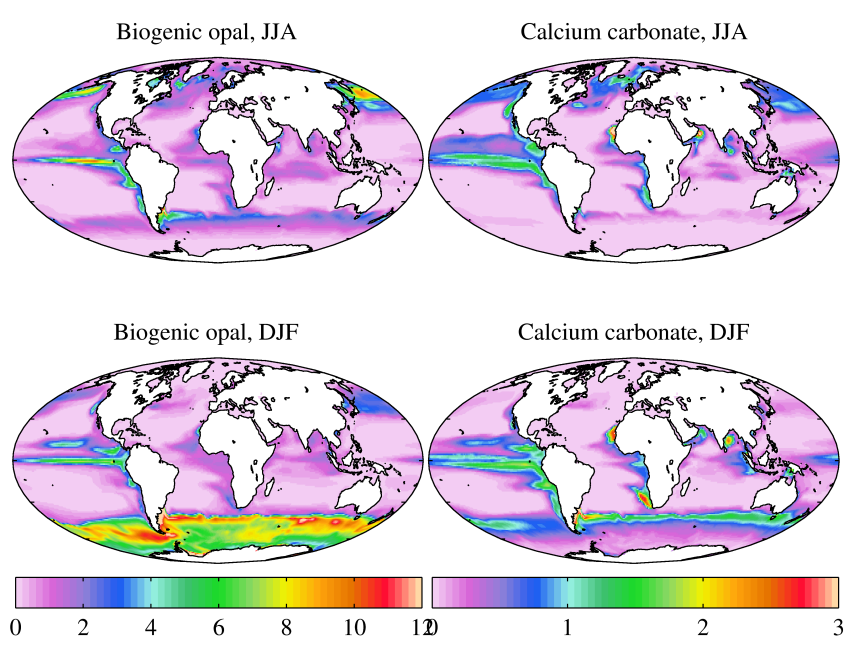

Fig. 31. Simulated diatom biogenic opal (left) and calcium carbonate (right) production for northern summer (June-July-August; top) and northern winter (December-January-February; bottom). Biogenic opal production in mmol Sim ${ }^{-2} \mathrm{~d}^{-1}$; calcium carbonate production in $\mathrm{mmolCm}^{-2} \mathrm{~d}^{-1}$.

MEdUSA-2.0's southern hemisphere summer peak of mesozooplankton is displaced northwards by more than $15^{\circ}$.

Figures 34 and 35 show the production of the two size classes of detritus in MEDUSA-2.0, and the export of this material to the deep ocean. As with MedusA-1.0, the production of small particles dominates in the surface ocean (70.6\%), but this dominance declines down the water column as these particles are quickly remineralised, such that, by $100 \mathrm{~m}$, small particles are the minority component of the 

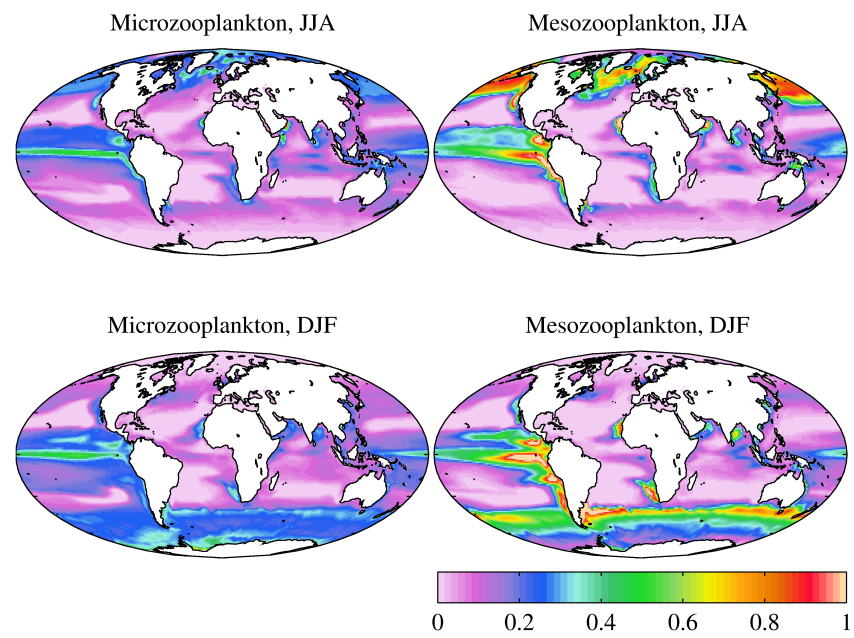

Fig. 32. Simulated surface microzooplankton (left) and mesozooplankton (right) concentrations for northern summer (June-JulyAugust; top) and northern winter (December-January-February; bottom). Concentrations in $\mathrm{mmolm}^{-3}$.
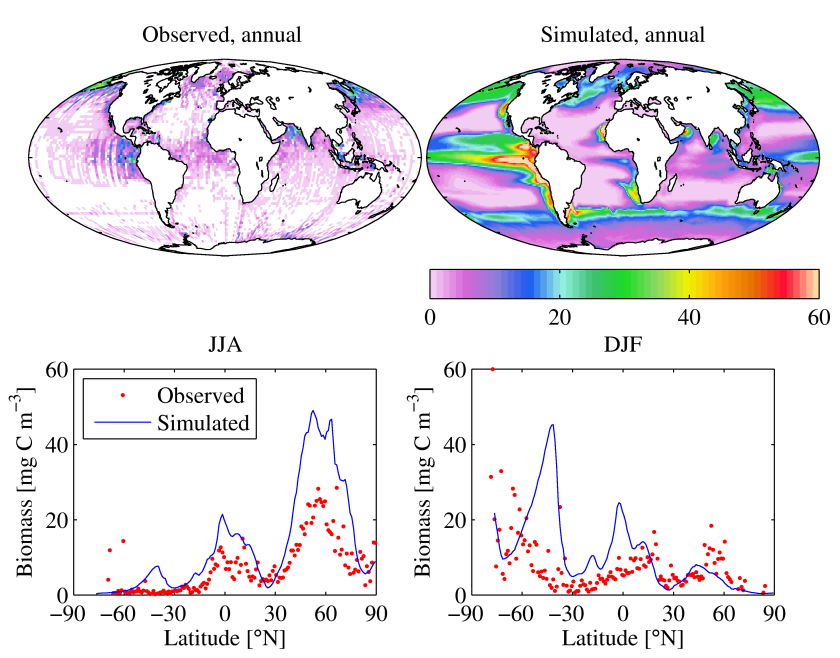

Fig. 33. Global, annual average observed (top left) and simulated (top right) surface mesozooplankton, and zonal average northern summer (June-July-August; bottom left) and northern winter (December-January-February; bottom right) surface mesozooplankton concentrations. Observations drawn from the COPEPOD database (O'Brien, 2005). Concentrations in $\mathrm{mg} \mathrm{Cm}^{-3}$.

export flux (38.8\%). By $1000 \mathrm{~m}$, small particles are of almost no importance to abyssopelagic or benthic communities $(2.2 \%)$. As an aside, since large, fast-sinking particles have a narrower spatial distribution of production than do slowsinking particles (per Fig. 34), deep water benthic communities in MEDUSA-2.0 experience greater variability in supply than do shallow water communities.

In terms of model performance, Fig. 36 compares the total flux of detritus in MEDUSA-2.0 at $2000 \mathrm{~m}$ with the synthesis data set of Honjo et al. (2008) (both expressed here in car-
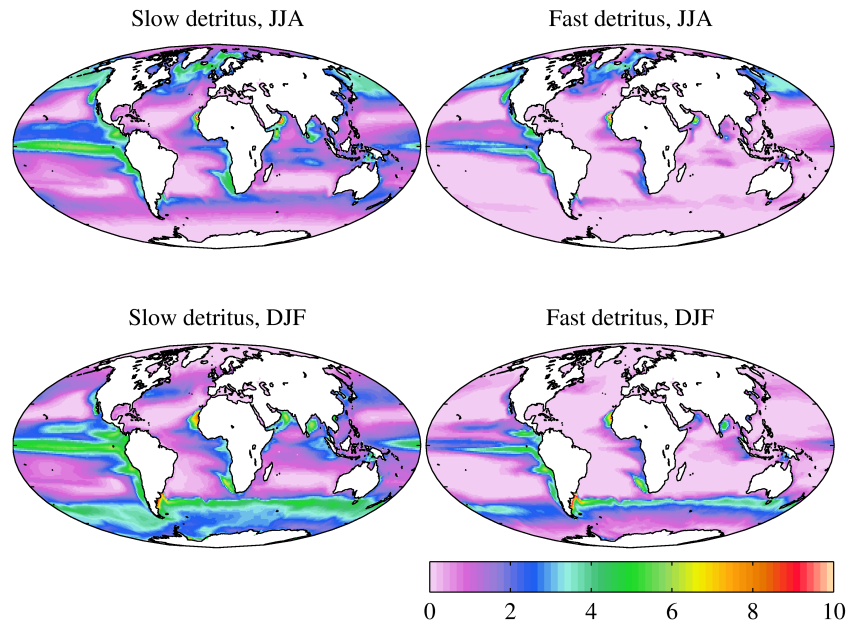

Fig. 34. Simulated slow (left) and fast (right) detritus production for northern summer (June-July-August; top) and northern winter (December-January-February; bottom). Detritus production in mmolNm ${ }^{-2} \mathrm{~d}^{-1}$.
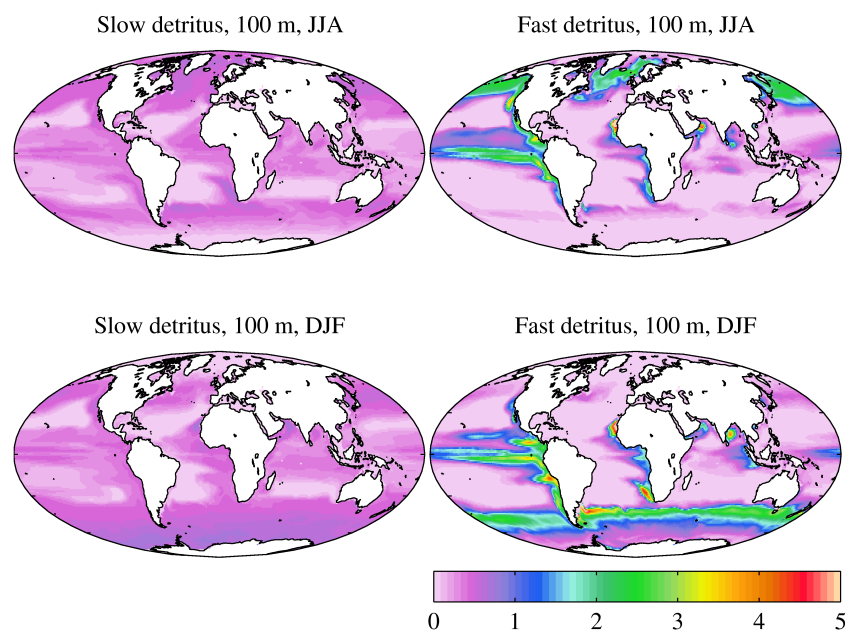

Fig. 35. Simulated slow (left) and fast (right) detrital sinking fluxes at $100 \mathrm{~m}$ for northern summer (June-July-August; top) and northern winter (December-January-February; bottom). Detritus production in $\mathrm{mmolNm}^{-2} \mathrm{~d}^{-1}$.

bon units). As with zooplankton earlier, such observational data is relatively rare, and is plotted here as individual sites on a global map. Model output is plotted as the field of detrital flux at $2000 \mathrm{~m}$ overlaid with $3^{\circ} \times 3^{\circ}$ averages of this field at the same locations as the observations. In general, MEDUSA-2.0 agrees relatively well with data, though there are a number of stations at which modelled fluxes are noticeably lower than those observed (e.g. in subtropical stations fringing the oligotrophic gyres). And in the equatorial Pacific region, MEDUSA-2.0's excessive productivity is responsible for a mismatch towards higher detrital fluxes than observed. In passing, note that observations are biased towards locations where fluxes are expected to be appreciable, and that 

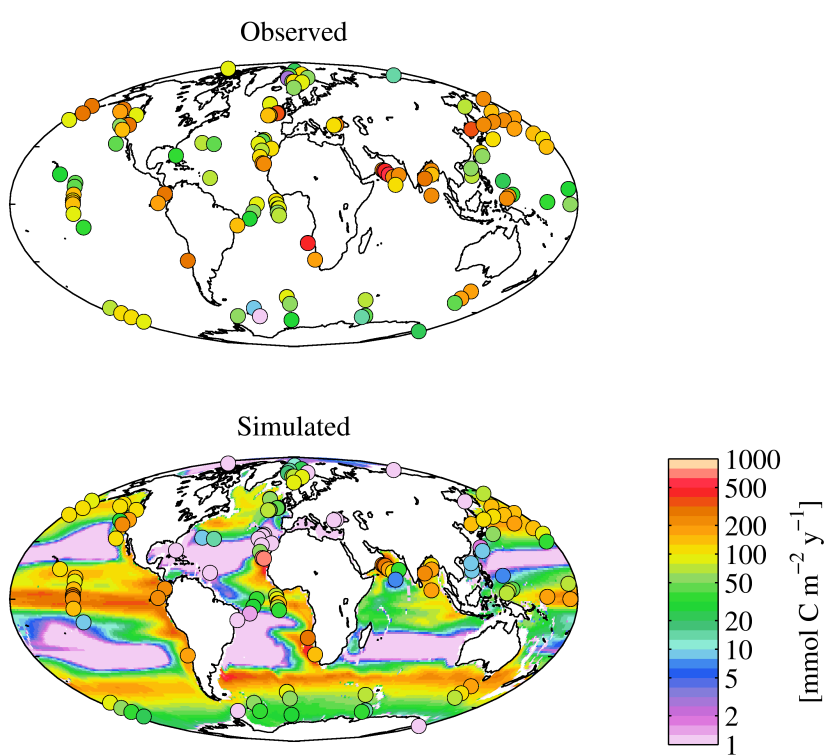

Fig. 36. Observed (top) and simulated (bottom) detrital sinking fluxes at $2000 \mathrm{~m}$. Observations drawn from Honjo et al. (2008). Detrital sinking flux in mmolC $\mathrm{C}^{-2} \mathrm{y}^{-1}$ and shown here on a logarithmic scale.

large regions of less productive ocean are much less wellsampled.

To illustrate longer-term trends in the performance of MEDUSA-2.0, Figs. 37-39 show basin-average vertical profiles of several of the model's major nutrient elements. Since the model is being simulated for a period during which climate change is comparatively limited (though anthropogenic $\mathrm{CO}_{2}$ is increasing), and since these directly influence the behaviour of MEDUSA-2.0's ecological actors (unlike DIC, alkalinity and oxygen; results not shown), they illustrate the degree to which the model has equilibrated.

In the case of nitrogen, per Fig. 37, while globally there is a steady rise in near-surface concentrations - and a steady decrease in deep (2000-5000 m) concentrations - this is largely driven by changes in the Pacific Ocean, with the other basins showing much weaker trends. The pattern of Pacific dominance in the global signal continues with silicon, per Fig. 38, but surface changes are broadly much less significant. Both elements show rapid and significant changes in the Southern Ocean that are consistent with the circulation and water mass changes described earlier. Figure 39 shows the corresponding situation for iron, where the situation is complicated by large removal (scavenging) and addition (aeolian/benthic) fluxes. Here, changes are greatest at depth, where continual scavenging removes deep iron, but there is also a slight general decrease in the surface ocean. An exception lies with the Indian Ocean, which shows almost static surface concentrations.

Complementing these profiles, Fig. 40 shows annual time series of surface nitrogen, silicon and chlorophyll, and integrated primary production for the duration of the simula-
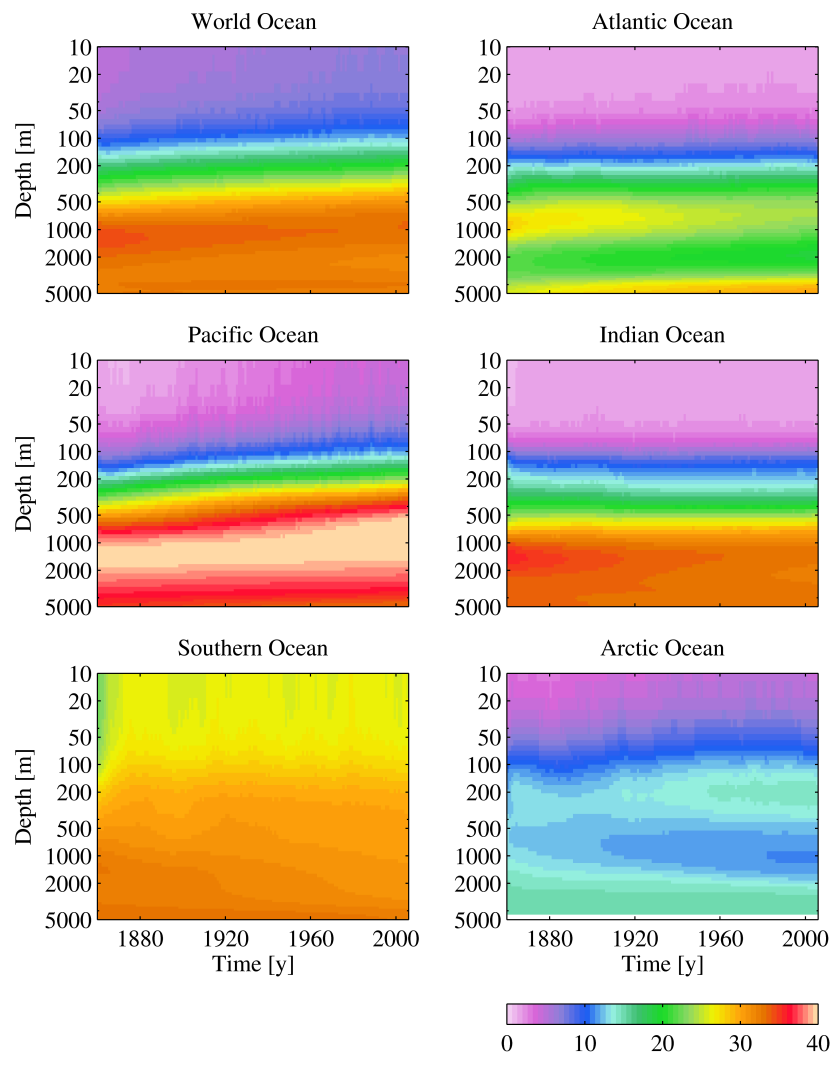

Fig. 37. Simulated vertical profiles of dissolved inorganic nitrogen concentration averaged for the World Ocean (top left) and 5 major regions. Concentrations in $\mathrm{mmolNm}^{-3}$. Note that depth is shown on a logarithmic scale.

tion. Note that the vertical scales have been focused to emphasise change across the simulation. Consistent with the profile plots above, both surface DIN and silicic acid show an increase during the simulation, but while DIN continues to gradually rise throughout its duration, silicic acid saturates relatively quickly (by 1880). In the case of DIN, this global trend generally reflects that at the surface of the $\mathrm{Pa}$ cific Ocean, but for silicic acid the global trend is driven by the large increase in surface concentrations in the Southern Ocean. The lower two panels show trends in biological variables that are similar to that of DIN, and this similarity extends to its source, with, again, changes in the Pacific Ocean driving the wider global trend. In the case of primary production, almost all of the increase during the simulation $\left(5 \mathrm{PgC} \mathrm{Cyr}^{-1}\right)$ is driven by the corresponding increase in the Pacific.

Finally, Tables 7 and 8 intercompare MedusA-1.0 and MEdUSA-2.0 for a range of common properties on a basin average basis. Table 7 focuses on the surface concentrations of major model components, plankton and nutrients. Generally, the two models show very similar patterns, though this is unsurprising given the relatively minor differences between their core nutrient dynamics. However, there are several notable differences in nutrient concentrations. For 

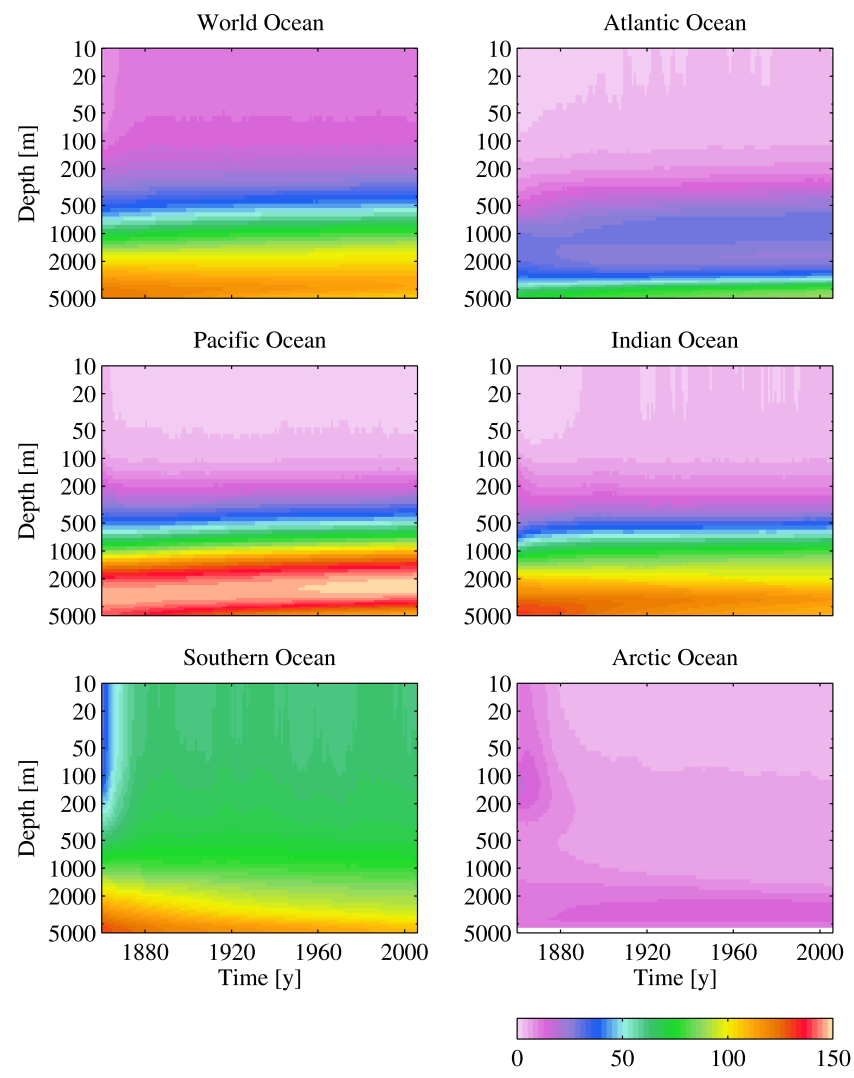

Fig. 38. Simulated vertical profiles of silicic acid concentration averaged for the World Ocean (top left) and 5 major regions. Concentrations in $\mathrm{mmol} \mathrm{Si} \mathrm{m}^{-3}$. Note that depth is shown on a logarithmic scale.

instance, surface nitrogen $(+9.1 \%)$, silicon $(+5.2 \%)$ and iron $(+5.8 \%)$ are elevated globally in MEDUSA-2.0, but there are strong regional biases. In the case of the Pacific Ocean, nitrogen increases by $+74.4 \%$, while iron falls by $-25.8 \%$. And some of the largest differences between the models occur in the Arctic Ocean (increased N, decreased Si). In part, the longer duration of MEDUSA-2.0's simulation (146 yr versus $40 \mathrm{yr}$ ) appears responsible for these differences, but the change in iron deposition forcing, especially in the Pacific, also appears a key factor in the change between the otherwise very similar models.

In terms of major biogeochemical fluxes, Table 8 shows, again, much congruence between the two versions of the model. As mentioned previously, the simulation of MEDUSA-2.0 exhibits lower productivity ( $-8.1 \%)$, with knock-on consequences in phytoplankton biomass $(-5.3 \%)$ and opal production $(-12.3 \%) . \mathrm{CaCO}_{3}$ production is more substantially impacted $(-31.3 \%)$, reflecting the compounded declines in both organic production and rain ratio in MedusA-2.0. Via the ballast submodel, decline in the production of both opal and $\mathrm{CaCO}_{3}$ has a further impact on export production: in MEDUSA-1.0, 5.3\% of the $100 \mathrm{~m}$ flux of organic matter reached $1000 \mathrm{~m}$, while in MEDUSA-2.0, only $4.4 \%$ did.
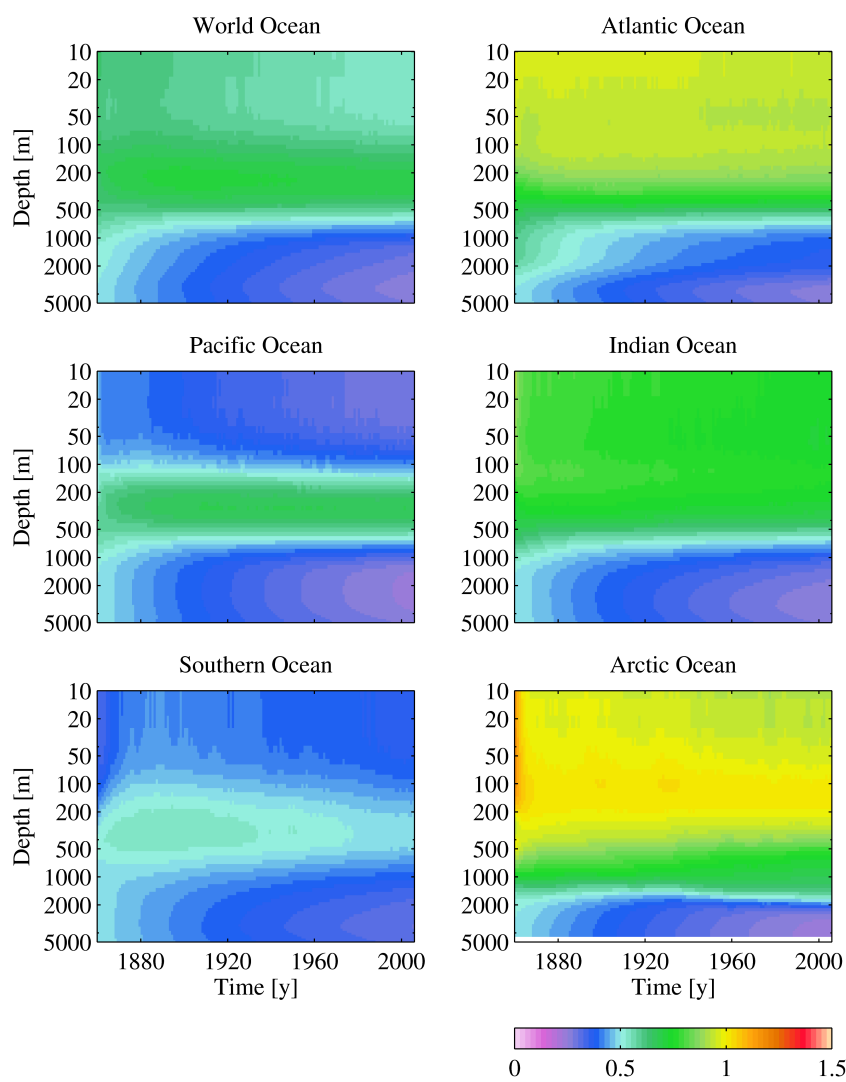

Fig. 39. Simulated vertical profiles of iron concentration averaged for the World Ocean (top left) and 5 major regions. Concentrations in $\mu \mathrm{molFe} \mathrm{m}^{-3}$. Note that depth is shown on a logarithmic scale.

Table 7. Mean annual (2000-2004) surface concentrations of Medus A-1.0 (upper row) and MedusA-2.0 (lower row) tracers for. All concentrations are in $\mathrm{mmol} \mathrm{m}^{-3}$, except $\mathrm{Fe}$ which is in $\mu \mathrm{mol} \mathrm{m}{ }^{-3}$.

\begin{tabular}{lcccccc}
\hline Field & World & Atlantic & Pacific & Indian & Southern & Arctic \\
\hline Pn & 0.2589 & 0.2449 & 0.2821 & 0.2796 & 0.2228 & 0.1363 \\
& 0.2484 & 0.1931 & 0.3024 & 0.2061 & 0.2403 & 0.1632 \\
\hline Pd & 0.1100 & 0.1076 & 0.1027 & 0.1276 & 0.1261 & 0.0646 \\
& 0.1017 & 0.0886 & 0.1051 & 0.0780 & 0.1346 & 0.1104 \\
\hline $\mathrm{Z \mu}$ & 0.1391 & 0.1269 & 0.1523 & 0.1567 & 0.1170 & 0.0767 \\
& 0.1361 & 0.0929 & 0.1715 & 0.1064 & 0.1372 & 0.1069 \\
\hline $\mathrm{Zm}$ & 0.1643 & 0.1575 & 0.1928 & 0.1869 & 0.0984 & 0.0440 \\
& 0.1691 & 0.1320 & 0.2233 & 0.1108 & 0.1461 & 0.1082 \\
\hline \multirow{2}{*}{$\mathrm{DIN}$} & 6.0084 & 2.0798 & 2.3835 & 2.3214 & 26.4194 & 2.3620 \\
& 6.5577 & 1.7054 & 4.1569 & 1.5622 & 25.8858 & 4.3875 \\
\hline $\mathrm{Si}$ & 10.6727 & 1.3420 & 1.8965 & 2.2839 & 57.4320 & 9.5829 \\
& 11.2299 & 2.5587 & 1.3104 & 2.6514 & 62.0107 & 2.8387 \\
\hline $\mathrm{Fe}$ & 0.5059 & 0.7179 & 0.3759 & 0.6497 & 0.3732 & 0.7301 \\
& 0.5354 & 0.9454 & 0.2791 & 0.7427 & 0.3599 & 0.9050 \\
\hline
\end{tabular}



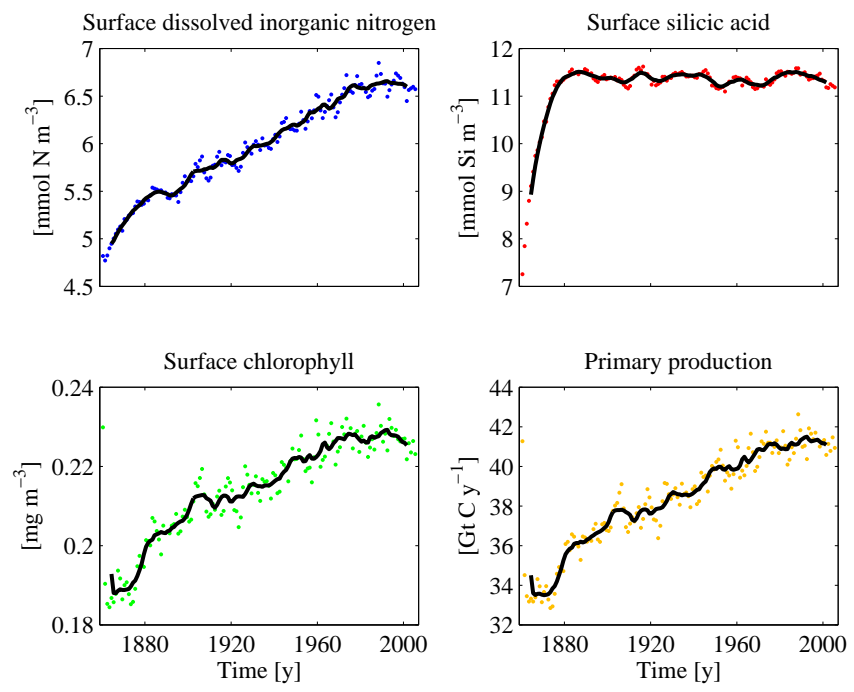

Fig. 40. Globally averaged surface dissolved inorganic nitrogen (top left), surface silicic acid (top right), surface chlorophyll (bottom left) and integrated primary production (bottom right). Solid black lines are annual averages/integral; individual points are individual months. Note that individual monthly primary production values have been normalised so that they appear on the same scale as annual integrals.

\subsection{CMIP5 intercomparison}

The preceding agreement between the behaviour of MedusA-1.0 and MedusA-2.0 is to be expected given the parental role of the former in the latter. Their similar disagreement with observations is also to be expected since most of the evolution leading to MEdusA-2.0 relates to extending the model to include additional elemental cycles rather than alterations to the core plankton ecosystem model. Of greater importance, however, is the performance of MEDUSA-2.0 relative to comparable biogeochemical models. To examine this, a series of standard outputs already examined above (DIN, silicic acid, chlorophyll, primary production, DIC and alkalinity) were collated from simulations of nine CMIP5 models. Table 9 lists the models examined, together with the number of biogeochemical tracers in each, which serves as a crude measure of their complexity and computational cost. In each case, model output was averaged for the same time period in the preceding analysis, and was compared - together with that from Medus A-2.0 - against the same observational data sets (see also Appendix B). Note that these models do not share a common physical model framework, and it is not possible to deconvolute the performance of the biogeochemical models from that of their underlying physical models. As such, any weaker performance here may actually be driven by deficiencies in modelled physics rather than in modelled biogeochemistry.
Table 8. Mean annual (2000-2004) biogeochemical properties in MEdus A-1.0 (upper row) and Medus A-2.0 (lower row). Units indicated for each property.

\begin{tabular}{|c|c|c|c|c|c|c|}
\hline Field & World & Atlantic & Pacific & Indian & Southern & Arctic \\
\hline$(\mathrm{Pn}+\mathrm{Pd})$ & 0.8413 & 0.1909 & 0.3402 & 0.1619 & 0.1397 & 0.0085 \\
\hline $\mathrm{PgC}$ & 0.7968 & 0.1636 & 0.3472 & 0.1311 & 0.1444 & 0.0104 \\
\hline TPP & 45.3024 & 9.8854 & 20.6498 & 9.1584 & 5.2567 & 0.3521 \\
\hline $\mathrm{PgCyr}-1$ & 41.6278 & 7.9429 & 21.0785 & 5.9938 & 6.0846 & 0.5235 \\
\hline Pd fraction & 16.2971 & 16.7576 & 14.1766 & 16.4800 & 23.1119 & 21.2283 \\
\hline$\%$ & 15.8900 & 18.7965 & 13.0309 & 14.4124 & 22.5187 & 26.9237 \\
\hline ML fraction & 73.4297 & 66.8833 & 74.4158 & 69.6741 & 89.6516 & 54.8974 \\
\hline$\%$ & 67.3252 & 58.7899 & 67.9296 & 58.2734 & 85.8437 & 60.8860 \\
\hline Opal & 221.1951 & 39.7958 & 76.6536 & 42.5510 & 59.6807 & 2.5142 \\
\hline $\mathrm{Tmol} \mathrm{Si} \mathrm{yr}^{-3}$ & 193.9731 & 34.3463 & 66.7915 & 24.3439 & 67.0384 & 1.4530 \\
\hline $\mathrm{CaCO}_{3}$ & 0.5952 & 0.1222 & 0.3032 & 0.1269 & 0.0411 & 0.0018 \\
\hline $\mathrm{PgCyr}^{-1}$ & 0.4092 & 0.0860 & 0.2248 & 0.0553 & 0.0399 & 0.0031 \\
\hline Rain ratio & 7.5702 & 7.0905 & 8.1046 & 8.1189 & 5.2348 & 3.6604 \\
\hline$\%$ & 6.4065 & 6.5353 & 6.6294 & 7.5332 & 4.6307 & 3.7528 \\
\hline $\mathrm{D}, 100 \mathrm{~m}$ & 8.1505 & 1.7183 & 3.6140 & 1.5491 & 1.2007 & 0.0683 \\
\hline $\mathrm{PgCyr}^{-1}$ & 8.1274 & 1.5883 & 3.9629 & 1.0937 & 1.3828 & 0.0996 \\
\hline $\mathrm{D}, 1000 \mathrm{~m}$ & 0.4312 & 0.0739 & 0.2075 & 0.0909 & 0.0580 & 0.0008 \\
\hline $\mathrm{PgCyr}^{-1}$ & 0.3575 & 0.0676 & 0.1754 & 0.0492 & 0.0638 & 0.0014 \\
\hline
\end{tabular}

Figure 41 shows the resulting intercomparison as a series of Taylor diagrams based on the annual means of each ocean property. In broad outline, the models tend to show similar patterns of variability and correlation with observations between the considered fields. Fields that MedusA-2.0 previously correlated well with are generally also well correlated with for CMIP5 models, and vice versa. DIN, DIC and alkalinity, for instance, show strongly clustered, good correlation across all models, while all models show very poor correlation for chlorophyll and intermediate correlation for primary production. Though there are clearly differences between the models, none stand out as being noticeably better or worse than their rivals, in spite of a range of model complexity from 13 to 30 prognostic tracers. Nonetheless, for the fields examined, MEDUSA-2.0 is typically among the best models in terms of model-observation correlation, and exhibits spatial variability that is comfortably within the range of models assessed.

Figures $42-47$ show corresponding global fields of the same properties for all of the CMIP5 models examined as well as Medusa-2.0 and observations. Almost all of the models capture the broad zonal patterns in DIN distribution of moderate concentrations in equatorial upwelling regions, very low concentrations in the subtropics and high concentrations at high latitudes, particularly in the Southern Ocean (Fig. 42). The deficiencies already noted in MedusA-2.0 adjacent to South America are not unique, though they are the most extreme. Significant deficiencies in other models include elevated gyre concentrations in one model, and excessive Arctic nutrient concentrations in two others (see also Popova et al., 2012). Regarding surface silicic acid, while MEdusA-2.0's Southern Ocean concentrations are too high, 
Table 9. CMIP5 models used for intercomparison with MEDUS A-2.0. Each entry lists the component biogeochemical submodel, the number of state variables (in brackets) and the host institution for each model.

\begin{tabular}{llll}
\hline CMIP5 model & BGC & Institute & Reference \\
\hline HadGEM2-CC & Diat-HadOCC (13) & Met Office Hadley Centre (UK) & Collins et al. (2011) \\
HadGEM2-ES & Diat-HadOCC (13) & $\begin{array}{l}\text { Met Office Hadley Centre (UK), } \\
\text { Instituto Nacional de Pesquisas Espaciais (Brazil) }\end{array}$ & Collins et al. (2011) \\
GFDL-ESM2M & TOPAZ2 (30) & Geophysical Fluid Dynamics Laboratory (USA) & Dunne et al. (2013) \\
NorESM1 & HAMOCC 5.1 (18) & Norwegian Climate Centre (Norway) & Maier-Reimer et al. (2005) \\
MPI-ESM1 & HAMOCC 5.2 (17) & Max Planck Institute for Meteorology (Germany) & Ilyina et al. (2013) \\
CNRM-CM5 & PISCES (18) & Centre National de Recherches Meteorologiques (France), & Lengaigne et al. (2007) \\
& & Centre Europeen de Recherche et Formation Avancees & Gregg and Casey (2007) \\
en Calcul Scientifique (France) & Lengaigne et al. (2007) \\
IPSL-CM5A & PISCES (18) & Institut Pierre-Simon Laplace (France) & Lengaigne et al. (2007) \\
IPSL-CM5B & PISCES (18) & Institut Pierre-Simon Laplace (France) & \\
\hline
\end{tabular}

and those of its North Pacific too low, the range in behaviour of the other CMIP5 models examined is noticeably more divergent (Fig. 43). For instance, the two HadGEM2 model runs systematically overpredict silicic acid throughout much of the World Ocean. Of the other models, they split between over-/under-predicting Southern Ocean silicic acid, and almost all underpredict North Pacific conditions to a stronger degree than MEDUSA-2.0. As Fig. 41 has already suggested, none of the models examined does well at predicting the geographical pattern of surface chlorophyll (Fig. 44). Several models do better than MEDUSA-2.0 in predicting higher (but still low) gyre conditions, but they do so with significantly larger gyre regions than observed. And several models predict large regions with chlorophyll concentrations markedly higher than either observations or MEdus A-2.0 - particularly within the Southern Ocean. Interestingly, in spite of the foregoing issues with surface chlorophyll, the models examined are noticeably better in terms of primary production (Fig. 45). No one model stands out as globally better than the others, but several show much better Southern Ocean productivity than MEDUSA-2.0, though most exhibit even lower productivity in the North Atlantic. Finally, Figs. 46 and 47 compare surface DIC and alkalinity across the models. As previously noted, excessive ventilation in MEdus A-2.0's Southern Ocean is responsible for the largest discrepancy with observations for both fields. However, most of the CMIP5 models examined exhibit larger discrepancies, most notably in the North Atlantic, where concentrations of both tracers are elevated by more than $100 \mathrm{mmol} \mathrm{m}^{-3}$ (or meq ${ }^{-3}$ ) in several models. Nonetheless, for both fields, it is noticeable that the GFDL-ESM2M model (Dunne et al., 2013) performs best.

In passing, that observed fields are fairly consistently represented better or worse across different models is suggestive of a gradation of difficulty in modelling aspects of oceanic biogeochemistry. Bulk properties, such as nutrients, which place a strong constraint on all biological activity, and for which there are relatively good and widespread measurements, are tightly constrained, whereas primary production, for which there are global estimates but far fewer direct observations, is less well-constrained. Chlorophyll, by contrast, is something of a confounding factor here, since its surface values have become extremely well-observed since the beginning of the satellite era. This unexpected disparity likely stems from the strong plasticity of chlorophyll : C ratios in phytoplankton, which acts to decouple its concentrations both from well-observed ambient factors such as nutrients and more poorly observed aspects such as phytoplankton biomass.

\section{Discussion}

Despite the ever-increasing processing power of supercomputers, incorporating marine ecosystem models into global GCMs is a computationally expensive business when it comes to undertaking climate simulations, especially if high resolution is desired and/or the ocean is coupled to an atmospheric model. MEDUSA-1.0, the precursor to the version of the model described herein, was explicitly developed with this consideration in mind as an "intermediate complexity" plankton ecosystem model for global biogeochemical modelling. It simulates primary production, grazing and export of detritus to the deep ocean, the sinking particles containing both organic and inorganic $\mathrm{C}$ with the latter via a latitudinally dependent "rain ratio". The base currency of MEDUSA-1.0 is nitrogen, the selection of a nutrient element $(\mathrm{N}$ or $\mathrm{P})$ for this purpose being a necessity given the role of nutrients in limiting primary production in the ocean. Although MEDUSA-1.0 predicts the fluxes and cycling of organic carbon, simulating the full carbon cycle in the ocean, including ventilation of $\mathrm{CO}_{2}$ with the atmosphere and the resulting impact of ocean 

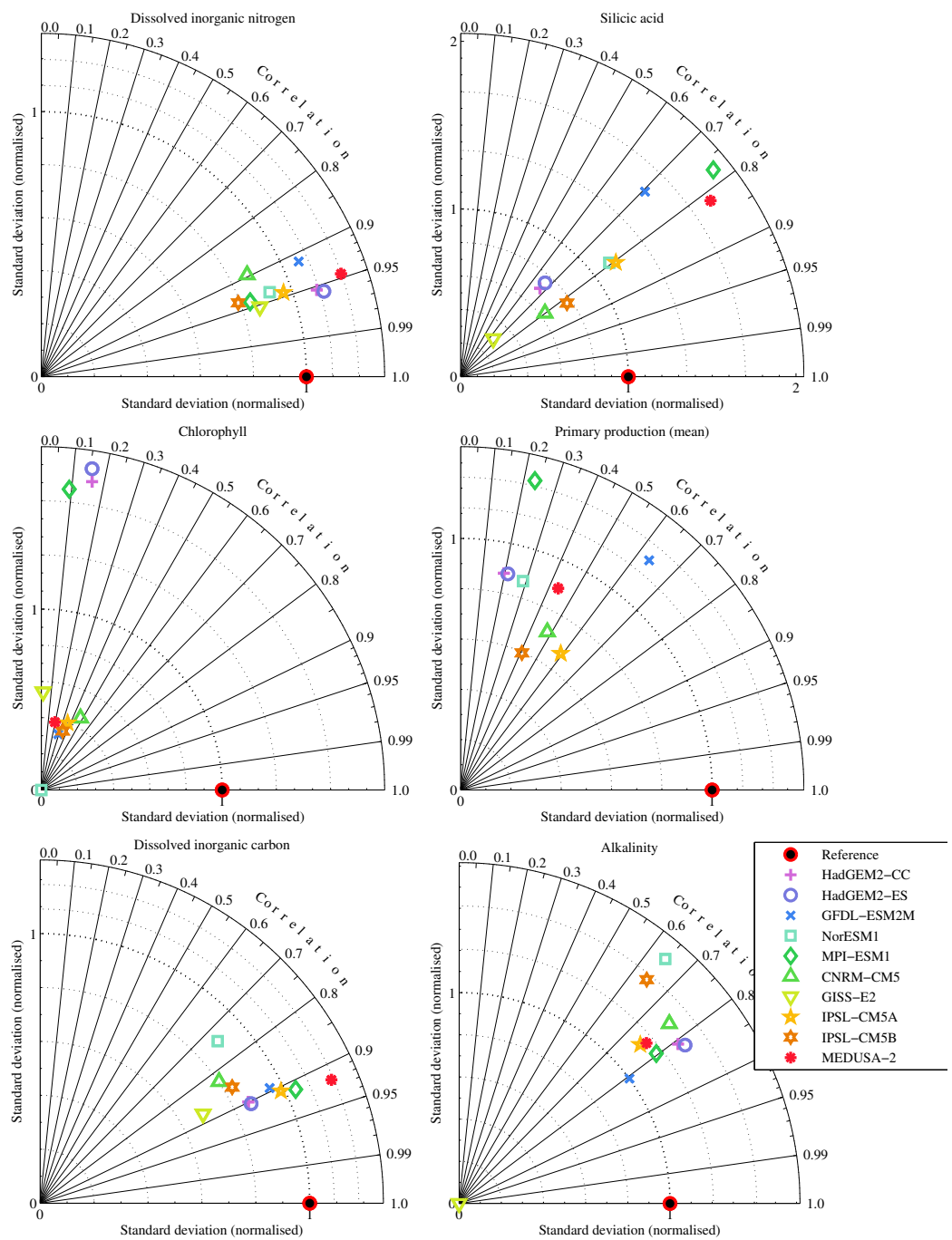

Fig. 41. Taylor diagrams of the performance of MEDUSA-2.0 and a selection of CMIP5 models for a range of biogeochemical properties: dissolved inorganic nitrogen (top left), silicic acid (top right), chlorophyll (middle left), primary production (middle right), dissolved inorganic carbon (bottom left) and alkalinity (bottom right). In each case, diagrams show spatial model-observation comparisons based on annual average fields. All diagrams share a common model key.

acidification on marine ecosystems, requires additional tracers. Here, we describe MEDUSA-2.0, an expanded successor model which includes dissolved inorganic carbon, alkalinity, dissolved oxygen and detrital carbon as additional state variables, as well as a simple representation of the benthos.

In principle, the two versions of the model ought to give similar predictions given that phytoplankton, at the base of the food chain, are not limited by the availability of dissolved inorganic carbon (at least in the model - work such as Riebesell et al., 2007, suggests that the availability of DIC species may actually affect carbon fixation). Differences do occur, however, for several reasons. Principally, the simulation described here used forcing from output of the HadGEM2-ES coupled model and was run for 145 yr (18602005), rather than observationally derived DFS4.1 forcing and a simulation length of only $40 \mathrm{yr}$ (1966-2005) as used with MedusA-1.0 (Yool et al., 2011). There were also minor parameter tweaks to adjust near-surface nutrients (see later), as well as parameter changes and additions to accommodate the carbon and oxygen cycles.

However, in general, the performance of the two models is very similar, in both cases successfully reproducing major features such as the oligotrophic gyres and the seasonal progression of plankton blooms at high latitudes. At the global scale, predicted primary production of 45.3 and 41.6 $\mathrm{PgC} \mathrm{yr}^{-1}$ for MedusA versions 1.0 and 2.0 respectively, are in line with, although slightly below, observationally derived estimates of 46.3-60.4 $\mathrm{PgCyr}^{-1}$ (Behrenfeld and Falkowski, 1997; Carr et al., 2006; Westberry et al., 2008). The lower primary production in MEDUSA-2.0 is in 

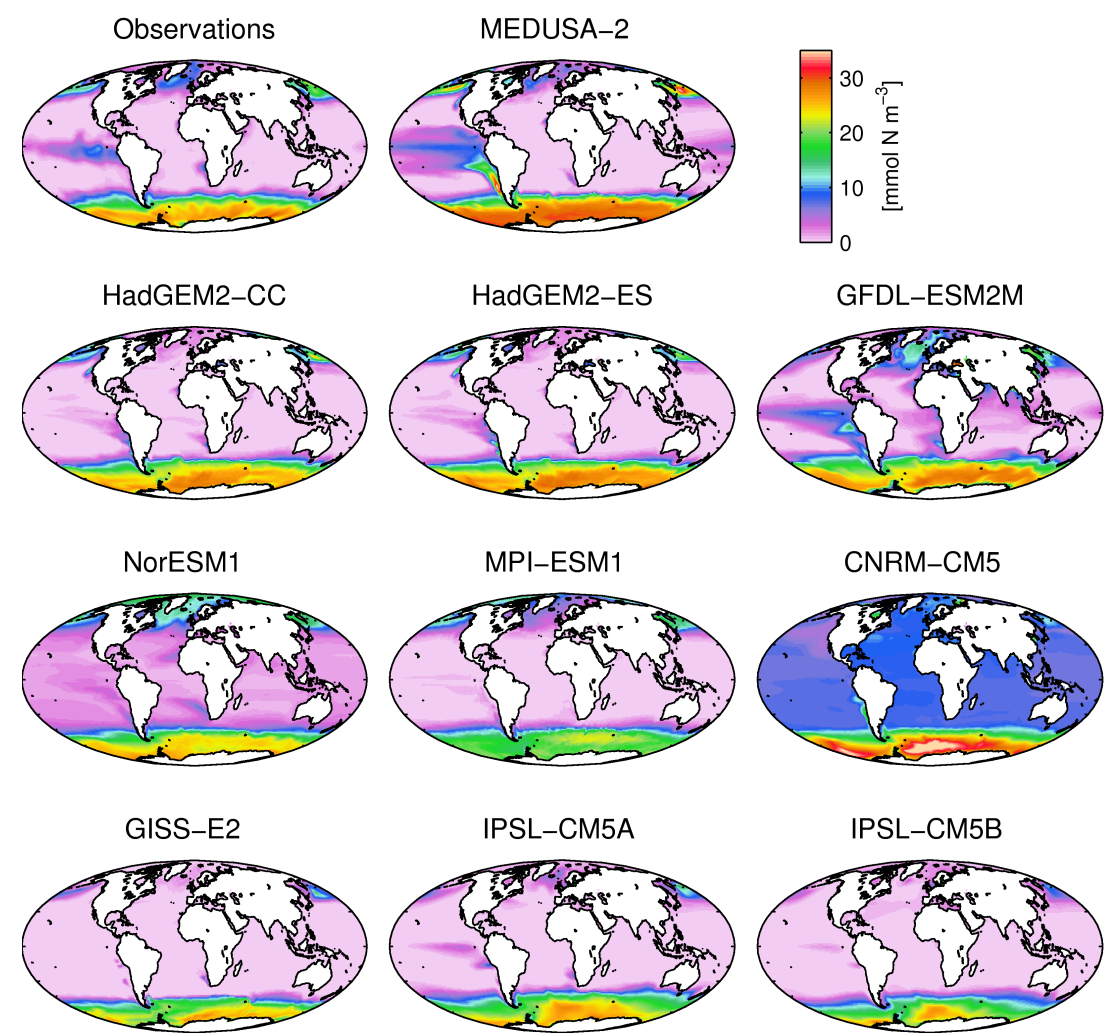

Fig. 42. Intercomparison of annual mean surface dissolved inorganic nitrogen for MEDUSA-2.0 and a range of comparable CMIP5 models. DIN concentration in $\mathrm{mmolNm}^{-3}$.
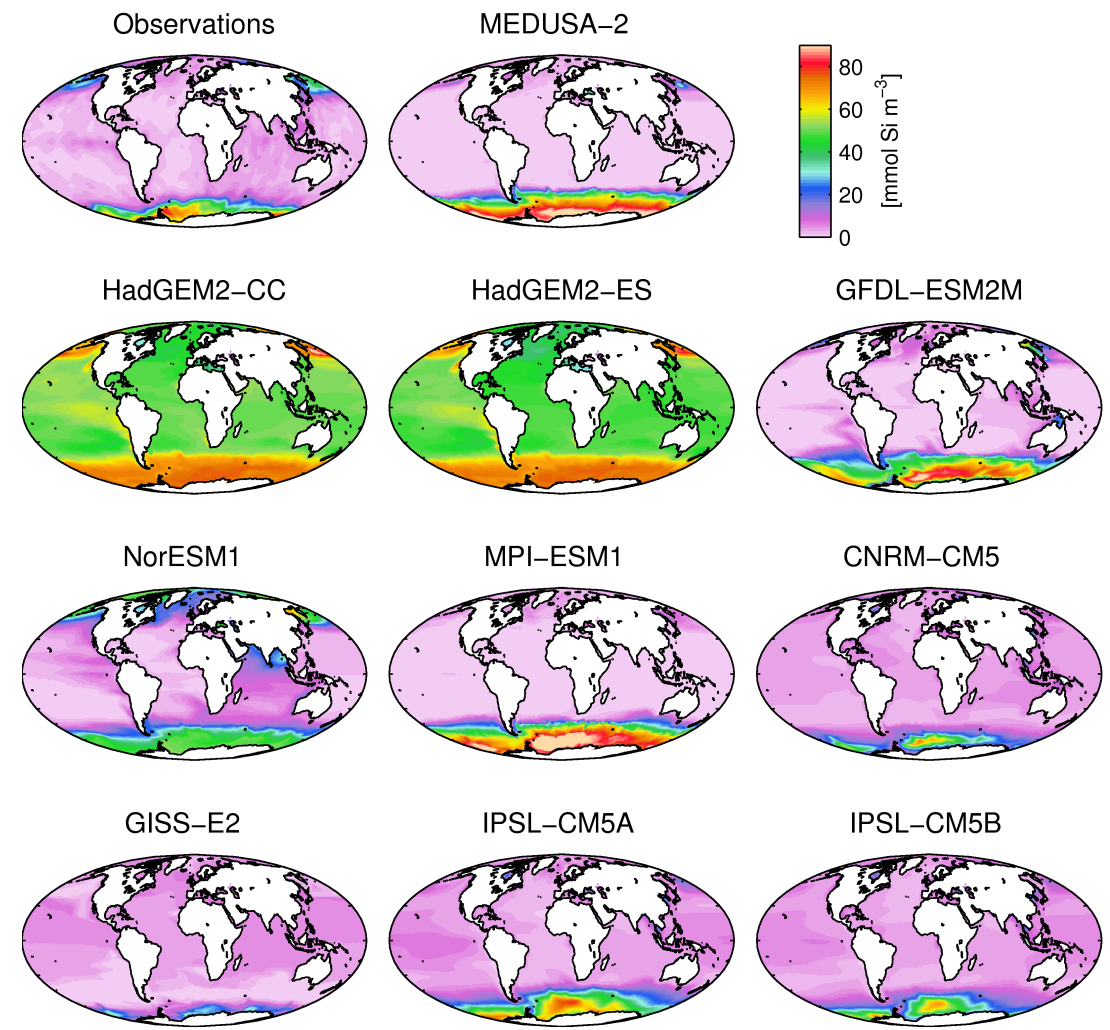

Fig. 43. Intercomparison of annual mean surface silicic acid for MEDUSA-2.0 and a range of comparable CMIP5 models. Silicic acid concentration in $\mathrm{mmolSim}^{-3}$. 

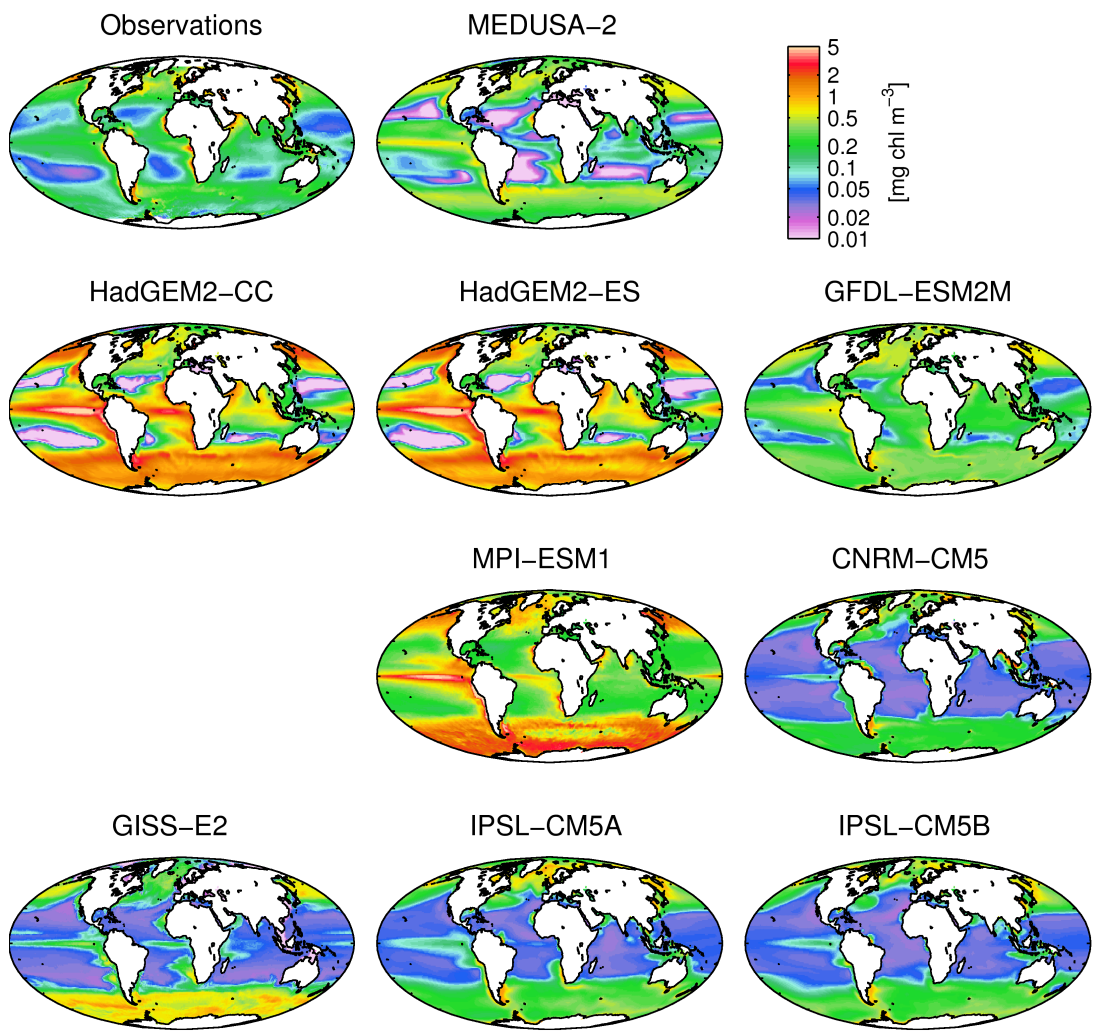

Fig. 44. Intercomparison of annual mean surface chlorophyll for MEDUSA-2.0 and a range of comparable CMIP5 models. Chlorophyll concentration in $\mathrm{mgchlm}^{-3}$ and is shown on a logarithmic scale.
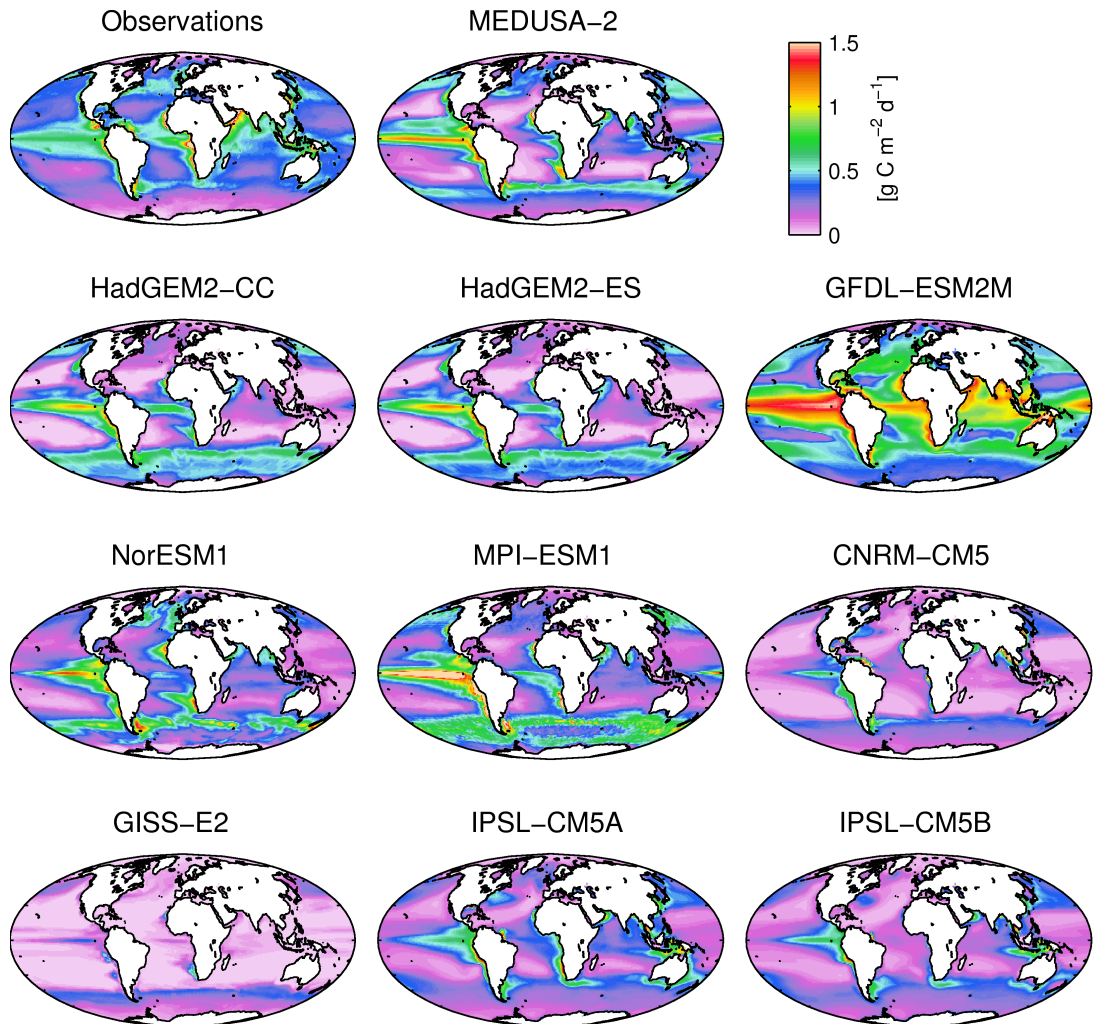

Fig. 45. Intercomparison of annual mean primary production for MEDUSA-2.0 and a range of comparable CMIP5 models. Primary production in $\mathrm{gCm}^{-2} \mathrm{~d}^{-1}$. 

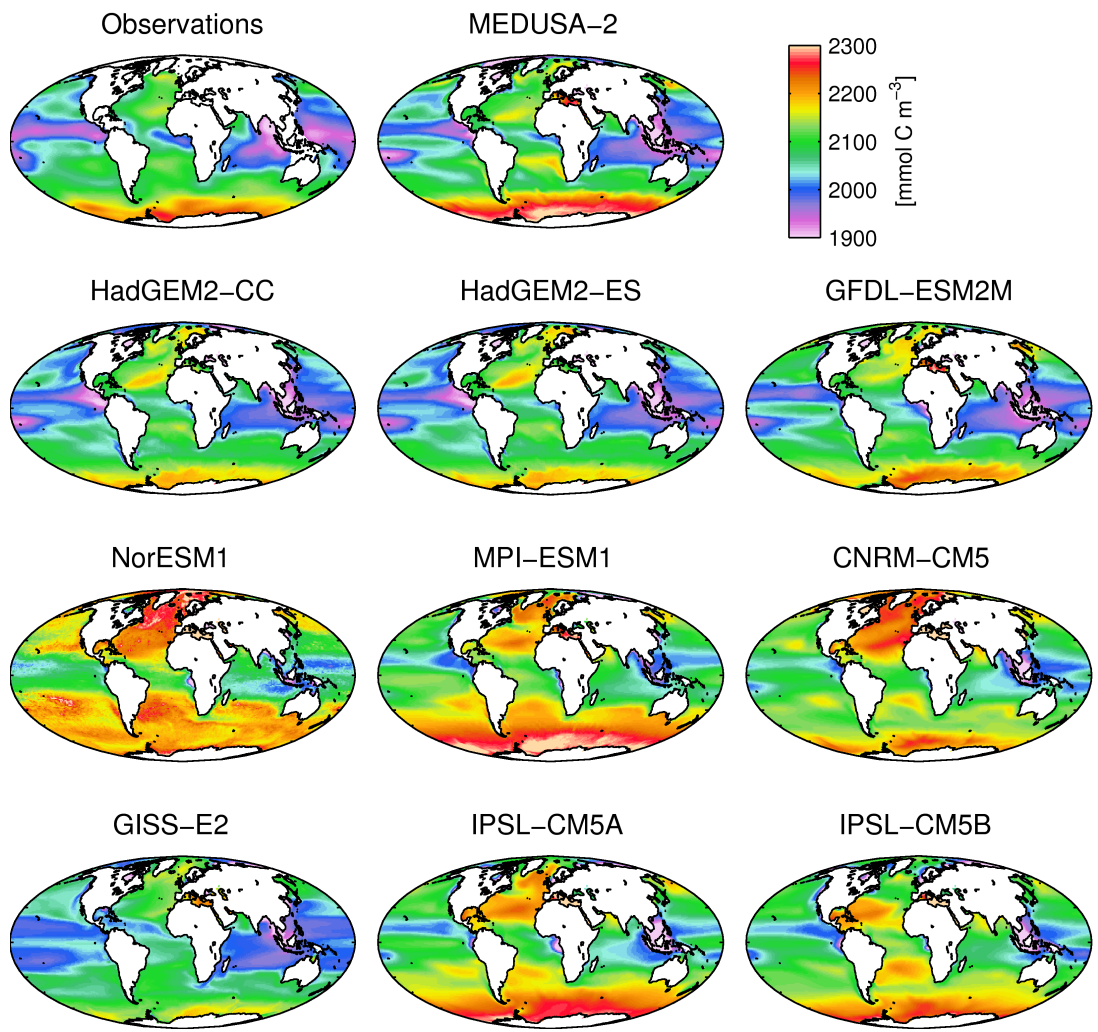

Fig. 46. Intercomparison of annual mean surface dissolved inorganic carbon for MEDUSA-2.0 and a range of comparable CMIP5 models. Surface DIC in $\mathrm{mmolCm} \mathrm{m}^{-3}$.
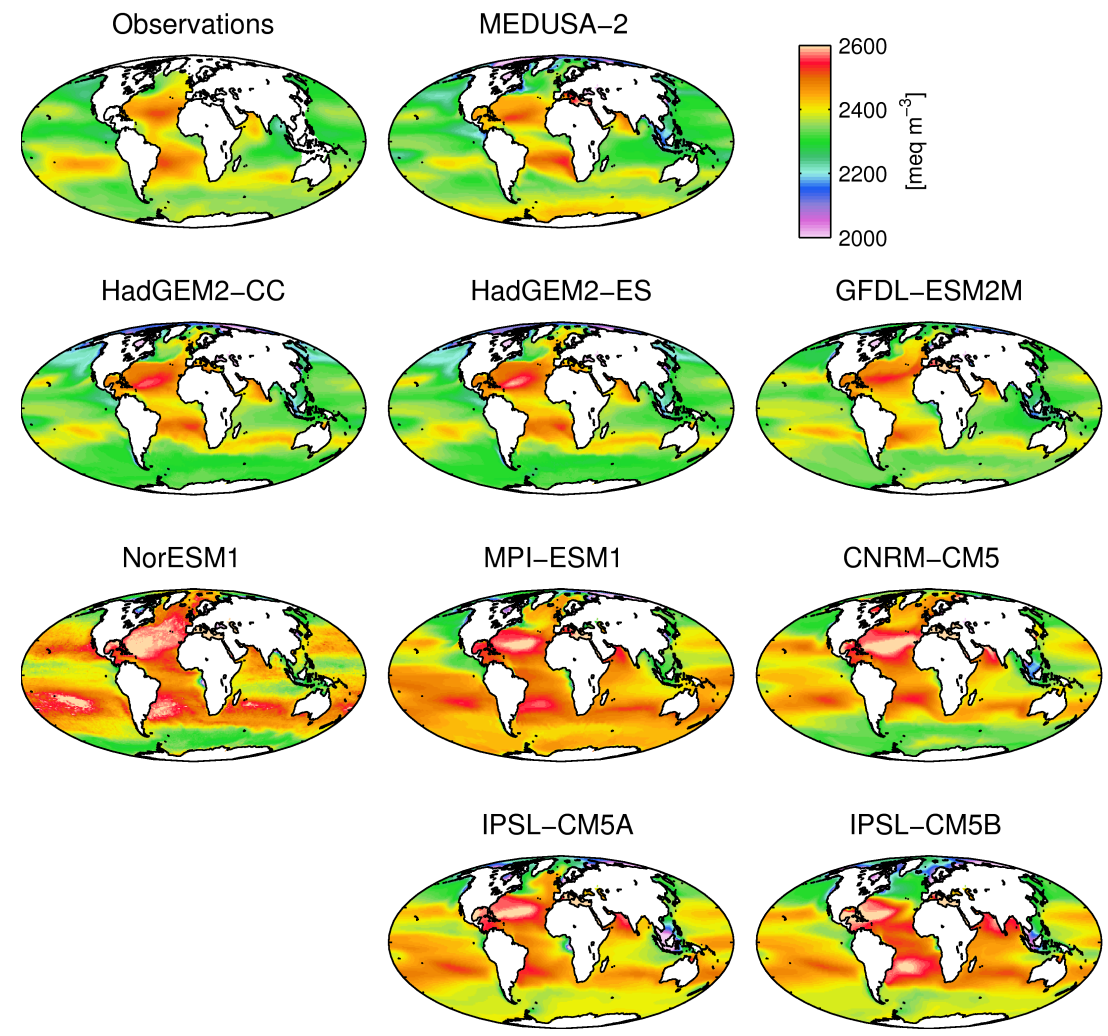

Fig. 47. Intercomparison of annual mean surface alkalinity for MEDUSA-2.0 and a range of comparable CMIP5 models. Surface alkalinity in meq $^{-3}$. 


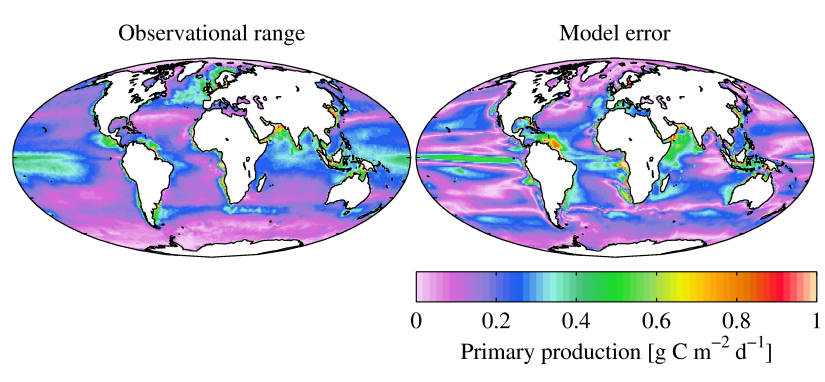

Fig. 48. Comparison of range of annually averaged observational estimates (VGPM, Eppley-VGPM and CbPM) of total oceanic primary production (left) with annually averaged [model - mean(observational estimate)] error (right). Range and error in units of $\mathrm{gCm}^{-2} \mathrm{~d}^{-1}$.

part a consequence of changes to productivity in the Pacific that result from the switch in MEDUSA-2.0 to a more modern aeolian deposition field (Mahowald, 2005). The resulting deficiency of iron leads, in part, to excess DIN in the surface waters of the equatorial Pacific, though this is convoluted with excessively shallow remineralisation in this region which more generally increases near-surface concentrations of DIN (and DIC). Both models do a reasonable job at capturing the spatial and seasonal patterns of productivity, although various discrepancies with observations are seen including lower primary production in the subtropical gyres and elevated productivity in iron limited high-nutrient-lowchlorophyll (HNLC) regions including the Southern Ocean, equatorial Pacific and subarctic North Pacific. Predicted concentrations of DIN and, especially, silicic acid are too high in the Southern Ocean, a result of excessive ventilation in this basin which acts to homogenise horizontal and vertical gradients. The problem is somewhat worse in MEDUSA-2.0 because ocean circulation in this region is strong under the HadGEM2-ES forcing used here. Note, however, that the longer duration of the MEDUSA-2.0 simulation allows for any deficiencies in either physics or biogeochemistry to more obviously manifest themselves.

A new feature of MEDUSA-2.0 is the inclusion of a simple benthic model. This serves as a series of four reservoirs for detrital material (slow- and fast-sinking) that reaches the seafloor - nitrogen, silicon, organic carbon, $\mathrm{CaCO}_{3}$; but not iron, which is coupled to nitrogen. In MEDUSA-1.0 such material was instantaneously remineralised (or dissolved) upon reaching the seafloor. While this latter, simplistic approach has limited consequences in the deep ocean where the recycled dissolved inorganic nutrients cannot be consumed by phytoplankton growth, in shallower regions such as the shelves it has the potential to unrealistically enhance production. Patterns in the supply of organic matter to the seafloor closely mirror those of primary production in the surface ocean in the model. This supply thus shows strong seasonality at high latitudes and low seasonality in the tropics. However, given the turnover of sinking particles as they descend through the water column, the magnitude of benthic supply is closely tied to seafloor depth.

As was the case with MEDUSA-1.0, the modelling of iron is still problematic. Aeolian deposition balances uneasily with scavenging, with the result that iron distributions diverge from those of the initial condition (admittedly modelderived; Dutkiewicz et al., 2005) at both the surface and, especially, at depth. The latter discrepancy has limited impact on the simulations here and in Yool et al. (2011) but it does illuminate gaps in understanding of this elemental cycle. While understanding of iron in the ocean has progressed in recent years (e.g. Boyd and Ellwood, 2010; Breitbarth et al., 2010), accurately representing iron in ecosystem models remains difficult for a number of reasons. For instance, accurate estimation of the iron supply to the ocean is hampered by our ignorance of both dust supply and dust solubility once in the ocean (Schulz et al., 2012). Furthermore, even once in the ocean, iron's bioavailability is influenced by its various speciation and redox states, biological cycling and the various uptake strategies of phytoplankton and bacteria. And though increasingly complex representations of iron are being developed and incorporated into ecosystem models (e.g. Weber et al., 2007; Ye et al., 2009), the current generation of ocean biogeochemical GCMs typically only include a single iron pool and so cannot account for the roles of ligand complexation and nonbiological processes (light and temperature) in controlling bioavailable Fe and therefore the extent of phytoplankton limitation (Tagliabue et al., 2009).

Moving on to the carbon cycle, predicted patterns of $p \mathrm{CO}_{2}$ and air-sea $\mathrm{CO}_{2}$ exchange throughout the world ocean generally compare favourably to maps based on observations (Takahashi et al., 2009). Some areas, such as the northeast Pacific, show exaggerated patterns whereas in others, such as the Southern Ocean, seasonality in MEDUSA-2.0 is not as pronounced as that observed. Integrating to net $\mathrm{CO}_{2}$ flux finds MEDUSA-2.0 in relatively close agreement with Takahashi et al. (2009). However, while the surface carbon cycle in MEDUSA-2.0 performs well, there are some issues with midwater distributions and, more importantly, the duration of the simulation here is extremely restricted relative to overturning timescales (Ostlund and Stuiver, 1980). As such, deep waters will not be fully equilibrated with the modelled circulation or biogeochemistry, a problem compounded by unavoidable gaps (and resulting interpolation) in the GLODAP data set used to initialise MEDUSA-2.0; Key et al., 2004). Inadequate spin-up is a common issue in ocean modelling, one that has traditionally been solved by brute force and long duration equilibrium simulations (e.g. Orr et al., 2005), but for which techniques are being developed (Khatiwala, 2007).

A significant consideration in MEDUSA-2.0 has been how to model calcification given the ongoing acidification of the ocean in response to increasing atmospheric $\mathrm{CO}_{2}$ (Caldeira and Wickett, 2003). The physico-chemical factors controlling calcification in marine organisms are poorly understood, 
leading to a diverse range of approaches in models (e.g. Tyrrell and Taylor, 1996; Moore et al., 2002; Gehlen et al., 2007; Ridgwell et al., 2007; Gregg and Casey, 2007; Zahariev et al., 2008; Yool et al., 2010). Anderson (2005) used calcifiers as an example of how difficult it is to reliably parameterize complex models for use in forecast projections. For example, the ecology of coccolithophores is poorly understood including the relative roles of bottom-up (via different nutrients) and top-down (grazing, viral lysis) controls on their dynamics. Further, calcifiers are a diverse group of organisms, including hundreds of species of coccolithophores, as well as foraminiferans and pteropods. Grouping them into a single model state variable and then parameterizing based on, for example, the well-known species Emiliania huxleyi is a potentially hazardous strategy. Ecosystem models used in global biogeochemical modelling studies have therefore adopted relatively simple approaches to the representation of calcification.

In MedusA-1.0, where nutrient cycles were of greater concern, the rain ratio of $\mathrm{CaCO}_{3}: \mathrm{C}_{\text {org }}$ was made a simple empirical function of latitude (following Dunne et al., 2007). This approach captured some of the first order features of the rain ratio (e.g. equator-pole gradients) but prevented any sensitivity to physico-chemical changes (though changes in productivity would still impact the absolute quantity of calcification). For MEDUSA-2.0, the parameterization of calcification was therefore improved to permit dynamic change under the influence of ambient marine chemistry (Riebesell et al., 2000; Zondervan et al., 2001). As noted above, there are good reasons why a representation of a $\mathrm{CaCO}_{3}$ production via a dedicated state variable ("coccolithophorid phytoplankton", "pteropod zooplankton") may be problematic. To this end, MEDUSA-2.0 adopts a calcification parameterization which straightforwardly replaces that in MEDUSA-1.0, and which was developed for, and optimised to, the global scale (Ridgwell et al., 2007). Though developed within the framework of a low resolution Earth System Model, GENIE, and coupled to a simple "nutrient-restoring" biogeochemical framework, this parameterization serves the same purpose there as in MEDUSA-2.0 - the production of exported $\mathrm{CaCO}_{3}$. Of course, the relationship that it assumes between $\Omega_{\text {calcite }}$ and $\mathrm{CaCO}_{3}$ export is known to be diverse (e.g. Buitenhuis et al., 1999; Iglesias-Rodriguez et al., 2008; Langer et al., 2006), but it serves here as an obvious stepping stone in complexity for MEDUSA-2.0, and the potential impacts of adopting it are explored in a separate study (Yool et al., 2013).

In terms of future developments for MEDUSA-2.0, a number of avenues suggest themselves. The performance of the chlorophyll submodel remains somewhat problematic (though see the comparable CMIP5 results), with the model failing to simulate spring bloom concentrations as high as those observed, while having much lower concentrations in the unproductive oligotrophic gyres. The literature contains more sophisticated treatments of phytoplankton physiology than that used here (up to long-standing submodels such as Flynn, 2001) and the adoption of such a submodel may improve this aspect of MEDUSA-2.0. With the inclusion of the oxygen cycle, and the simulation of suboxic regions, MEDUSA-2.0's omission of denitrification could also be addressed (Deutsch et al., 2007). At the other end of the nitrogen cycle, the factors regulating the distribution of nitrogen fixation are increasingly well-understood (e.g. Moore and Doney, 2007; Monteiro and Follows, 2012), and this process both interacts with denitrification (Deutsch et al., 2007; Fernandez et al., 2011) and is expected to change into the future (Levitan et al., 2007; Barcelos e Ramos et al., 2007). It should be noted that such changes would have additional implications beyond the nitrogen and oxygen cycles including, for instance, impacts in the distribution of ocean alkalinity (Wolf-Gladrow et al., 2007). Though much has been made above of MEDUSA-2.0's more sophisticated treatment of $\mathrm{CaCO}_{3}$, it is clear that this remains just one "solution" for this aspect of the ocean's carbon (and alkalinity) cycle. The broad range of ongoing research into the impacts of ocean acidification on calcifiers will continue to inform the modelling of $\mathrm{CaCO}_{3}$, and will hopefully provide a more "universal" understanding and formulation - for instance, a consensus on the ecophysiological factors that govern calcifier abundance. On a related point, the role played by $\mathrm{CaCO}_{3}$ in the export of organic material to the deep ocean has been questioned (Passow and De La Rocha, 2006; Wilson et al., 2012), and MEDUSA-2.0's utilisation of the ballast hypothesis may require revisiting. And there are further omissions of MEDUSA-2.0, less immediately pressing, that could be considered. For example, $\mathrm{CO}_{2}$-enhanced carbon fixation (Riebesell et al., 2007) or DOM production (Engel, 2002), a more thorough treatment of elemental ratios (Burkhardt et al., 1999), the importance of food quality in grazing interactions (Mitra and Flynn, 2005) or phytoplankton mixotrophy (Hartmann et al., 2012).

Another route to model improvement lies with parameterization. As remarked upon earlier, MEDUSA-2.0 features several minor parameter changes to amend problems that appeared following its evolution from MEDUSA-1.0. One set of such changes aimed to increase nutrient retention in near-surface waters by decreasing the export of sinking detritus (Sect. 2.4). However, as noted subsequently (Sect. 4), MEDUSA-2.0's midwater distributions of nutrients and oxygen in the Pacific, as well as its CCD depth, feature errors that arise from remineralisation of organic material occurring at depths that are too shallow; errors that, in part, are caused by this very "fix". These, and other, changes were made to MEDUSA-2.0's parameters in a relatively ad hoc fashion, being both "best guess" solutions to (usually) nutrient distribution problems, and were "resolved" by short duration test runs. This inefficient approach is driven by the expense (in compute and wall-clock time) of 3-D simulations, which favours limited numbers of limited duration "nudges" to resolve errors. Limiting the spatial domain of 
simulations to 0-D (Fasham and Evans, 1995) or 1-D (Schartau and Oschlies, 2003) does permit a more time-efficient "solution" but at the expense of critically neglecting the horizontal transports that are convoluted with biogeochemical processes to create important gradients throughout the ocean (but see Hemmings and Challenor, 2012). However, in recent years, techniques such as that of Khatiwala (2007) have been developed to permit efficient, offline simulation of ocean biogeochemistry in 3-D, and recent studies such as Kriest et al. $(2010,2012)$ have used this approach to assess the performance and evaluate the parameter sensitivity of simple NPZD models. Development of such approaches offers the potential in the future of optimising the parameterization of models like MEDUSA-2.0, such that the full consequences of changes to parameters (or even model structure) can be properly investigated and accounted for.

However, notwithstanding the considerable room for improvement - or expansion - outlined above, the further development of MEDUSA-2.0 runs counter to the stated intention that the model occupies the "intermediate complexity" niche of biogeochemical modelling. Furthermore, while potentially extending the reach - and utility - of MEDUSA-2.0 on several fronts, they present no method for expanding the model in a systematic or quasi-objective fashion. Piecemeal additions to model complexity, however warranted and justifiable, run the risk of creating a succession of "specialist models", that while individually useful may not sit within a consistent hierarchy of complexity. As such, it may be difficult to fine-tune the biogeochemical complexity to suit a particular task (with particular resources) to hand.

Nonetheless, despite the limitations outlined above, MEDUSA-2.0 still represents an efficiently sized tool for realistically simulating the ocean's major biogeochemical cycles.

\section{Conclusions}

- Medusa-2.0 builds traceably on Medusa-1.0 by adding carbon, alkalinity and oxygen cycles, a simple benthos submodel and options for $\mathrm{CaCO}_{3}$ production and export remineralisation.

- Calcification submodel permits dynamic response to ambient seawater chemistry allowing investigation of ocean acidification feedbacks at an appropriate level of additional complexity.

- Medusa-2.0 performace evaluated at the global scale using observational nutrient, chlorophyll and carbon cycle fields following a century-scale simulation (1860-2005).

- Similarly to its predecessor model, MedusA-2.0 has excessive nutrient concentrations in Southern Ocean and low chlorophyll and productivity in oligotrophic gyres.
- Global productivity is slightly lower than in MEDUSA-1.0, in part due to changes in aeolian iron deposition that decrease Pacific productivity and increase excess surface DIN.

- Excessive circulation-driven ventilation and tooshallow remineralisation of sinking organic material introduce discrepancies to interior concentrations of biogeochemical tracers.

- MedusA-2.0 has generally good agreement on surface carbon cycle properties $\left(\Delta p \mathrm{CO}_{2}\right.$ and air-sea flux $)$ and $\mathrm{CaCO}_{3}$ production within observational range, but discrepancies created in CCD field by too-shallow remineralisation.

- Though not without discrepancies, intercomparison with CMIP5 models of similar (or greater) complexity places MEDUSA-2.0's performance among the best of those examined.

\section{Appendix A}

\section{MeduSA-2.0 code}

The following provides a structural outline of the computer code that accompanies this description of MedusA-2.0. As in Yool et al. (2011), this code does not encompass the entire NEMO model, but includes those modules that either include Medus A-2.0's calculations, or those in which Medusa-2.0 makes an appearance for operational reasons.

The MEDUSA-2.0 model is organised almost identically to MedusA-1.0, and in a similar manner to other passive tracer modules in the NEMO model. The majority of the code directly associated with MEDUSA-2.0 is located within the NEMO/TOP_SRC/MEDUSA directory. The actual model code is distributed across 11 separate routines as follows. Nine of these are common with MedusA-1.0, but the last two are new additions for MEDUSA-2.0 that deal primarily with air-sea gas exchange.

- par_medusa.F90

this routine declares the tracer and diagnostic arrays required for MEDUSA-2.0

- sms_medusa.F90 this routine declares the parameters required for MedusA-2.0

- trcctI_medusa.F90 this routine checks that the correct number of passive tracers is specified

- trcini_medusa.F90 this routine initialises the passive tracers to default values unless they are provided by a restart file 
- trclsm_medusa.F90

this routine initialises the parameters to the values specified in namelist.trc.sms

- trcsms_medusa.F90

this routine is called by the NEMO model during a simulation and in turn calls the MEDUSA-2.0 routines that calculate biogeochemical sources and sinks

- trcopt_medusa.F90

this routine calculates the submarine light field

- trcbio_medusa.F90

this is the main model routine and includes (almost) all of the ecosystem equations used for the biogeochemical sources and sinks for tracers

- trcsed_medusa.F90

this routine both initialises the aeolian iron deposition and $\Omega_{\text {calcite }}$ CCD fields (if required) and (for historical reasons) calculates the sinking of the slow detritus tracer

- trcco2_medusa.F90

this routine is called by trcbio_medusa.F90 to perform calculations associated with carbonate chemistry and air-sea $\mathrm{CO}_{2}$ flux; while modified to interface with MEDUSA-2.0, it is derived from Blackford et al. (2007)

- trcoxy_medusa.F90

this routine is called by trcbio_medusa.F90 to perform calculations associated with saturation concentration and air-sea $\mathrm{O}_{2}$ flux; while modified to interface with MEDUSA-2.0, it is derived from Najjar and Orr (1999)

As with Medus A-1.0, the above routines are included in the Supplement that accompanies this article.

\section{Appendix B}

\section{CMIP5 intercomparison}

As part of the evaluation of MEDUSA-2.0, an intercomparison was performed for a number of surface ocean biogeochemical properties against a selection of nine models drawn from the 5th round of the Coupled Model Intercomparison Project (CMIP5; Taylor et al., 2012). Output from these models was accessed and downloaded via the CMIP5/OCMIP5 FileFinderAR5 Web Application

(Brockmann, 2012; http://ocmip5.ipsl.fr/FileFinderAR5/).

The fields downloaded were global-scale annual averages of surface dissolved inorganic nitrogen (= nitrate + ammonium for some CMIP5 models), surface silicic acid, surface chlorophyll, vertically integrated primary production, surface dissolved inorganic carbon and surface alkalinity. In each case, the output used in the intercomparison was generated from model output covering the same temporal periods described in 4 . Note that not all of the models selected were able to supply all of the fields examined (NorESM1, chlorophyll; GISS-E2, alkalinity).

The CMIP5 models used in the intercomparison, their underlying ocean biogeochemistry submodel, together with the groups that performed the simulations and provided output, are listed in Table 9. The bracketed numbers indicate the total number of tracers in each model and serves as a proxy of model complexity and computational burden (MEDUSA-2.0 has 15 tracers).

\section{Supplementary material related to this article is available online at http://www.geosci-model-dev.net/6/ 1767/2013/gmd-6-1767-2013-supplement.zip.}

Acknowledgements. The authors gratefully acknowledge the financial support of the Natural Environmental Research Council (NERC). This work was performed as part of the Regional Ocean Modelling project (ROAM; grant number NE/H017372/1) of the NERC UK Ocean Acidification research programme (UKOA). The work was part-funded by the European Union Seventh Framework Programme EURO-BASIN (FP7/2007-2013,ENV.2010.2.2.11; grant agreement no. 264933).

The HadGEM2-ES atmospheric forcing was produced by the UKMO and made available for use by NEMO by Dan Bernie (UKMO). Work to perform HadGEM2-ES simulations was supported by the EU-FP7 COMBINE project (grant number 226520). The carbonate chemistry scheme utilised by MEDUSA-2.0 to calculate, among other things, air-sea $\mathrm{CO}_{2}$ flux was generously supplied by Jerry Blackford (PML). The simple benthic reservoir scheme used here is based on a similar scheme developed, and supplied, by Momme Butenschön (PML).

The authors are especially grateful to three anonymous referees who provided extensive and detailed commentary and criticism on an earlier draft of this manuscript. Their suggestions led to a number of substantial improvements and extensions that have greatly improved the final form of this manuscript.

We are additionally grateful to the NEMO development team at NOC for their technical support throughout this work. In particular, the assistance of Andrew Coward, Beverly de Cuevas and Steven Alderson has been invaluable in the implementation and simulation of Medus A-2.0.

The development of MEDUSA-2.0 greatly benefitted from discussions with a number of local and nonlocal colleagues, including: John Hemmings, Stephanie Henson, Adrian Martin, Bablu Sinha and Ian Totterdell. We would also like to acknowledge suggestions from colleagues in the ROAM project and from fellow participants in the UKOA programme, and are grateful to Alexandre Forest (U. Laval) for identifying errors in the description of the chlorophyll submodel of MEDUSA-2.0.

Finally, we acknowledge the World Climate Research Programme's Working Group on Coupled Modelling, which is responsible for CMIP, and we thank the climate modelling groups (listed in Appendix B of this paper) for producing and making available their model output. For CMIP the U.S. Department of 
Energy's Program for Climate Model Diagnosis and Intercomparison provides coordinating support and led development of software infrastructure in partnership with the Global Organization for Earth System Science Portals.

Edited by: R. Marsh

\section{References}

Anderson, L. A.: On the hydrogen and oxygen content of marine phytoplankton, Deep-Sea Res. Pt I, 42, 1675-1680, 1995.

Anderson, T. R.: Plankton functional type modelling: running before we can walk?, J. Plankton Res., 27, 1073-1081, doi:10.1093/plankt/fbi076, 2005.

Anderson, T. R. and Pondaven, P.: Non-redfield carbon and nitrogen cycling in the Sargasso Sea: pelagic imbalances and export flux, Deep-Sea Res. Pt. I, 50, 573-591, 2003.

Anderson, T. R., Gentleman, W. C., and Sinha, B.: Influence of grazing formulations on the emergent properties of a complex ecosystem model in a global ocean general circulation model, Prog. Oceanogr., 87, 201-213, doi:10.1016/j.pocean.2010.06.003, 2010.

Antonov, J. I., Seidov, D., Boyer, T. P., Locarnini, R. A., Mishonov, A. V., Garcia, H. E., Baranova, O. K., Zweng, M. M., and Johnson, D. R.: World ocean atlas 2009, volume 2: Salinity, in: NOAA Atlas NESDIS 69, edited by: Levitus, S., US Government Printing Office, Washington, DC, USA, 184 pp., 2010.

Archer, D.: Modeling the calcite lysocline, J. Geophys. Res., 96, 17037-17050, 1991.

Armstrong, R. A., Lee, C., Hedges, J. I., Honjo, S., and Wakeham, S. G.: A new, mechanistic model for organic carbon fluxes in the ocean: based on the quantitative association of POC with ballast minerals, Deep-Sea Res. Pt. II, 49, 219-236, 2002.

Artoili, Y., Blackford, J. C., Butenschon, M., Holt, J. T., Wakelin, S. L., Thomas, H., Borges, A. V., and Allen, J. I.: The carbonate system of the North Sea: sensitivity and model validation, J. Marine Syst., 102, 1-13, 2012.

Barcelos e Ramos, J., Biswas, H., Schulz, K. G., LaRoche, J., and Riebesell, U.: Effect of rising atmospheric carbon dioxide on the marine nitrogen fixer Trichodesmium, Global Biogeochem. Cy., 21, GB2028, doi:10.1029/2006GB002898, 2007.

Barnier, B., Madec, G., Penduff, T., Molines, J-M., Treguier, AM., Le Sommer, J., Beckmann, A., Boning, C., Dengg, J., Derval, C., Durand, E., Gulev, S., Remy, E., Talandier, C., Theerren, S.,Maltrud, M., McClean, J., and de Cuevas, B.: Impact of partial steps and momentum advection schemes in a global ocean circulation model at eddy-permitting resolution, Ocean Dynam., 56, 543-567, doi:10.1007/s10236-006-0082-1, 2006.

Behrenfeld, M. J. and Falkowski, P. G.: Photosynthetic rates derived from satellite-based chlorophyll concentration, Limnol. Oceanogr., 42, 1-20, 1997.

Behrenfeld, M. J., Olley, R. T., Siegel, D. A., McClain, C. R., Sarmiento, J. L., Feldman, G. C., Milligan, A. J., Falkowski, P. G., Letelier, R. M., and Boss, E. S.: Climatedriven trends in contemporary ocean productivity, Nature, 444, 752-755, 2006.

Blackford, J. C. and Gilbert, F. J.: pH variability and $\mathrm{CO}_{2}$ induced acidification in the North Sea, J. Marine Syst., 64, 229-241, doi:10.1016/j.jmarsys.2006.03.016, 2007.
Blain, S., Leynaert, A., Tréguer, P., Chretiennot-Dinet, M. C., and Rodier, M.: Biomass, growth rates and limitation of equatorial Pacific diatoms, Deep-Sea Res. Pt. I, 44, 1255-1275, 1997.

Bopp, L., Monfray, P., Aumont, O., Dufresne, J.-L., Le Treut, H., Madec, G., Terray, L., and Orr, J. C.: Potential impact of climate change on marine export production, Global Biogeochem. Сy., 15, 81-99, doi:10.1029/1999GB001256, 2001.

Boyce, D. G., Lewis, M. R., and Worm, B.: Global phytoplankton decline over the past century, Nature, 466, 591-596, doi:10.1038/nature09268, 2010.

Boyd, P. W. and Ellwood, M. J.: The biogeochemical cycle of iron in the ocean, Nat. Geosci., 3, 675-682, 2010.

Boye, M., Aldrich, A. P., van den Berg, C. M. G., de Jong, J. T. M., Veldhuis, M., and de Baar, H. J. W.: Horizontal gradient of the chemical speciation of iron in surface waters of the northeast Atlantic Ocean, Mar. Chem., 80, 129-143, 2003.

Breitbarth, E., Achterberg, E. P., Ardelan, M. V., Baker, A. R., Bucciarelli, E., Chever, F., Croot, P. L., Duggen, S., Gledhill, M., Hassellöv, M., Hassler, C., Hoffmann, L. J., Hunter, K. A., Hutchins, D. A., Ingri, J., Jickells, T., Lohan, M. C., Nielsdóttir, M. C., Sarthou, G., Schoemann, V., Trapp, J. M., Turner, D. R., and Ye, Y.: Iron biogeochemistry across marine systems progress from the past decade, Biogeosciences, 7, 1075-1097, doi:10.5194/bg-7-1075-2010, 2010.

Brockmann, P.: FileFinderAR5, 3 pp., available at: http:// ocmip5.ipsl.fr/FileFinderAR5/docs/FileFinderAR5.pdf, last access: 15 August 2013, 2012.

Brzezinski, M. A., Villareal, T. A., and Lipschultz, F.: Silica production and the contribution of diatoms to new and primary production in the central North Pacific, Mar. Ecol.-Prog. Ser., 167, 89-104, 1998.

Buitenhuis, E. T., de Baar, H. J. W., and Veldhuis, M. J. W.: Photosynthesis and calcification by Emiliania huxleyi (Prymnesiophyceae) as a function of inorganic carbon species, J. Phycol., 35, 949-959, doi:10.1046/j.1529-8817.1999.3550949.x, 1999.

Burkhardt, S., Riebesell, U., and Zondervan, I.: Effects of $\mathrm{CO}_{2}$ concentration on $\mathrm{C}: \mathrm{N}: \mathrm{P}$ ratio in marine phytoplankton: a species comparison, Limnol. Oceanogr., 44, 683-690, 1999.

Caldeira, K. and Wickett, M. E.: Anthropogenic carbon and ocean pH, Nature, 425, 365-365, doi:10.1038/425365a, 2003.

Carr, M.-E., Friedrichs, M. A. M., Schmeltz, M., Aita, M. N., Antoine, D., Arrigo, K. R., Asanuma, I., Aumont, O., Barber, R., Behrenfeld, M., Bidigare, R., Buitenhuis, E. T., Campbell, J., Ciotti, A., Dierssen, H., Dowell, M., Dunne, J., Esaias, W., Gentili, B., Gregg, W., Groom, S., Hoepffner, N., Ishizaka, J., Kameda, T., Le Quéré, C., Lohrenz, S., Marra, J., Mélin, F., Moore, K., Morel, A., Reddy, T. E., Ryan, J., Scardi, M., Smyth, T., Turpie, K., Tilstone, G., Waters, K., and Yamanaka, Y.: A comparison of global estimates of marine primary production from ocean color, Deep-Sea Res. Pt. II, 53, 741770, 2006.

Chen, B. Z., Landry, M. R., Huang, B. Q., and Liu, H. B.: Does warming enhance the effect of microzooplankton grazing on marine phytoplankton in the ocean?, Limnol. Oceanogr., 57, 519526, doi:10.4319/lo.2012.57.2.0519, 2012.

Collins, W. J., Bellouin, N., Doutriaux-Boucher, M., Gedney, N., Halloran, P., Hinton, T., Hughes, J., Jones, C. D., Joshi, M., Liddicoat, S., Martin, G., O'Connor, F., Rae, J., Senior, C., Sitch, S., Totterdell, I., Wiltshire, A., and Woodward, S.: Development 
and evaluation of an Earth-system model - HadGEM2, Geosci. Model Dev. Discuss., 4, 997-1062, doi:10.5194/gmdd-4-9972011, 2011.

Deutsch, C., Sarmiento, J. L., Sigman, D. M., Gruber, N., and Dunne, J. P.: Spatial coupling of nitrogen inputs and losses in the ocean, Nature, 445, 163-167, doi:10.1038/nature05392, 2007.

Doney, S. C., Fabry, V. J., Feely, R. A., and Kleypas, J. A.: Ocean acidification: the other $\mathrm{CO}_{2}$ problem, Annual Review of Marine Science, 1, 169-192, 2009.

Doney, S. C., Ruckelshaus, M., Duffy, J. E., Barry, J. P., Chan, F., English, C. A., Galindo, H. M., Grebmeier, J. M., Hollowed, A. B., Knowlton, N., Polovina, J., Rabalais, N. N., Sydeman, W. J., and Talley, L. D.: Climate change impacts on marine ecosystems, Annual Review of Marine Science, 4, 11-37, 2012.

DRAKKAR Group: Eddy-permitting ocean circulation hindcasts of past decades, CLIVAR-Exchanges, 42, 8-10, 2007.

Dunne, J. P., Sarmiento, J. L., and Gnanadesikan, A.: A synthesis of global particle export from the surface ocean and cycling through the ocean interior and on the seafloor, Global Biogeochem. Cy., 21, GB4006, doi:10.1029/2006GB002907, 2007.

Dunne, J. P., John, J. G., Shevliakova, E., Stouffer, R. J., Krasting, J. P., Malyshev, S. L., Milly, P. C. D., Sentman, L. T., Adcroft, A. J., Cooke, W., Dunne, K. A., Griffies, S. M., Hallberg, R. W., Harrison, M. J., Levy, H., Wittenberg, A. T., Phillips, P. J., and Zadeh, N.: GFDL's ESM2 Global Coupled Climate-Carbon Earth System Models. Part II: Carbon System Formulation and Baseline Simulation Characteristics, J. Climate, 26, 2247-2267, doi:10.1175/JCLI-D-12-00150.1, 2013.

Dutkiewicz, S., Follows, M. J., and Parekh, P.: Interactions of the iron and phosphorus cycles: a three-dimensional model study, Global Biogeochem. Cy., 19, GB1021, doi:10.1029/2004GB002342, 2005.

Edwards, A. M. and Yool, A.: The role of higher predation in plankton population models, J. Plankton Res., 22, 1085-1112, 2000.

Engel, A.: Direct relationship between $\mathrm{CO}_{2}$-uptake and transparent exopolymer particles (TEP) production in natural phytoplankton, J. Plankton Res., 24, 49-53, 2002.

Eppley, R. W.: Temperature and phytoplankton growth in the sea, Fish. Bull. Nat. Ocean Atmos. Adm., 70, 1063-1085, 1972.

Fabry, V. J., Seibel, B. A., Feely, R. A., and Orr, J. C.: Impacts of ocean acidification on marine fauna and ecosystem processes, ICES J. Mar. Sci., 65, 414-432, 2008.

Fasham, M. J. R.: Modelling the marine biota, in: The Global Carbon Cycle, edited by: Heimann, M., Springer-Verlag, New York, USA, 457-504, 1993.

Fasham, M. J. R., Ducklow, H. W., and McKelvie, S. M.: A nitrogen-based model of plankton dynamics in the oceanic mixed layer,J. Mar. Res., 48, 591-639, 1990.

Fasham, M. J. R. and Evans, G. T.: The use of optimization techniques to model marine ecosystem dynamics at the JGOFS station at 47 degrees N 20 degrees W, Philos. T. Roy. Soc. B, 348, 203-209, doi:10.1098/rstb.1995.0062, 1995.

Fasham, M. J. R., Flynn, K. J., Pondaven, P., Anderson, T. R., and Boyd, P. W.: Development of a robust marine ecosystem model to predict the role of iron in biogeochemical cycles: a comparison of results for iron-replete and iron-limited areas, and the SOIREE iron-enrichment experiment, Deep-Sea Res. Pt. I, 53, 333-366, doi:10.1016/j.dsr.2005.09.011, 2006.
Fernandez, C., Farías, L., and Ulloa, O.: Nitrogen fixation in denitrified marine waters, PLoS ONE, 6, e20539, doi:10.1371/journal.pone.0020539, 2011.

Fichefet, T. and Morales Maqueda, M. A.: Sensitivity of a global sea ice model to the treatment of ice thermodynamics and dynamics, J. Geophys. Res., 102, 12609-12646, 1997.

Flynn, K. J.: A mechanistic model for describing dynamic multi-nutrient, light, temperature interactions in phytoplankton,J. Plankton Res., 23, 977-997, 2001.

Frankignoulle, M., Canon, C., and Gattuso, J.-P.: Marine calcification as a source of carbon dioxide: Positive feedback of increasing atmospheric $\mathrm{CO}_{2}$, Limnol. Oceanogr., 39, 458-462, 1994.

Gangstø, R., Joos, F., and Gehlen, M.: Sensitivity of pelagic calcification to ocean acidification, Biogeosciences, 8, 433-458, doi:10.5194/bg-8-433-2011, 2011.

Garcia, H. E., Locarnini, R. A., Boyer, T. P., Antonov, J. I., Baranova, O. K., Zweng, M. M., and Johnson, D. R.: World ocean atlas 2009, volume 3: dissolved oxygen, apparent oxygen utilization, and oxygen saturation, in: NOAA Atlas NESDIS 70, edited by: Levitus, S., US Government Printing Office, Washington, DC, 344 pp., 2010a.

Garcia, H. E., Locarnini, R. A., Boyer, T. P., Antonov, J. I., Zweng, M. M., Baranova, O. K., and Johnson, D. R., World ocean atlas 2009, volume 4: nutrients (phosphate, nitrate, silicate),in: NOAA Atlas NESDIS 71, edited by: Levitus, S., US Government Printing Office, Washington, DC, 398 pp., 2010 b.

Gaspar, P., Grégoris, Y., and Lefevre, J.-M.: A simple eddy kinetic energy model for simulations of the oceanic vertical mixing tests at station papa and long-term upper ocean study site,J. Geophys. Res., 95, 16179-16193, 1990.

Gehlen, M., Gangst $\varnothing$, R., Schneider, B., Bopp, L., Aumont, O., and Ethe, C.: The fate of pelagic $\mathrm{CaCO}_{3}$ production in a high $\mathrm{CO}_{2}$ ocean: a model study, Biogeosciences, 4, 505-519, doi:10.5194/bg-4-505-2007, 2007.

Gledhill, M. and van den Berg, C.: Determination of complexation of iron (III) with natural organic complexing ligands in seawater using cathodic stripping voltammetry, Mar. Chem., 47, 41-54, 1994.

Gregg, W. W. and Casey, N. W.: Modeling coccolithophores in the global oceans, Deep-Sea Res. Pt. II, 54, 447-477, doi:10.1016/j.dsr2.2006.12.007, 2013.

Hartmann, M., Grob, C., Tarran, G. A., Martin, A. P., Burkhill, P. H., Scanlan, D. J., and Zubkov, M. V.: Mixotrophic basis of Atlantic oligotrophic ecosystems, P. Natl. Acad. Sci. USA, 109, 57565760, doi:10.1073/pnas.1118179109, 2012.

Heinze, C.: Simulating oceanic $\mathrm{CaCO}_{3}$ export production in the greenhouse, Geophys. Res. Lett., 31, L16308, doi:10.1029/2004g1020613, 2004.

Hemmings, J. C. P. and Challenor, P. G.: Addressing the impact of environmental uncertainty in plankton model calibration with a dedicated software system: the Marine Model Optimization Testbed (MarMOT 1.1 alpha), Geosci. Model Dev., 5, 471-498, doi:10.5194/gmd-5-471-2012, 2012.

Henson, S. A., Sanders, R., Madsen, E., Morris, P. J., Le Moigne, F., and Quartly, G. D.: A reduced estimate of the strength of the ocean's biological carbon pump, Geophys. Res. Lett., 38, L04606, doi:10.1029/2011GL046735, 2011.

Henson, S. A., Sanders, R., and Madsen, E.: Global patterns in efficiency of particulate organic carbon export and transfer 
to the deep ocean, Global Biogeochem. Cy., 26, GB1028, doi:10.1029/2011GB004099, 2012.

Hibler, W. D.: A dynamic thermodynamic sea ice model, J. Phys. Oceanogr., 9, 815-846, 1979.

Honjo, S., Manganini, S. J., Krishfield, R. A., and Francois, R.: Particulate organic carbon fluxes to the ocean interior and factors controlling the biological pump: A synthesis of global sediment trap programs since 1983, Prog. Oceanogr., 76, 217-285, doi:10.1016/j.pocean.2007.11.003, 2008.

Houghton, J. T. Ding, Y., Griggs, D. J., Noguer, M., van der Linden, P. J., Dai, X., Maskell, K., and Johnson, C. A. (Eds.): Intergovernmental Panel on Climate Change 2001: the Scientific Basis, Cambridge University Press, Cambridge, UK, 881 pp., 2001.

Iglesias-Rodriguez, M. D., Halloran, P. R., Rickaby, R. E. M., Hall, I. R., Colmenero-Hidalgo, E., Gittins, J. R., Green, D. R. H., Tyrrell, T., Gibbs, S. J., von Dassow, P., Rehm, E., Armbrust, E. V., and Boessenkool, K. P.: Phytoplankton calcification in a high- $\mathrm{CO}_{2}$ world, Science, 320, 336-340, doi:10.1126/science.1154122, 2008 .

Ilyina, T., Six, K. D., Segschneider, S., Maier-Reimer, E., Li, H., and Núñez-Riboni, I.: Global ocean biogeochemistry model HAMOCC: Model architecture and performance as component of the MPI-Earth system model in different CMIP5 experimental realizations, J. Adv. Model. Earth Syst., 5, 287-315, doi:10.1029/2012MS000178, 2013.

Johns, T. C., Durman, C. F., Banks, H. T., Roberts, M. J., McLaren, A. J., Ridley, J. K., Senior, C. A., Williams, K. D., Jones, A., Rickard, G. J., Cusack, S., Ingram, W. J., Crucifix, M., Sexton, D. M. H., Joshi, M. M., Dong, D.-W., Spencer, H., Hill, R. S. R., Gregory, J. M., Keen, A. B., Pardaens, A. K., Lowe, J. A., Bodas-Salcedo, A., Stark, S., and Searl, Y.: The new Hadley Centre Climate Model (HadGEM1): evaluation of coupled simulations, J. Climate, 19, 1327-1353, 2006.

Jones, C. D., Hughes, J. K., Bellouin, N., Hardiman, S. C., Jones, G. S., Knight, J., Liddicoat, S., O’Connor, F. M., Andres, R. J., Bell, C., Boo, K.-O., Bozzo, A., Butchart, N., Cadule, P., Corbin, K. D., Doutriaux-Boucher, M., Friedlingstein, P., Gornall, J., Gray, L., Halloran, P. R., Hurtt, G., Ingram, W. J., Lamarque, J.-F., Law, R. M., Meinshausen, M., Osprey, S., Palin, E. J., Parsons Chini, L., Raddatz, T., Sanderson, M. G., Sellar, A. A., Schurer, A., Valdes, P., Wood, N., Woodward, S., Yoshioka, M., and Zerroukat, M.: The HadGEM2-ES implementation of CMIP5 centennial simulations, Geosci. Model Dev., 4, 543-570, doi:10.5194/gmd-4-543-2011, 2011.

Key, R. M., Kozyr, A., Sabine, C. L., Lee, K., Wanninkhof, R., Bullister, J. L., Feely, R. A., Millero, F. J., Mordy, C., and Peng, T.-H.: A global ocean carbon climatology: results from Global Data Analysis Project (GLODAP), Global Biogeochem. Cy., 18, GB4031, doi:10.1029/2004GB002247, 2004.

Khatiwala, S.: A computational framework for simulation of biogeochemical tracers in the ocean, Global Biogeochem. Cy., 21, GB3001, doi:10.1029/2007GB002923, 2007.

Klaas, C. and Archer, D.: Association of sinking organic matter with various types of mineral ballast in the deep sea: implications for the rain ratio, Global Biogeochem. Cy., 16, 1116, doi:10.1029/2001GB001765, 2002.

Kriest, I., Khatiwala, S., and Oschlies, A.: Towards an assessment of simple global marine biogeochemical mod- els of different complexity, Prog. Oceanogr., 86, 337-360, doi:10.1016/j.pocean.2010.05.002, 2010.

Kriest, I., Oschlies, A., and Khatiwala, S.: Sensitivity analysis of simple global marine biogeochemical models, Global Biogeochem. Cy., 26, GB2029, doi:10.1029/2011GB004072, 2012.

Langer, G., Geisen, M., Baumann, K. H., Kläs, J., Riebesell, U., Thoms, S., and Young, J. R.: Species-specific responses of calcifying algae to changing seawater carbonate chemistry, Geochem. Geophy. Geosy., 7, Q09006, doi:10.1029/2005GC001227, 2006.

Lengaigne, M., Menkes, C., Aumont, O., Gorgues, T., Bopp, L., André, J.-M., and Madec, G.: Influence of the oceanic biology on the tropical Pacific climate in a coupled general circulation model, Clim. Dynam., 28, 503-516, doi:10.1007/s00382-0060200-2, 2007.

Levitan, O., Rosenberg, G., Setlik, I., Setlikova, E., Grigel, J., Klepetar, J., Prasil, O., and Berman-Frank, I.: Elevated $\mathrm{CO}_{2}$ enhances nitrogen fixation and growth in the marine cyanobacterium Trichodesmium, Global Change Biol., 13, 531-538, 2007.

Levy, M., Klein, P., and Treguier, A.-M.: Impacts of sub-mesoscale physics on phytoplankton production and subduction, J. Mar. Res., 59, 535-565, doi:10.1357/002224001762842181, 2001.

Locarnini, R. A., Mishonov, A. V., Antonov, J. I., Boyer, T. P., Garcia, H. E., Baranova, O. K., Zweng, M. M., and Johnson, D. R.: World ocean atlas 2009, volume 1: Temperature, in: NOAA Atlas NESDIS 68, edited by: Levitus, S., US Government Printing Office, Washington, DC, USA, 184 pp., 2010.

Madec, G.: NEMO Reference Manual, Ocean Dynamic Component: NEMO-OPA, Note du Pole de modélisation, Technical Report 27, Note du Pole de Modélisation, Institut Pierre Simmon Laplace, Paris, France, No. 27, ISSN 1288-1619, 2008.

Madec, G., Delecluse, P., Imbard, M., and Lévy, C.: OPA 8.1 Ocean General Circulation Model Reference Manual, Technical Report 11, Note du Pole de Modélisation, Institut Pierre Simon Laplace, Paris, France, 91 pp., 1998.

Mahowald, N. M., Baker, A. R.,Bergametti, G., Brooks, N., Duce, R. A., Jickells, T. D., Kubilay, N., Prospero, J. M., and Tegen, I.: Atmospheric global dust cycle and iron inputs to the ocean, Global Biogeochem. Cy., 19, GB4025, doi:10.1029/2004GB002402, 2005.

Meier-Reimer, E., Kriest, I., Segschneider, J., and Wetzel, P.: The HAMburg Ocean Carbon Cycle Model HAMOCC 5.1 - Technical Description Release 1.1, Tech. Report 14, Reports on Earth System Science, Max Planck Institute for Meteorology, Hamburg, Germany, 2005.

Mann, D. G.: The species concept in diatoms, Phycologia, 38, 437495, 1999.

Martin, J. H., Knauer, G. A., Karl, D. M., and Broenkow, W. W.: VERTEX: carbon cycling in the northeastern Pacific, Deep-Sea Res. Pt. I, 34, 267-285, 1987.

Martin-Jézéquel, V., Hildebrand, M., and Brzezinski, M. A.: Silicon metabolism in diatoms: implications for growth, J. Phycol., 36, 821-840, 2000.

Meijers, A. J. S., Shuckburgh, E., Bruneau, N., Sallee, J.-B., Bracegirdle, T. J., and Wang, Z.: Representation of the Antarctic circumpolar current in the CMIP5 climate models and future changes under warming scenarios, J. Geophys. Res., 117, C12008, doi:10.1029/2012JC008412, 2012. 
Mitra, A. and Flynn, K. J.: Predator-prey interactions: is "ecological stoichiometry" sufficient when good food goes bad?, J. Plankton Res., 27, 393-399, doi:10.1093/plankt/fbi022, 2005.

Mongin, M., Nelson, D. M., Pondaven, P., and Tréguer, P.: Simulation of upper-ocean biogeochemistry with a flexible-composition phytoplankton model: $\mathrm{C}, \mathrm{N}$ and $\mathrm{Si}$ cycling and Fe limitation in the Southern Ocean, Deep-Sea Res. Pt. II, 53, 601-619, 2006.

Monteiro, F. M. and Follows, M. J.: On nitrogen fixation and preferential remineralization of phosphorus, Geophys. Res. Lett., 39, L06607, doi:10.1029/2012GL050897, 2012.

Moore, J. K. and Doney, S. C.: Iron availability limits the ocean nitrogen inventory stabilizing feedbacks between marine denitrification and nitrogen fixation, Global Biogeochem. Cy., 21, GB2001, doi:10.1029/2006GB002762, 2007.

Moore, J. K., Doney, S. C., Kleypas, J. A., Glover, D. M., and Fung, I. Y.: An intermediate complexity marine ecosystem model for the global domain, Deep-Sea Res. Pt. II, 49, 403-462, 2002.

Moore, J. K., Doney, S. C., and Lindsay, K.: Upper ocean ecosystem dynamics and iron cycling in a global threedimensional model, Global Biogeochem. Cy., 18, GB4028, doi:10.1029/2004GB002220, 2004.

Najjar, R. G. and Orr, J. C.: Biotic-HOWTO, OCMIP-2 Project, 15 pp., available at: http://ocmip5.ipsl.jussieu.fr/OCMIP/phase2/ simulations/Biotic/HOWTO-Biotic.html, last access: 18 February $2013,1999$.

Najjar, R. G., Jin, X., Louanchi, F., Aumont, O., Caldeira, K., Doney, S. C., Dutay, J.-C., Follows, M., Gruber, N., Joos, F., Lindsay, K., Maier-Reimer, E., Matear, R. J., Matsumoto, K., Monfray, P., Mouchet, A., Orr, J. C., Plattner, G.-K., Sarmiento, J. L., Schlitzer, R., Slater, R. D., Weirig, M.-F., Yamanaka, Y., and Yool, A.: Impact of circulation on export production, dissolved organic matter, and dissolved oxygen in the ocean: results from phase II of the Ocean Carbon-cycle Model Intercomparison Project (OCMIP-2), Global Biogeochem. Cy., 21, GB3007, doi:10.1029/2006GB002857, 2007.

Nelson, D. M. and Brzezinski, M. A.: Diatom growth and productivity in an oligotrophic mid-ocean gyre: a 3-year record from the Sargasso Sea near Bermuda, Limnol. Oceanogr., 42, 473-486, 1997.

O'Brien, T. D.: COPEPOD: A Global Plankton Database, U.S. Dep. Commerce, NOAA Tech. Memo., NMFS-F/SPO-73, 136 pp., available at: http://www.st.nmfs.noaa.gov/copepod/ 2005/tm-download.html, last access: 15 August 2013, 2005.

O'Reilly, J. E., Maritorena, S., Mitchell, B. G., Siegal, D. A., Carder, K. L., Garver, S. A., Kahru, M., and McClain, C.: Ocean color chlorophyll algorithms for SeaWiFS, J. Geophys. Res., 103, 24937-24953, 1998.

Orr, J. C., Fabry, V. J., Aumont, O., Bopp, L., Doney, S. C., Feely, R. A., Gnanadesikan, A., Gruber, N., Ishida, A., Joos, F., Key, R. M., Lindsay, K., Maier-Reimer, E., Matear, R., Monfray, P., Mouchet, A., Najjar, R. G., Plattner, G.-K., Rodgers, K. B., Sabine, C. L., Sarmiento, J. L., Schlitzer, R., Slater, R. D., Totterdell, I. J., Weirig, M.-F., Yamanaka, Y., and Yool, A.: Anthropogenic ocean acidification over the twentyfirst century and its impact on calcifying organisms, Nature, 437, 681-686, 2005.

Östlund, G. and Stuiver, M.: GEOSECS Pacific radiocarbon, Radiocarbon, 22, 25-53, 1980.
Parekh, P., Follows, M. J., and Boyle, E. A.: Decoupling of iron and phosphate in the global ocean, Global Biogeochem. Cy., 19, GB2020, doi:10.1029/2004GB002280, 2005.

Passow, U. and De La Rocha, C. L.: Accumulation of mineral ballast on organic aggregates, Global Biogeochem. Cy., 20, GB1013, doi:10.1029/2005GB002579, 2006.

Paulmier, A., Kriest, I., and Oschlies, A.: Stoichiometries of remineralisation and denitrification in global biogeochemical ocean models, Biogeosciences, 6, 923-935, doi:10.5194/bg-6923-2009, 2009.

Penduff, T., Le Sommer, J., Barnier, B., Treguier, A.-M., Molines, J.-M., and Madec, G.: Influence of numerical schemes on current-topography interactions in $1 / 4^{\circ}$ global ocean simulations, Ocean Sci., 3, 509-524, doi:10.5194/os-3-509-2007, 2007.

Penduff, T., Juza, M., Brodeau, L., Smith, G. C., Barnier, B., Molines, J.-M., Treguier, A.-M., and Madec, G.: Impact of global ocean model resolution on sea-level variability with emphasis on interannual time scales, Ocean Sci., 6, 269-284, doi:10.5194/os6-269-2010, 2010.

Pollard, R. T., Salter, I., Sanders, R. J., Lucas, M. I., Moore, M., Mills, R. A., Statham, P. J., Allen, J. T., Baker, A. R., Bakker, D. C. E., Charette, M. A., Fielding, S., Fones, G. R., French, M., Hickman, A. E., Holland, R. J., Hughes, J. A., Jickells, T. D., Lampitt, R. S., Morris, P. J., Nédélec, F. H., Nielsdóttir, M., Planquette, H., Popova, E. E., Poulton, A. J., Read, J. F., Seeyave, S., Smith, T., Stinchcombe, M., Taylor, S., Thomalla, S., Venables, H. J., Williamson, R., and Zubkov, M. V.: Southern Ocean deep-water carbon export enhanced by natural iron fertlization, Nature, 457, 577-580, doi:10.1038/nature07716, 2009.

Popova, E. E., Coward, A. C., Nurser, G. A., de Cuevas, B., Fasham, M. J. R., and Anderson, T. R.: Mechanisms controlling primary and new production in a global ecosystem model - Part I: Validation of the biological simulation, Ocean Sci., 2, 249-266, doi:10.5194/os-2-249-2006, 2006.

Popova, E. E., Yool, A., Coward, A. C., Dupont, F., Deal, C., Elliott, S., Hunke, E., Jin, M., Steele, M., and Zhang, J.: What controls primary production in the Arctic Ocean? Results from an intercomparison of five general circulation models with biogeochemistry, J. Geophys. Res., 117, 2156-2202, doi:10.1029/2011JC007112, 2012.

Ridgwell, A., Zondervan, I., Hargreaves, J. C., Bijma, J., and Lenton, T. M.: Assessing the potential long-term increase of oceanic fossil fuel $\mathrm{CO}_{2}$ uptake due to $\mathrm{CO}_{2}$-calcification feedback, Biogeosciences, 4, 481-492, doi:10.5194/bg-4-481-2007, 2007.

Riebesell, U., Zondervan, I., Rost, B., Tortell, P. D., Zeebe, R. E., and Morel, F. M. M.: Reduced calcification of marine plankton in response to increased atmospheric $\mathrm{CO}_{2}$, Nature, 407, 364-367, doi:10.1038/35030078, 2000.

Riebesell, U., Schulz, K. G., Bellerby, R. G. J., Botros, M., Fritsche, P., Meyerhöfer, M., Neill, C., Nondal, G., Oschlies, A., Wohlers, J., and Zöllner, E.: Enhanced biological carbon consumption in a high $\mathrm{CO}_{2}$ ocean, Nature, 450, 545-548, doi:10.1038/nature06267, 2007.

Rose, A. L. and Waite, T. D.: Kinetics of iron complexation by dissolved natural organic matter in coastal waters, Mar. Chem., 84, 85-103, 2003. 
Rowe, G. T. and Deming, J. W.: An alternative view of the role of heterotrophic microbes in the cycling of organic matter in deep-sea sediments, Mar. Biol. Res., 7, 629-636, doi:10.1080/17451000.2011.560269, 2011.

Sabine, C. L., Feely, R. A., Gruber, N., Key, R. M., Lee, K., Bullister, J. L., Wanninkhof, R., Wong, C. S., Wallace, D. W. R., Tilbrook, B., Millero, F. J., Peng, T. H., Kozyr, A., Ono, T., and Rios, A. F.: The oceanic sink for anthropogenic $\mathrm{CO}_{2}$, Science, 305, 367-71, 2004.

Schartau, M. and Oschlies, A.: Simultaneous data-based optimization of a 1D-ecosystem model at three locations in the North Atlantic: Part 1 - Method and parameter estimates, J. Mar. Res., 61, 765-793, 2003.

Schulz, M., Prospero, J. M., Baker, A. R., Dentener, F., Ickes, L., Liss, P. S., Mahowald, N. M., Nickovic, S., García-Pando, C. P., Rodríguez, S., Sarin, M., Tegen, I., and Duce, R. A.: Atmospheric transport and deposition of mineral dust to the ocean: implications for research needs, Environ. Sci. Technol., 46, 1039010404, doi:10.1021/es300073u, 2012.

Semtner, A. J.: A model for the thermodynamic growth of sea ice in numerical investigation of climate, J. Phys. Oceanogr., 6, 376389, 1976

Smith, S. L., Yamanaka, Y., Pahlow, M., and Oschlies, A.: Optimal uptake kinetics: physiological acclimation explains the pattern of nitrate uptake by phytoplankton in the ocean, Mar. Ecol.-Prog. Ser., 384, 1-12, doi:10.3354/meps08022, 2009.

Steele, J. H. and Henderson, E. W.: The role of predation in plankton models, J. Plankton Res., 14, 157-172, 1992.

Steinacher, M., Joos, F., Frölicher, T. L., Bopp, L., Cadule, P., Cocco, V., Doney, S. C., Gehlen, M., Lindsay, K., Moore, J. K., Schneider, B., and Segschneider, J.: Projected 21 st century decrease in marine productivity: a multi-model analysis, Biogeosciences, 7, 979-1005, doi:10.5194/bg-7-979-2010, 2010.

Tagliabue, A., Bopp, L., Aumont, O., and Arrigo, K. R.: Influence of light and temperature on the marine iron cycle: from theoretical to global modeling, Global Biogeochem. Cy., 23, GB2017, doi:10.1029/2008GB003214, 2009.

Takahashi, T., Sutherland, S. C., Wanninkhof, R., Sweeney, C., Feely, R. A., Chipman, D. W., Hales, B., Friederich, G., Chavez, F., Sabine, C., Watson, A., Bakker, D. C. E., Schuster, U., Metzl, N., Yoshikawa-Inoue, H., Ishii, M. Midorikawa, T., Nojiri, Y., Kortzinger, A., Steinhoff, T., Hoppema, M., Olafsson, J., Arnarson, T. S., Tillbrook, B., Johannessen, T., Olsen, A., Bellerby, R., Wong, C. S., Delille, B., Bates, N. R., and de Baar, H. J. W.: Climatological mean and decade change in surface ocean $p \mathrm{CO}_{2}$, and net sea-air $\mathrm{CO}_{2}$ flux over the global oceans, Deep-Sea Res. Pt. II, 56, 554-577, doi:10.1016/j.dsr2.2008.12.009, 2009.

Taucher, J. and Oschlies, A.: Can we predict the direction of marine primary production change under global warming?, Geophys. Res. Lett., 38, L02603,doi:10.1029/2010GL045934, 2011.

Taylor, A. H., Geider, R. J., and Gilbert, F. J. H.: Seasonal and latitudinal dependencies of phytoplankton carbon-to-chlorophyll $a$ ratios: results of a modelling study, Mar. Ecol.-Prog. Ser., 152, 5166, 1997.

Taylor, K. E., Stouffer, R. J., and Meehl, G. A.: An Overview of CMIP5 and the experiment design, B. Am. Meteorol. Soc., 93, 485-498, doi:10.1175/BAMS-D-11-00094.1, 2012.
Timmermann, R., Goosse, H., Madec, G., Fichefet, T., Ethe, C., and Duliere, V.: On the representation of high latitude processes in the ORCA-LIM global coupled sea ice-ocean model, Ocean Model., 8, 175-201, doi:10.1016/j.ocemod.2003.12.009, 2005.

Tréguer, P., Nelson, D. M., Van Bennekom, A. J., DeMaster, D. J., Leynaert, A., and Quéguiner, B.: The silica balance in the world ocean: a reestimate, Science, 268, 375-379, 1995.

Tyrrell, T. and Taylor, A. H.: A modelling study of Emiliania huxleyi in the NE Atlantic, J. Marine Syst., 9, 83-112, 1996.

Volk, T. and Hoffert, M. I.: Ocean carbon pumps: analysis of relative strengths and efficiencies in ocean-driven atmospheric $\mathrm{CO}_{2}$ changes, Geoph. Monog. Series, 32, 99-110, doi:10.1029/GM032p0099, 1985.

Weber, L., Völker, C., Oschlies, A., and Burchard, H.: Iron profiles and speciation of the upper water column at the Bermuda Atlantic Time-series Study site: a model based sensitivity study, Biogeosciences, 4, 689-706, doi:10.5194/bg-4-689-2007, 2007.

Westberry, T., Behrenfeld, M. J., Siegel, D. A., and Boss, E.: Carbon-based primary productivity modeling with vertically resolved photoacclimation, Global Biogeochem. Cy., 22, GB2024, doi:10.1029/2007GB003078, 2008.

Wilson, J. D., Barker, S., and Ridgwell, A.: Assessment of the spatial variability in particulate organic matter and mineral sinking fluxes in the ocean interior: Implications for the ballast hypothesis, Global Biogeochem. Cy., 26, GB4011, doi:10.1029/2012GB004398, 2012.

Wolf-Gladrow, D., Zeebe, R. E., Klaas, C., Körtzinger, A., and Dickson, A. G.: Total alkalinity: The explicit conservative expression and its application to biogeochemical processes, Mar. Chem., 106, 287-300, doi:10.1016/j.marchem.2007.01.006, 2007.

Ye, Y., Völker, C., and Wolf-Gladrow, D. A.: A model of Fe speciation and biogeochemistry at the Tropical Eastern North Atlantic Time-Series Observatory site, Biogeosciences, 6, 20412061, doi:10.5194/bg-6-2041-2009, 2009.

Yool, A. and Tyrrell, T.: The role of diatoms in regulating the ocean's silicon cycle, Global Biogeochem. Cy., 17, 1103, doi:10.1029/2002GB002018, 2003.

Yool, A., Oschlies, A., Nurser, A. J. G., and Gruber, N.: A modelbased assessment of the TrOCA approach for estimating anthropogenic carbon in the ocean, Biogeosciences, 7, 723-751, doi:10.5194/bg-7-723-2010, 2010.

Yool, A., Popova, E. E., and Anderson, T. R.: Medusa-1.0: a new intermediate complexity plankton ecosystem model for the global domain, Geosci. Model Dev., 4, 381-417, doi:10.5194/gmd-4381-2011, 2011.

Yool, A., Popova, E. E., Coward, A. C., Bernie, D., and Anderson, T. R.: Climate change and ocean acidification impacts on lower trophic levels and the export of organic carbon to the deep ocean, Biogeosciences, 10, 5831-5854, doi:10.5194/bg-10-5831-2013, 2013.

Zahariev, K., Christian, J. R., and Denman, K. L.: Preindustrial, historical, and fertilization simulations using a global ocean carbon model with new parameterizations of iron limitation, calcification, and $\mathrm{N}_{2}$ fixation, Prog. Oceanogr., 77, 56-82, 2008.

Zondervan, I., Zeebe, R. E., Rost, B., and Rieblesell, U.: Decreasing marine biogenic calcification: a negative feedback on rising atmospheric $\mathrm{CO}_{2}$, Global Biogeochem. Cy., 15, 507-516, doi:10.1029/2000GB001321, 2001. 